APPLICATIONS OF GEOTHERMALLYPRODUCED COLLOIDAL SILICA IN RESERVOIR MANAGEMENT - SMART GELS

Jonathan Hunt, Souheil Ezzedine, William Bourcier, and Sarah Roberts

January 31, 2013 
Lawrence Livermore National Laboratory

\section{Applications of Geothermally-Produced Colloidal Silica in Reservoir Management - SMART GELS}

Jonathan Hunt, Souheil Ezzedine, William Bourcier, and Sarah Roberts 


\section{Disclaimer}

This document was prepared as an account of work sponsored by an agency of the United States government. Neither the United States government nor Lawrence Livermore National Security, LLC, nor any of their employees makes any warranty, expressed or implied, or assumes any legal liability or responsibility for the accuracy, completeness, or usefulness of any information, apparatus, product, or process disclosed, or represents that its use would not infringe privately owned rights. Reference herein to any specific commercial product, process, or service by trade name, trademark, manufacturer, or otherwise does not necessarily constitute or imply its endorsement, recommendation, or favoring by the United States government or Lawrence Livermore National Security, LLC. The views and opinions of authors expressed herein do not necessarily state or reflect those of the United States government or Lawrence Livermore National Security, LLC, and shall not be used for advertising or product endorsement purposes.

\section{Auspices Statement}

This work performed under the auspices of the U.S. Department of Energy by Lawrence Livermore National Laboratory under Contract DE-AC52-07NA27344.

\section{Acknowledgment}

This work was sponsored by the Geothermal Technologies Office in the Department of Energy. 


\section{TABLE OF CONTENTS}

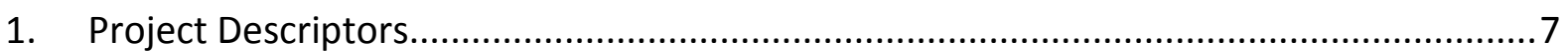

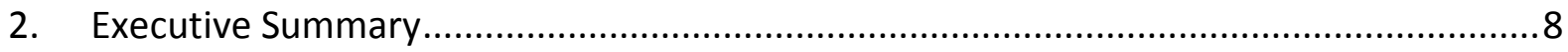

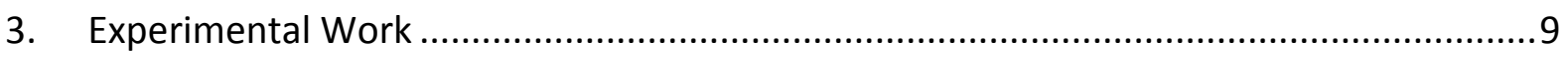

3.1 Previous work and determination of current work focus .....................................

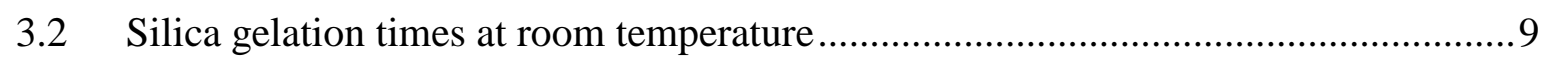

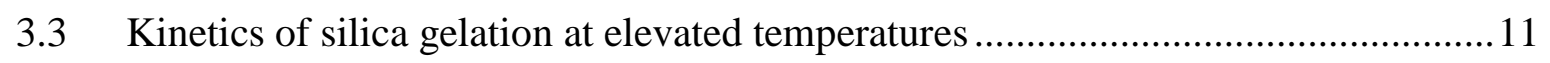

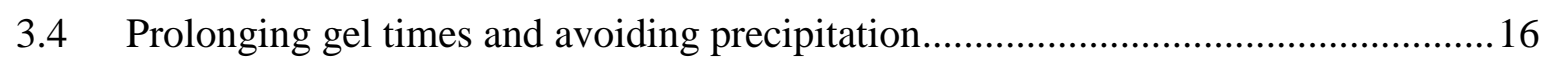

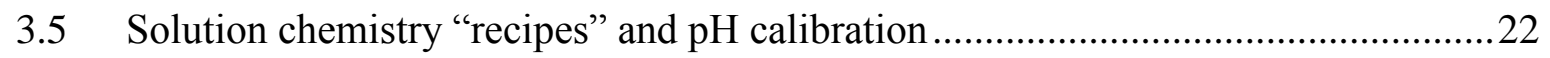

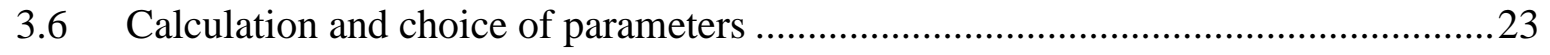

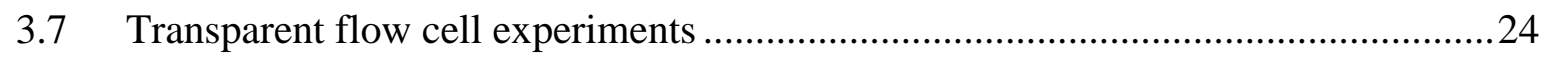

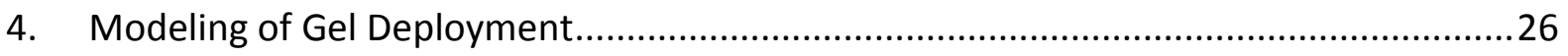

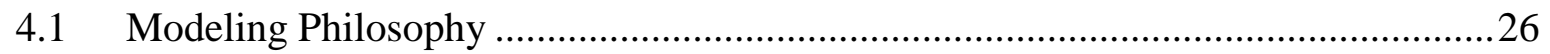

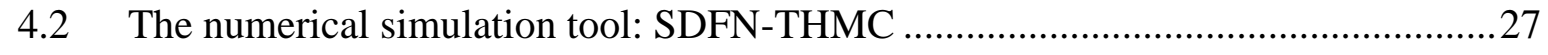

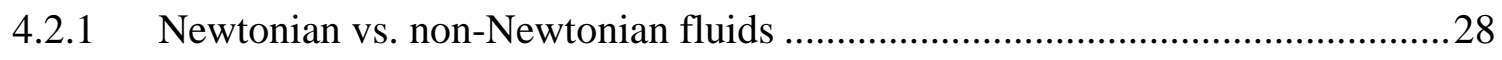

4.2.2 Two dimensional simulations of gel deployment ...........................................28

4.3 Impact of uncertainties on gel deployment in an EGS ........................................29

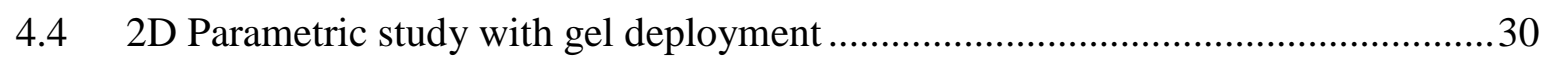

4.5 Minimizing water losses from EGS using gel emplacement .................................. 32

4.6 Gels in 3D porous media: sedimentary geothermal reservoirs ................................34

4.7 Modeling of gel deployment for remediating short-circuits ....................................35

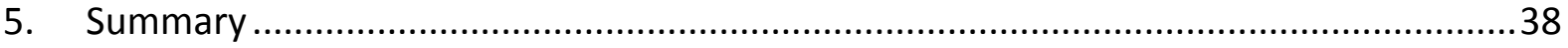

$5.1 \quad$ Summary of Laboratory Experiments …....................................................... 38

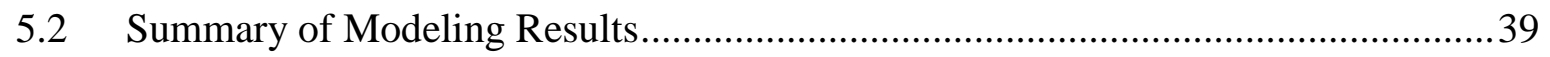

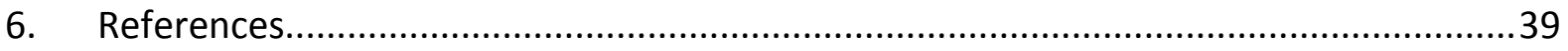




\section{LisT OF FIgURES, EqUATIONS AND TABLES}

Figure 1. Silica gel produced from the Mammoth Lakes geothermal fluid. The gel is made up of a network of

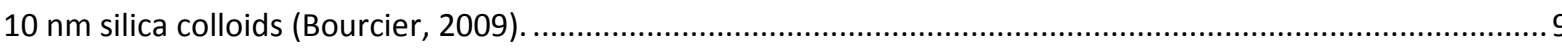

Figure 2. Log gel time versus silica concentration. Dashed lines represent $95 \%$ confidence intervals .............. 10 Figure 3. Log gel time versus salt/silica ratio and log gel time versus $\mathrm{cl}^{-} / \mathrm{na}^{+}$(UN) ratio. Dashed lines represent

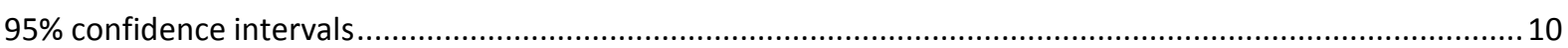

Figure 4. Percent error in gel times vs. observed gel times........................................................................... 11

Figure 5. Viscosity, oil bath temperature and sample temperature measurements as a function of time........13

Figure 6. Viscosity, oil bath temperature and sample temperature as a function of time, at a nominal experimental temperature of $200^{\circ} \mathrm{C}$

Figure 7. Gel time as a function of heating path.

Figure 8. Gel (right) produced in a $300{ }^{\circ} \mathrm{C}$ oven. Water was prevented from escaping by sealing the colloidal solution in a Swagelok capsule (left). The shape of the gel reflects the internal geometry of the capsule. ......17 Figure 9. Above: gel after 20 minutes at $300^{\circ} \mathrm{C}$. Below: 4 hours (left), 18 hours (middle), 72 hours (right)...17 Figure 10. Viscosity, oil bath temperature and sample temperature measurements as a function of time. This solution did not gel but merely deposited amorphous silica on the sample chamber walls. ............................18

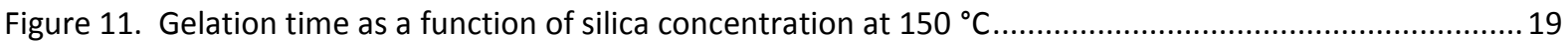

Figure 12. Ductile paste formed in the transition between gelation and non-gelation regimes. .....................19

Figure 13. Contour plot of modeled gel times at $150{ }^{\circ} \mathrm{C}$ as a function of silica concentration and $\mathrm{pH}$.............20

Figure 14. Transparent flow cell experimental setup showing gel emplacement .............................................24

Figure 15. Flow-through apparatus to observe fluid diversion in porous media ...........................................25

Figure 16. Closeup of Figure 15. Isolated circulation cell in porous media. Silica gel is dyed green (on the left) and blue (on the right) to indicate location of blockages. The injection and production wells are still able to communicate with each other....

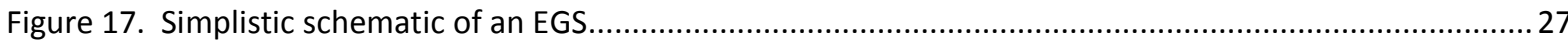

Figure 18. SDFN-THMC (Ezzedine, 2005) offers an ideal numerical framework to address the problem of deploying silica gel in EGS. The model allows for flow, thermal, and mechanical \& chemical simulation in a $3 \mathrm{~d}$ stochastic discrete fracture network

Figure 19. Normalized velocity profile of fluid within fracture aperture. Parameters $\mathrm{m}$ and $\mathrm{n}$ are characteristics of the fluid and the profile. Red profile, parabolic, is the Newtonian, the other two (blue and green) are nonNewtonian

Figure 20. Two dimensional doublet flow simulations in a single fracture. Left: flow network (pressure and streamlines) in a smooth fracture. Center: aperture random field, red depicts large aperture while blue depicts small aperture. Right: flow network in a rough fracture.

Figure 21. Two dimensional doublet flow and transport simulations of gel in a single rough fracture. Left: Thermal test protocol and temperature responses as function of time. Center: aperture random field with crescent-like diverter e.g. gelled silica. Right: flow network showing the impact of gelled silica on streamlines and flow cells.

Figure 22. Flowchart of uncertainty propagation and quantification for EGS applications. Using a Monte Carlo (MC) scheme one can assess the impact of characterization uncertainties on the EGS response. Here the impact of the size of fracture on production rate is quantified through a sensitivity analysis using MC simulations.

Figure 23. Snapshots of two dimensional doublet flow and transport simulations of gel in a single rough fracture. Time flows from top to bottom and left to right. Top left picture depicts the hydrological conditions. Painted colors are not at the same scale; these pictures are for illustration purposes. 
Figure 24. Illustration of different outcomes of gel deployment as a function of the key physico-chemical parameters that govern flow, heat, gel transport and gelation time......

Figure 25. Snapshots of two dimensional doublet flow and transport simulations of gel in a single smooth (left) rough fracture (right). Time flows from top to bottom. Each frame depicts the gel location and the flownet. In the 4 top frames the production well is off, while in the last row the production well is on.

Figure 26. Initial (left) and final (right) snapshots of two dimensional doublet flow and transport simulations of gel in a single smooth (top) rough fracture (bottom). Each frame depicts the gel location and the flownet. In the left frames the production well is off, while in the right frames the production well is on.

Figure 27. Illustration of 3D sedimentary geothermal reservoir. This figure shows both injection and production wells intersecting the injection/extraction horizon.

Figure 28. Illustration of 3D sedimentary geothermal reservoir. Snapshots A-F depict the time evolution of the injected silica while frame $(G)$ depicts the complex streamlines around the silica gel.

Figure 29. Schematic of a vertical cross-section through a 3D geothermal reservoir. Figure shows the operational wells which are embedded in a double porosity medium (DP), the background reservoir is considered as a single porous medium (SP). Several fractures are also embedded with the reservoir; two of them intersect both wells. The bottom fracture, unseen by both wells, plays the role of high conductive fracture and thus short-circuiting both "wells".

Figure 30. Schematic of a vertical cross-section through a 3D geothermal reservoir. Figure shows the operational wells. Adaptive mesh refinement was used to represent the fractures with high fidelity and illustrated though several zoom-outs.

Figure 31. Schematic of a vertical cross-section through a 3D geothermal reservoir near the injection well. Figure depicts streamlines with the domain. Adaptive mesh refinement was used to represent the fractures and the streamlines with high fidelity and illustrated though several zoom-outs. Streamlines are essential for tracking the silica gel deployment and to assess the impact of mixing within fractures on the gelation time.... 37 Figure 32. Schematic of a vertical cross-section through a 3D geothermal reservoir before gel deployment. A tracer (thermal) test was injected. Figure depicts time-snapshots of the tracer/heat transfer through the reservoir. Time flows from left to right and top to bottom. Blue color depicts cold regions while red color represents hot regions. One can see that the bottom fracture plays the role of a fast-path short-circuiting fracture, note the arrival of cold water at the heel of the extraction well.

Figure 33. Schematic of a vertical cross-section through a 3D geothermal reservoir after gel deployment. A tracer (thermal) test was injected. Figure depicts time-snapshots of the tracer/heat transfer through the reservoir. Time flows from left to right and top to bottom. Blue color depicts cold regions while red color represents hot regions. One can see that the bottom fracture is obstructed after silica gel has been deployed and that the cold region initially observed before gel deployment has vanished.

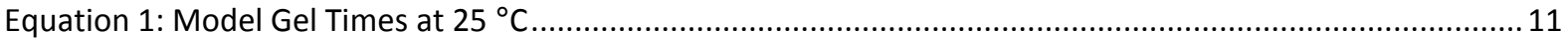

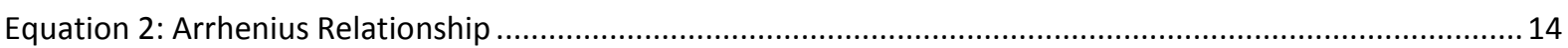

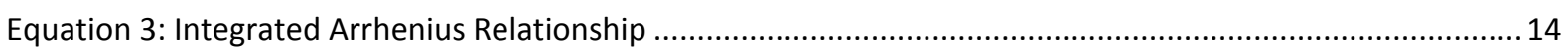

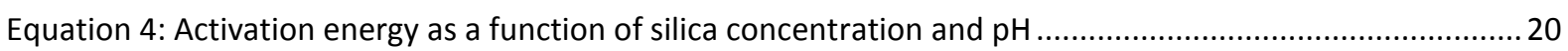

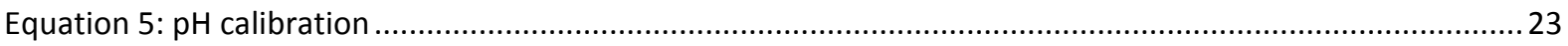

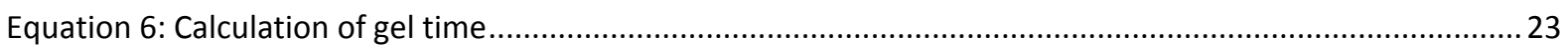

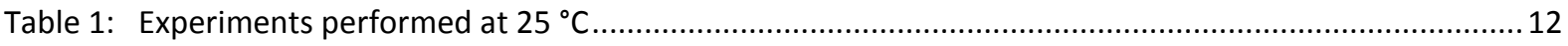

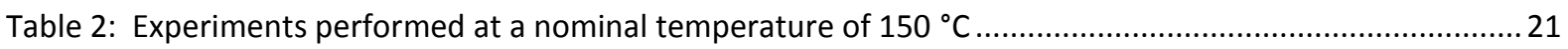




\section{Project Descriptors}

\section{Reporting Period: FY 2013}

DOE Grant / Contract \#: DE-AC52-07NA27344

Performing Organization: Lawrence Livermore National Laboratory, 7000 East Avenue, P.O. Box 808, Livermore, CA 94551

Principal Investigators: Bill Bourcier, Sarah Roberts

Phone: (925) 422-9885, (925) 423-4112

E-Mail: bourcier1@1lnl.gov, roberts28@1lnl.gov

Collaborating Researchers: Jonathan Hunt (hunt50@1lnl.gov), Souheil Ezzedine (ezzedine1@1lnl.gov)

Program Area: Reservoir Sustainability/Coproduced Fluids/EGS Technology

DOE Program Manager: Lauren Boyd, EGS Technology and Timothy Reinhardt, CoProduced Fluids

DOE GTP Point of contact: Joshua Mengers 


\section{Executive Summary}

\section{Project Objective: Determine the suitability of co-extracted colloidal silica as a zonal isolation material in EGS and conventional geothermal reservoir management and optimization.}

In enhanced geothermal systems (EGS) the reservoir permeability is often enhanced or created using hydraulic fracturing. In hydraulic fracturing, high fluid pressures are applied to confined zones in the subsurface usually using packers to fracture the host rock. This enhances rock permeability and therefore conductive heat transfer to the circulating geothermal fluid (e.g. water or supercritical carbon dioxide). The ultimate goal is to increase or improve the thermal energy production from the subsurface by either optimal designs of injection and production wells or by altering the fracture permeability to create different zones of circulation that can be exploited in geothermal heat extraction. Moreover, hydraulic fracturing can lead to the creation of undesirable short-circuits or fast flow-paths between the injection and extraction wells leading to a short thermal residence time, low heat recovery, and thus a short-life of the EGS.

A potential remedy to these problems is to deploy a cementing (blocking, diverting) agent to minimize short-cuts and/or create new circulation cells for heat extraction. A potential diverting agent is the colloidal silica by-product that can be co-produced from geothermal fluids. Silica gels are abundant in various surface and subsurface applications, yet they have not been evaluated for EGS applications. In this study we are investigating the benefits of silica gel deployment on thermal response of an EGS, either by blocking short-circuiting undesirable pathways as a result of diverting the geofluid to other fractures; or creating, within fractures, new circulation cells for harvesting heat through newly active surface area contact. A significant advantage of colloidal silica is that it can be co-produced from geothermal fluids using an inexpensive membrane-based separation technology that was developed previously using DOE-GTP funding.

This co-produced silica has properties that potentially make it useful as a fluid diversion agent for subsurface applications. Colloidal silica solutions exist as low-viscosity fluids during their "induction period" but then undergo a rapid increase in viscosity (gelation) to form a solid gel. The length of the induction period can be manipulated by varying the properties of the solution, such as silica concentration and colloid size. We believe it is possible to produce colloidal silica gels suitable for use as diverting agents for blocking undesirable fast-paths which result in short-circuiting the EGS once hydraulic fracturing has been deployed. In addition, the gels could be used in conventional geothermal fields to increase overall energy recovery by modifying flow.

We believe there may be additional advantages for using colloidal silica as blocking agents:

- It can be inexpensively produced on site or at other geothermal sites (Figure 1)

- It is inorganic and environmentally friendly as opposite to organic gels often used in oil/gas industry

- Unlike conventional blocking agents, the gel material is not a brittle solid and if needed might be hydraulically removed after emplacement

- Colloidal silica gelation can be triggered externally, for example by mixing with salt solutions, changing the $\mathrm{pH}$, or increasing temperature 
- There should be fewer environmental restrictions and permitting requirements for its use given that the material originates in the same place it is to be injected

- Silica removal in itself benefits the power plant in terms of silica scale control

We believe the ability to use geothermally-produced silica as a zonal isolation material is a potential breakthrough technology for control and optimization of geothermal heat recovery.

In this work, we examine the use of colloidal silica as a blocking agent in the laboratory and using numerical models to scale the lab-derived measurements to field scale.

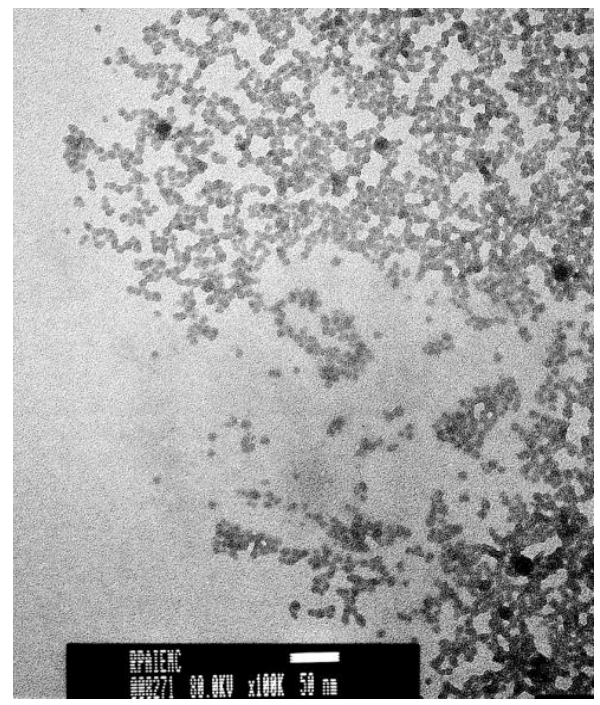

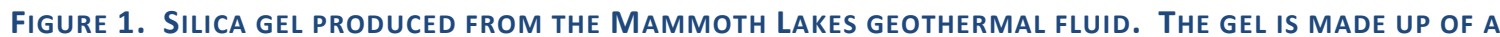
NETWORK OF 10 NM SILICA COLLOIDS (BOURCIER, 2009).

\section{Experimental Work}

\subsection{Previous work and determination of current work focus}

To accurately predict when an injected geothermal fluid will set up and turn to gel, a quantitative understanding of the kinetics of silica gelation is required. Although silica gelation has been studied for decades, even the most comprehensive resource (Iler, 1979) provides only a qualitative understanding of the various factors $(\mathrm{pH}$, salt concentration, temperature, colloid diameter, $\mathrm{SiO}_{2}$ concentration, etc.) that influence gelation times. We did not find any quantitative method or model for predicting gel times from colloidal silica compositions. Such a method is needed to develop formulations for colloidal silica solutions for given geothermal applications. In addition, there is very little information on gel times at elevated temperatures. Because of these needs, we began an effort to acquire additional data that could be combined with the existing data to develop a more comprehensive quantitative model for use in our geothermal application.

\subsection{Silica gelation times at room temperature}

We have determined the relationship between gelation time and silica concentration, $\mathrm{Cl}^{-} / \mathrm{Na}^{+}$ ratio, which is also known as the universal neutralization (UN) ratio, as a proxy for $\mathrm{pH}$, and added salinity in the form of $\mathrm{NaCl}$, all at $25^{\circ} \mathrm{C}$. The major finding of our investigation at $25^{\circ} \mathrm{C}$ was that there is a simple and clear relationship between gelation time and $\mathrm{SiO}_{2}$ concentration. Previous investigations varied $\mathrm{SiO}_{2}$ concentration while keeping $\mathrm{pH}$ and $\mathrm{NaCl}$ 
concentration constant. However, if the dilution is done by adding different amounts of water to identical mixtures of colloidal silica sol, $\mathrm{NaCl}$, and $\mathrm{HCl}$, a linear relationship arises between the logarithm of gelation time and the logarithm of the silica concentration, shown in Figure 2. Added salinity decreased gelation times markedly, with progressively smaller effects as more salt was added. Changing the $\mathrm{Cl}^{-} / \mathrm{Na}^{+}$ratio (and thereby $\mathrm{pH}$ ) via addition of $\mathrm{HCl}$ was more complex still, with competing rate-limiting steps at low and high $\mathrm{pH}$. The effects of $\mathrm{NaCl}$ and $\mathrm{pH}$ are shown in Figure 3.

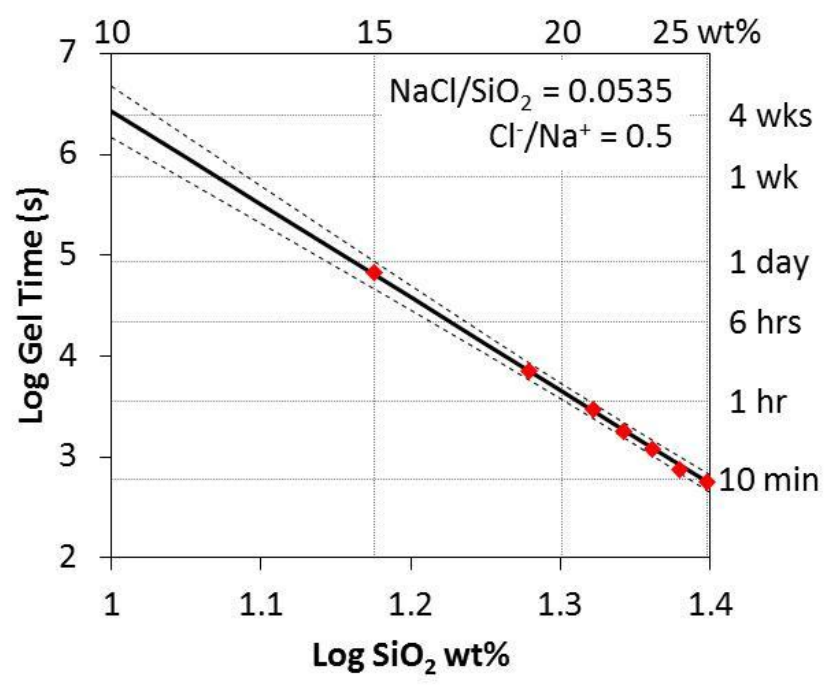

Figure 2. LOG GEL TIME VERSUS SiLICA CONCENTRATION.

DASHED LINES REPRESENT 95\% CONFIDENCE INTERVALS
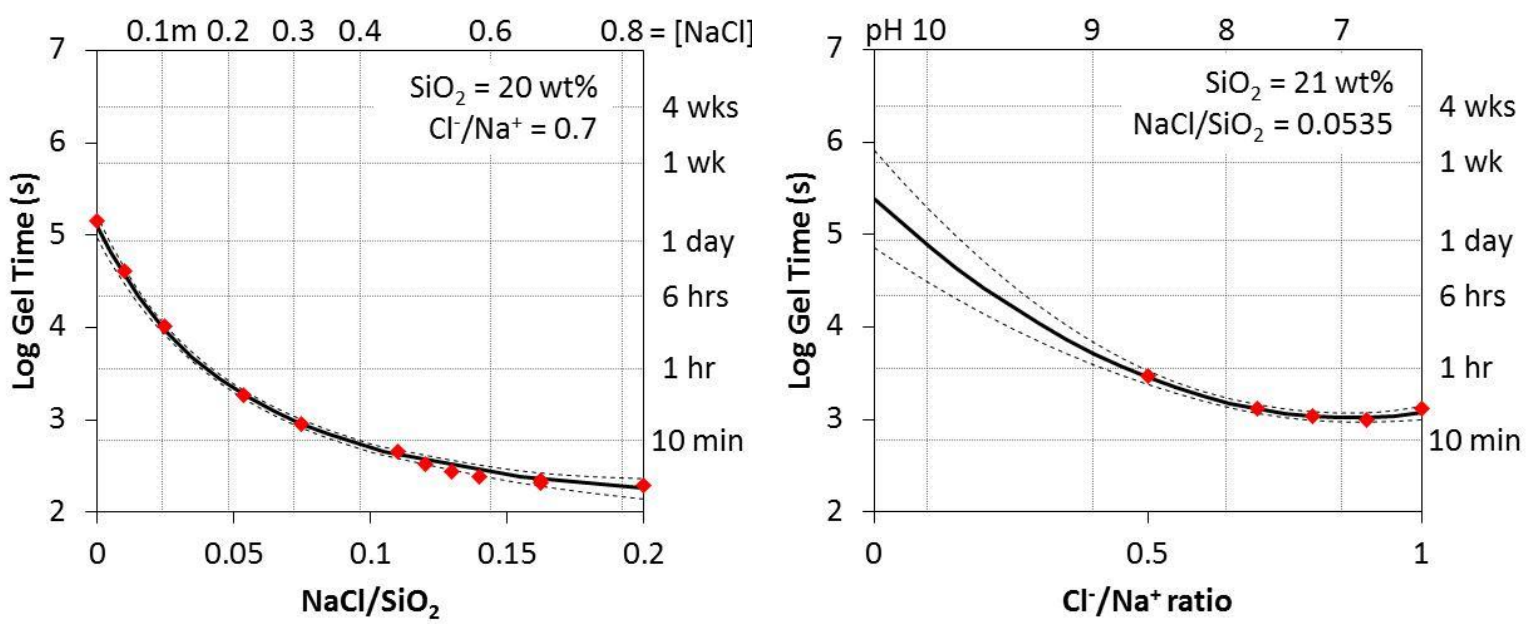

Figure 3. Log Gel time Versus Salt/Silica RATIO AND LOG GEL TIME VERSUS $\mathrm{CL}^{-} / \mathrm{NA}^{+}$(UN) RATIO.

DASHED LINES REPRESENT 95\% CONFIDENCE INTERVALS

The experiments, which are listed in Table 1, were fitted to a regression equation with 11 parameters as a function of silica concentration (wt \%), molar $\mathrm{NaCl} / \mathrm{SiO}_{2}$ ratio, and molar $\mathrm{Cl}^{-}$ $/ \mathrm{Na}^{+}$ratio (added $\mathrm{NaCl}$ is not included in the $\mathrm{Cl}^{-} / \mathrm{Na}^{+}$ratio, nor is the $\mathrm{NaCl}$ formed by addition of $\mathrm{HCl}$ included in the $\mathrm{NaCl} / \mathrm{SiO}_{2}$ ratio). The regression equation $\left(\mathrm{R}^{2}=0.9961\right)$ is as follows: 


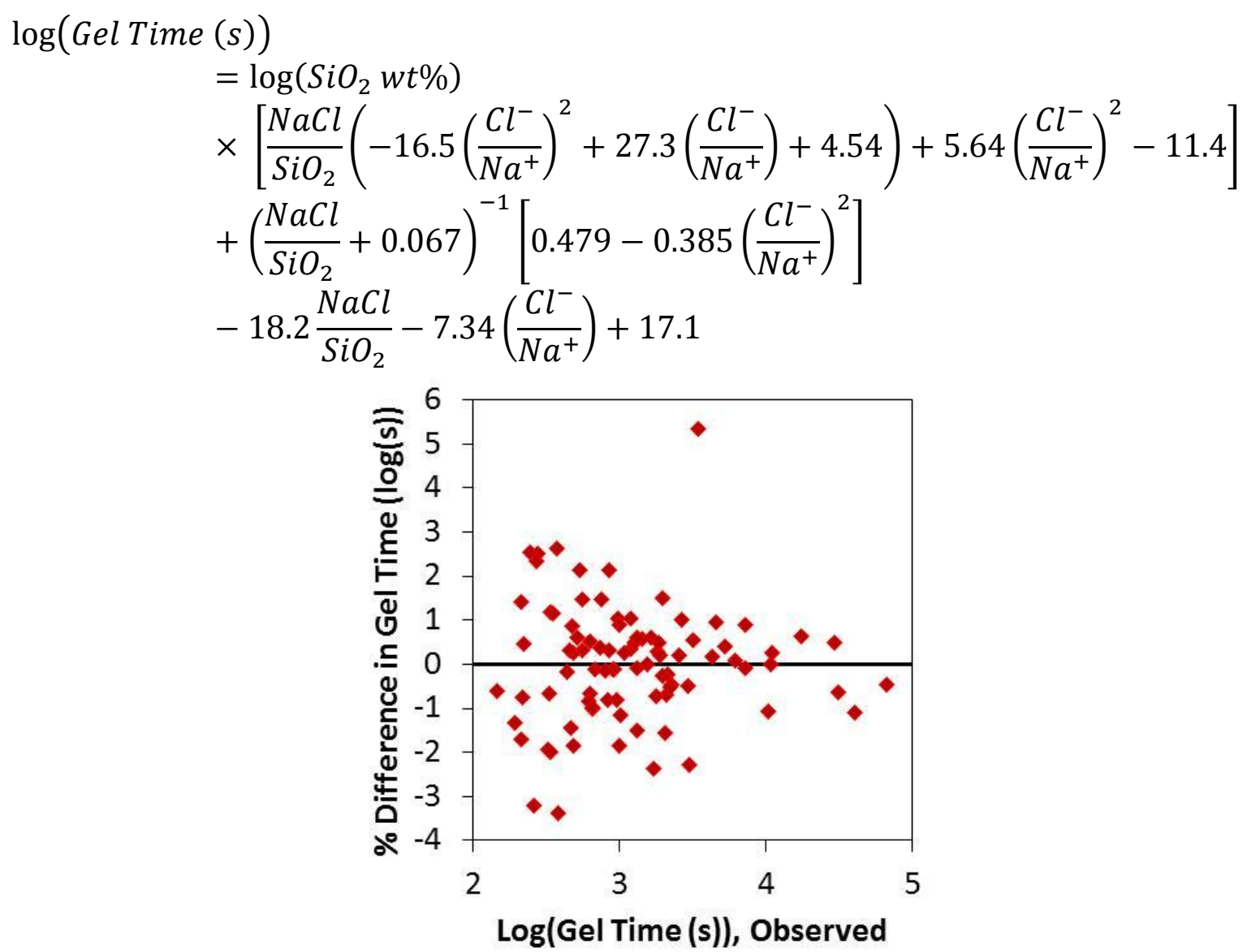

Figure 4. Percent error in Gel times Vs. observed gel times

Figure 4 shows the error between prediction and measurement for each experiment listed in Table 1. No systematic error was observed over $\mathrm{SiO}_{2}$ concentration, $\mathrm{Cl}^{-} / \mathrm{Na}^{+}$ratio, $\mathrm{NaCl} / \mathrm{SiO}_{2}$ ratio, or observed gelation time.

\subsection{Kinetics of silica gelation at elevated temperatures}

The kinetics of silica gelation follow an Arrhenius relationship. Activation energies found in the literature range from $5-20 \mathrm{kcal} / \mathrm{mol}$ (Iler, 1979). A rough approximation of this relationship is that the gelation time is halved for every increase of $10^{\circ} \mathrm{C}$. Due to this high dependence on temperature, nearly all of the chemistries specifically investigated at $25^{\circ} \mathrm{C}$ would turn to gel too rapidly for use in geothermal reservoirs. However, the model developed at $25^{\circ} \mathrm{C}$ can be used to extrapolate to higher $\mathrm{pH}$, lower $\mathrm{NaCl}$, and lower silica concentration, all of which would increase gel times at $25^{\circ} \mathrm{C}$ to months or years. These long gel times at low temperature implied gel times on the order of hours at geothermal reservoir temperatures. We investigated one solution chemistry in depth, with no added salt and a $\mathrm{Cl}^{-}$ $/ \mathrm{Na}^{+}$ratio of 0.5 , and varied the silica concentration. The finite time needed to heat the sample was taken into account, and activation energies were determined to vary with silica concentration from $18-26 \mathrm{kcal} / \mathrm{mol}$. The longest gel time achieved at a nominal bath temperature of $150{ }^{\circ} \mathrm{C}$ using this solution chemistry was approximately 45 minutes, including heating time. Figure 5 is a typical viscosity curve of gelation, illustrating the 45 minute experiment. 
TABLE 1: EXPERIMENTS PERFORMED AT $25^{\circ} \mathrm{C}$

\begin{tabular}{|c|c|c|c|c|c|c|c|c|c|c|c|c|c|c|}
\hline Exp. \# & $\begin{array}{c}\mathrm{Cl}^{-} \\
/ \mathrm{Na}^{+}\end{array}$ & $\mathrm{NaCl} / \mathrm{Si}$ & $\begin{array}{l}\text { SiO2 } \\
\text { wt\% } \\
\end{array}$ & $\begin{array}{c}\text { Gel Time } \\
\text { (s) }\end{array}$ & Exp.\# & $\begin{array}{c}\mathrm{Cl}^{-} \\
/ \mathrm{Na}^{+}\end{array}$ & $\mathrm{NaCl} / \mathrm{Si}$ & $\begin{array}{l}\text { SiO2 } \\
\text { wt\% } \\
\end{array}$ & $\begin{array}{c}\text { Gel Time } \\
\text { (s) }\end{array}$ & Exp. \# & $\begin{array}{c}\mathrm{Cl}^{-} \\
/ \mathrm{Na}^{+}\end{array}$ & $\mathrm{NaCl} / \mathrm{Si}$ & $\begin{array}{l}\mathrm{SiO2} \\
\text { wt\% }\end{array}$ & $\begin{array}{c}\text { Gel Time } \\
\text { (s) }\end{array}$ \\
\hline 1 & 0.7 & 0.0535 & 24 & 453 & 32 & 0.5 & 0.1622 & 17 & 486 & 62 & 0.7 & 0.1622 & 19 & 380 \\
\hline 2 & 0.7 & 0.0535 & 22 & 959 & 33 & 0.5 & 0.1622 & 16 & 832 & 63 & 0.7 & 0.1622 & 18 & 485 \\
\hline 3 & 0.7 & 0.0535 & 20 & 1876 & 34 & 0.5 & 0.1622 & 15 & 1201 & 64 & 0.7 & 0.1622 & 17 & 654 \\
\hline 4 & 0.7 & 0.0535 & 14 & 29033 & 35 & 0.5 & 0.1622 & 10 & 31147 & 65 & 0.7 & 0.1622 & 20 & 222 \\
\hline 5 & 0.7 & 0.0535 & 23 & 622 & 36 & 0.5 & 0.11 & 22 & 214 & 66 & 0.7 & 0.1622 & 16 & 892 \\
\hline 6 & 0.7 & 0.0535 & 21 & 1313 & 37 & 0.5 & 0.11 & 21 & 323 & 67 & 0.7 & 0.1622 & 15 & 1268 \\
\hline 7 & 0.7 & 0.0535 & 18 & 4266 & 38 & 0.5 & 0.11 & 20 & 440 & 68 & 1 & 0.1622 & 20 & 851 \\
\hline 8 & 0.7 & 0.0535 & 16 & 10803 & 39 & 0.5 & 0.11 & 19 & 675 & 69 & 1 & 0.1622 & 18 & 1324 \\
\hline 9 & 1 & 0.0535 & 25 & 476 & 40 & 0.5 & 0.11 & 18 & 983 & 70 & 1 & 0.1622 & 17 & 1759 \\
\hline 10 & 1 & 0.0535 & 23 & 738 & 41 & 0.5 & 0.11 & 17 & 1634 & 71 & 0.5 & 0.0535 & 15 & 66290 \\
\hline 11 & 1 & 0.0535 & 21 & 1317 & 42 & 0.5 & 0.11 & 16 & 2632 & 72 & 0.9 & 0.11 & 21 & 514 \\
\hline 12 & 1 & 0.0535 & 19 & 1970 & 43 & 0.5 & 0.11 & 15 & 4523 & 73 & 1 & 0.11 & 21 & 848 \\
\hline 13 & 1 & 0.0535 & 17 & 3190 & 44 & 0.5 & 0.1622 & 14 & 1960 & 74 & 0.7 & 0.2 & 20 & 193 \\
\hline 14 & 1 & 0.0535 & 15 & 6125 & 45 & 0.5 & 0.1622 & 20 & 146 & 75 & 0.7 & 0.14 & 20 & 244 \\
\hline 15 & 1 & 0.0535 & 22 & 1019 & 46 & 0.7 & 0.11 & 22 & 261 & 76 & 0.7 & 0.025 & 20 & 10317 \\
\hline 16 & 1 & 0.0535 & 24 & 654 & 47 & 0.7 & 0.11 & 21 & 338 & 77 & 0.7 & 0.01 & 20 & 40536 \\
\hline 17 & 0.9 & 0.0535 & 25 & 350 & 48 & 0.7 & 0.11 & 20 & 460 & 78 & 0.7 & 0.075 & 20 & 916 \\
\hline 18 & 0.9 & 0.0535 & 23 & 561 & 49 & 0.7 & 0.11 & 19 & 627 & 79 & 0.7 & 0.13 & 20 & 274 \\
\hline 19 & 0.9 & 0.0535 & 21 & 996 & 50 & 0.7 & 0.11 & 18 & 990 & 80 & 0.7 & 0.12 & 20 & 337 \\
\hline 20 & 0.9 & 0.0535 & 19 & 1854 & 51 & 0.7 & 0.1622 & 20 & 211 & 81 & 0.7 & 0 & 20 & 144418 \\
\hline 21 & 0.9 & 0.0535 & 15 & 7273 & 52 & 0.7 & 0.11 & 16 & 2070 & 82 & 0.7 & 0.025 & 25 & 1430 \\
\hline 22 & 0.5 & 0.0535 & 25 & 559 & 53 & 0.8 & 0.0535 & 23 & 615 & 83 & 0.7 & 0.025 & 24 & 2123 \\
\hline 23 & 0.5 & 0.0535 & 24 & 753 & 54 & 0.8 & 0.0535 & 22 & 800 & 84 & 0.7 & 0 & 25 & 17391 \\
\hline 24 & 0.5 & 0.0535 & 23 & 1199 & 55 & 0.8 & 0.0535 & 21 & 1075 & 85 & 1 & 0.11 & 16 & 2565 \\
\hline 25 & 0.5 & 0.0535 & 22 & 1809 & 56 & 0.8 & 0.0535 & 20 & 1534 & 86 & 0.9 & 0.11 & 16 & 2208 \\
\hline 26 & 0.5 & 0.0535 & 19 & 7200 & 57 & 0.8 & 0.0535 & 19 & 2268 & 87 & 0.7 & 0.01 & 25 & 5272 \\
\hline 27 & 0.5 & 0.0535 & 21 & 2954 & 58 & 0.7 & 0.1622 & 19 & 273 & 88 & 1 & 0 & 25 & 1711 \\
\hline 28 & 1.1 & 0.0535 & 22 & 9178 & 59 & 0.7 & 0.1622 & 18 & 370 & 89 & 1 & 0 & 24 & 2039 \\
\hline 29 & 1.1 & 0.0535 & 15 & 43137 & 60 & 0.7 & 0.1622 & 17 & 535 & 90 & 1 & 0.1622 & 15 & 3002 \\
\hline 30 & 0.5 & 0.1622 & 19 & 219 & 61 & 0.8 & 0.0535 & 15 & 10943 & 91 & 0.5 & 0 & 25 & 168043 \\
\hline 31 & 0.5 & 0.1622 & 18 & 331 & \multicolumn{10}{|c|}{$\begin{array}{l}{ }^{*} \mathrm{NaCl} / \mathrm{Si} \text { ratio does not include } \mathrm{NaCl} \text { formed by addition of } \mathrm{HCl} \text { to the } \mathrm{Na}+\text { stabilizer. } \\
\text { Likewise, the } \mathrm{Cl}^{-} / \mathrm{Na}^{+} \text {ratio does not include added } \mathrm{NaCl} \text {. }\end{array}$} \\
\hline
\end{tabular}




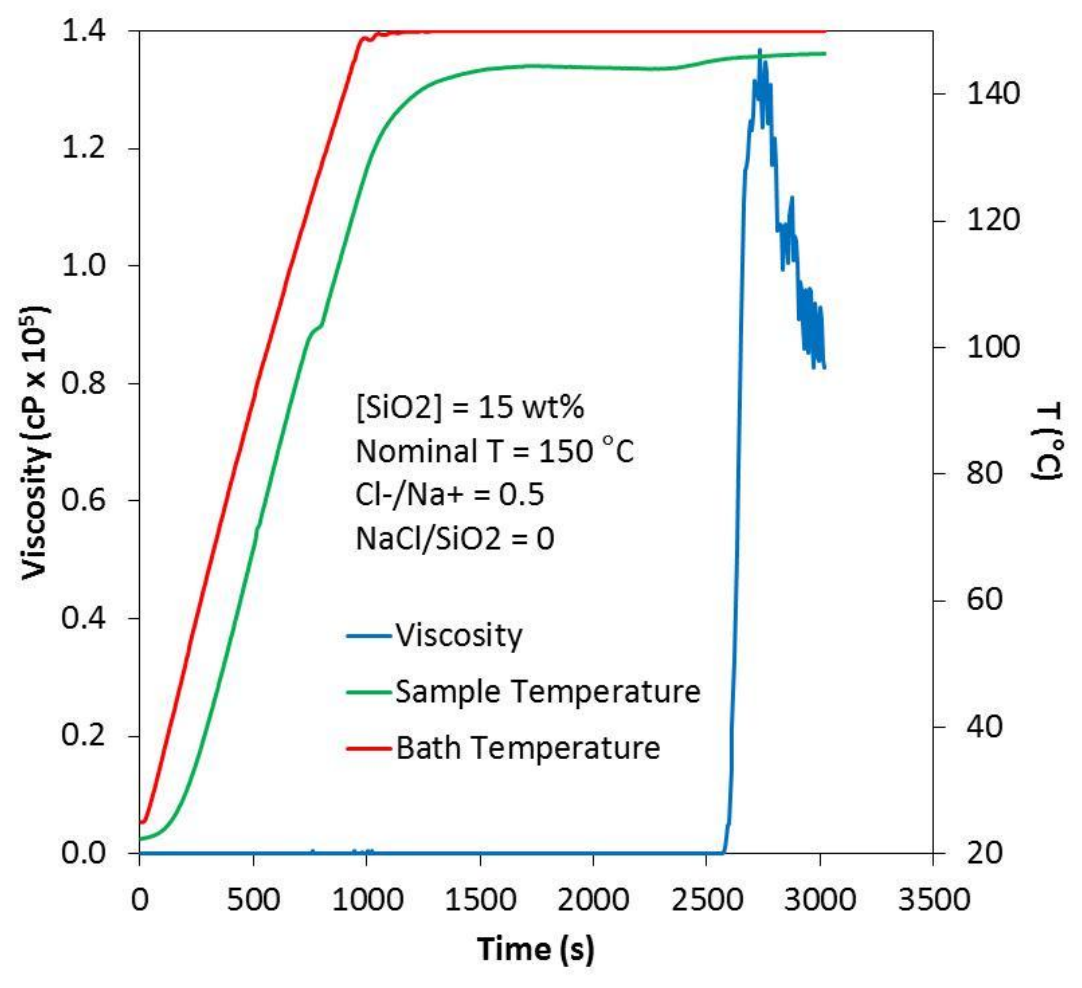

FIGURE 5. VISCOSITY, OIL BATH TEMPERATURE AND SAMPLE TEMPERATURE MEASUREMENTS AS A FUNCTION OF TIME.

The blue line in Figure 5 is the viscosity of the sample, measured in cP. As detailed in previous reports, the initial sol undergoes an induction period where the viscosity of the fluid is essentially that of water. After the induction period, the viscosity increases very rapidly and the fluid solidifies into a gel. The measured viscosity drops off after this occurs due to the gel slipping past the inner cylinder of the rheometer, and therefore exerting a lower torque on the sensor. The red line is the oil bath temperature, and the green line is the sample temperature.

In order to investigate kinetics experiments at elevated temperature, a finite sample heating time must be taken into account. In Figure 5, the sample temperature took approximately 15 minutes to approach the nominal temperature of the experiment, and gelled within 45 minutes of the start of the experiment. To say that the solution chemistry of Figure 5 gels in 45 minutes at $150{ }^{\circ} \mathrm{C}$ would therefore be inaccurate, as the sample did not reach its ultimate temperature for a full third of the duration of the experiment. Nor can we assume that because a finite heating time is always necessary, it can be cancelled out or ignored, as the heating path of the sample may not be the same in the laboratory and the field.

However, this is not a problem for laboratory experiments, as a finite heating time for the sample can be taken into account as long as the temperature of the solution is known at all times. The nominal temperature of the experiment is therefore less important than knowing the temperature vs. time history of the solution/gel. This is the main reason that the bath temperature in our experiments is not initially set to the nominal temperature of the experiment: by minimizing temperature gradients between the sample and the bath, we can rely on the sample temperature measurement. Figure 6 shows an experiment with a large 
temperature gradient between the bath and sample. This temperature gradient leads to a quicker gel time than would be inferred from the sample temperature profile. The temperature vs. time history will also be important when injecting gels into geothermal reservoirs - the solution will not immediately reach the nominal temperature of the reservoir, and this can be taken advantage of to ensure longer gelation times.

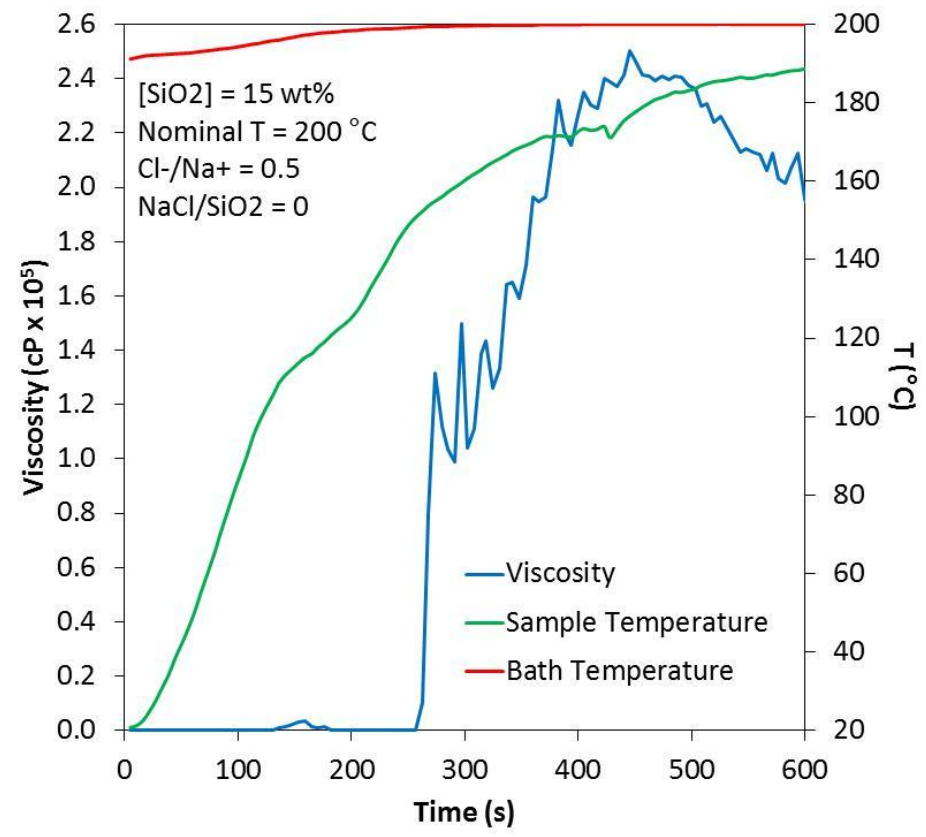

FIgURE 6. VISCOSITY, OIL BATH TEMPERATURE AND SAMPLE TEMPERATURE AS A FUNCTION OF TIME, AT A NOMINAL EXPERIMENTAL TEMPERATURE OF $200{ }^{\circ} \mathrm{C}$

Silica gels follow an Arrhenius relationship with temperature, shown in Equation 2.

Equation 2: ARrhenius Relationship

$$
\ln \left[\frac{t_{g e l}(T)}{t_{g e l}\left(T_{0}\right)}\right]=\frac{E_{A}}{R}\left[\frac{1}{T}-\frac{1}{T_{0}}\right]
$$

For any given experimental heating path, we are missing several parameters from this equation. While the gel time of the experiment is measured, and the gel time of the chemistry at $25^{\circ} \mathrm{C}$ can be modeled via Equation 1, we do not know the activation energy, nor do we have a single temperature to insert into the equation. To truly account for a finite heating time, Equation 2 must be integrated over time, with temperature being a function of time. This is shown in Equation 3.

Equation 3: Integrated Arrhenius Relationship

$$
t_{g e l}\left(T_{0}\right)=\int_{0}^{t_{g e l}} e^{\frac{-E_{A}}{R}\left(\frac{1}{T(t)}-\frac{1}{T_{0}}\right)} d t
$$

Unfortunately, even if the experimental temperature as a function of time can be described by a functional form, this is an integral with no closed form solution, and must therefore be 
numerically calculated. For a given heating path, such as the one in Figure 5 above, $t_{\text {gel }}\left(T_{0}\right)$ can be numerically calculated using Equation 3 for a given value of $\mathrm{E}_{\mathrm{A}}$. The activation energy can therefore be solved for by using the modeled $25^{\circ} \mathrm{C}$ gel time and a simple iterative solver, such as Excel's goal seek or solver functions. Once the activation energy is known for the particular experiment, a single "effective temperature" can be calculated using Equation 2. While it would of course be more accurate to measure the gel time of the same chemistry for multiple different heating paths (i.e., most likely to different nominal temperatures), set their integrals equal to each other to minimize the error in the activation energy and thereby avoid the use of extrapolated model values, this was not generally possible due to time constraints. However, this was performed on one solution chemistry, as a proof of concept and proof of the $25^{\circ} \mathrm{C}$ model, shown in Figure 7.

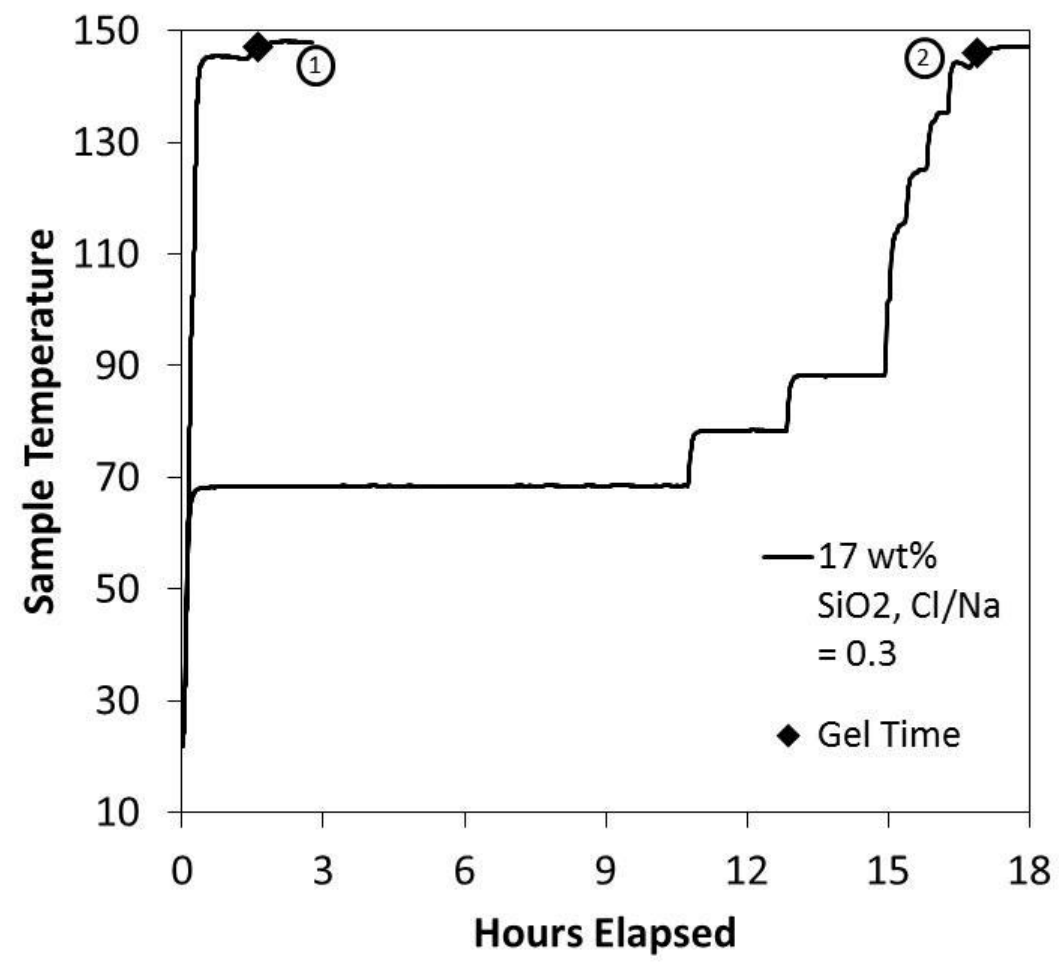

Figure 7. Gel time as a function of heating path.

This solution chemistry $\left(17 \mathrm{wt} \% \mathrm{SiO}_{2}, \mathrm{Cl}^{-} / \mathrm{Na}^{+}=0.3\right)$ was run in two separate experiments. In the first, represented by path 1 in Figure 7, the sample was placed in the bath, and the bath was then set to a nominal temperature of $150{ }^{\circ} \mathrm{C}$. This is roughly the same temperature path shown in Figure 5. The gel time using this temperature path was approximately 1 hour and 40 minutes. In the second experiment, represented by path 2 in Figure 7, the sample was held at $70^{\circ} \mathrm{C}$ for approximately 10 hours, and then allowed to increase in temperature incrementally until the bath reached a temperature of $150{ }^{\circ} \mathrm{C}$. The total gel time of this temperature path was approximately 17 hours. This is of course not a substitute for a solution chemistry that will remain near $150{ }^{\circ} \mathrm{C}$ for 17 hours before gelling, but it does tell us two important things. First, that silica solutions can be held at lower temperatures (e.g. during injection into a geothermal well) for long periods of time without gelling, before being subjected to the temperature of the actual formation. Second, these paths provide a check on the $25^{\circ} \mathrm{C}$ model. Using Equation 1, Equation 2, and Equation 3, the activation energy of the experiment following path 1 is $21.3 \mathrm{kcal} / \mathrm{mol}$, and the activation energy of the experiment following path 2 is $21.8 \mathrm{kcal} / \mathrm{mol}$. It is difficult to account for the experimental error 
involved in these paths, as changing the observed gel time involves changing the number of steps in the numerical integration, but given the calculated activation energies, an experimental error (in log units) of only $1.5 \%$ is needed to explain this discrepancy.

It should be noted that these reported activation energies are not true activation energies for a specific chemical mechanism of colloids networking together to create a gel. Colloid size plays an important role in the development of gels, and as a colloidal sol is heated, the equilibrium colloid size increases (Iler, 1979). As colloid size increases, there are fewer colloidal particles per unit volume, which actually should increase the gelation time. It is impossible to separate out these effects from each other unless the colloids are already larger than their high-T equilibrium size when they begin to heat. This is complicated even further when a complex temperature-time path is investigated, e.g. path 2 in Figure 7, as the colloids will have more time to come to their equilibrium size at an intermediate temperature. The most useful number, in this case, is the observed activation energy of the overall process, which is reported here and can be used to predict gelation times given a starting chemistry and temperature-time path.

There is no observed effect of pressure on the gelation time, based on the fact that measurements conducted below $100{ }^{\circ} \mathrm{C}$, without additional pressure, and measurements above $100{ }^{\circ} \mathrm{C}$ with 600 psi of $\mathrm{N}_{2}$ gas pressure to keep the sample from boiling fell on the same Arrhenius line within error. Pressure may have an effect if the density of water deviates significantly from $1 \mathrm{~g} / \mathrm{cc}$, but this is unlikely to occur in geothermal reservoirs short of boiling, which, based on early tests above $100{ }^{\circ} \mathrm{C}$ without additional pressure, will significantly affect gelation. If the water boils, the concentration of silica in the remaining water will increase significantly, and will promote immediate local gelation and/or scale deposition at the water-steam interface.

\subsection{Prolonging gel times and avoiding precipitation}

Our goal for this report is to find solution chemistries that extend the gel time at high $\left(150^{\circ} \mathrm{C}\right)$ temperatures as long as possible, while still forming a brittle gel. This last point is non-trivial, because one issue that arose in the course of our investigation at high temperature was that in some cases the silica precipitated on the walls of the sample chamber as scale, instead of forming a continuous gel. We will attempt to extend the gel time at high temperatures by lowering the amount of $\mathrm{HCl}$ added to the solution, and varying the silica concentration. We will also investigate the additive $\mathrm{NaBF}_{4}$ and the possibility of increasing the colloid size. If extended gel times can be achieved at $150{ }^{\circ} \mathrm{C}$, the known activation energies can be used to infer the gelation times at even higher $\left(175-200{ }^{\circ} \mathrm{C}\right)$ temperatures. Above $200{ }^{\circ} \mathrm{C}$, extremely fast gel times and the thermal stability limit of colloidal silica will be encountered.

While colloidal silica gels have a greater thermal stability than many organic gels, they will break down at sufficiently high temperatures. This process is shown in Figure 8 and Figure 9. Figure 8 shows a gel that was produced in a $300{ }^{\circ} \mathrm{C}$ oven, in a Swagelok capsule to keep water from escaping. The nominal temperature of the experiment was $300{ }^{\circ} \mathrm{C}$, but it is unclear what the temperature vs. time history of the gelation process was. It is doubtful that the actual temperature of gelation was $300^{\circ} \mathrm{C}$, because this process was completed within ten minutes. Figure 9 shows the same gel after twenty minutes in a $300{ }^{\circ} \mathrm{C}$ oven. The gel still retained its solidity, but had turned white. In a gel, the silica network forms without changing local density: in other words, the silica particles do not aggregate and separate themselves 
from the water. A white "gel" indicates that the silica is in the process of aggregating, so that light can scatter off the regions of higher and lower density. After four hours, the gel had completely decomposed into a milky fluid, and over the next several days, the silica particles grew, separated from the water and settled down to the bottom of the capsule. This experiment was carried out at $200{ }^{\circ} \mathrm{C}$ as well, where the gel was stable for between 1 and 2 weeks. This large dependence on temperature implies that gels will be stable for months to years at even lower temperatures, however silica gels will not be stable for long periods of time (>weeks) above $200{ }^{\circ} \mathrm{C}$.

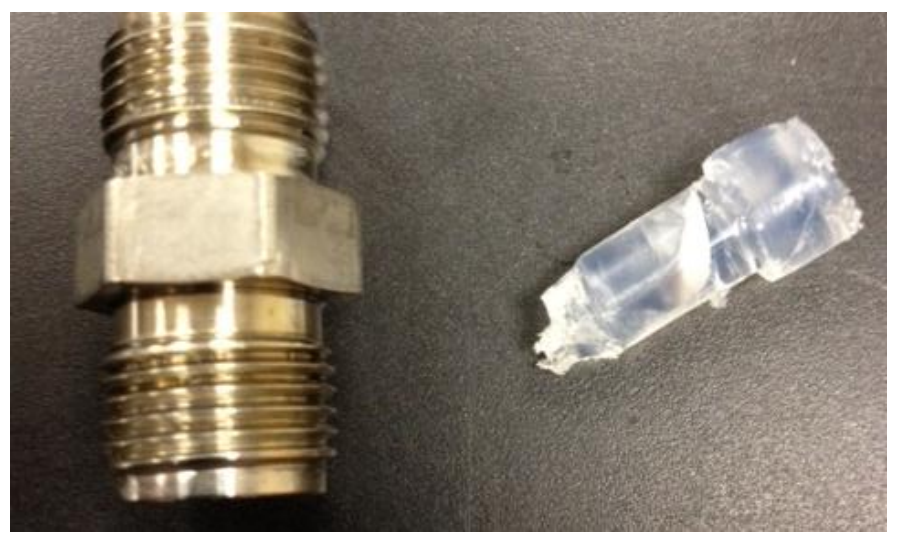

Figure 8. Gel (Right) PRoduced in a $300{ }^{\circ} \mathrm{C}$ oven. WATER WAS PREVEnted FROM ESCAPING BY SEALING THE COLLOIDAL SOLUTION IN A SWAGELOK CAPSULE (LEFT).

THE SHAPE OF THE GEL REFLECTS THE INTERNAL GEOMETRY OF THE CAPSUlE.

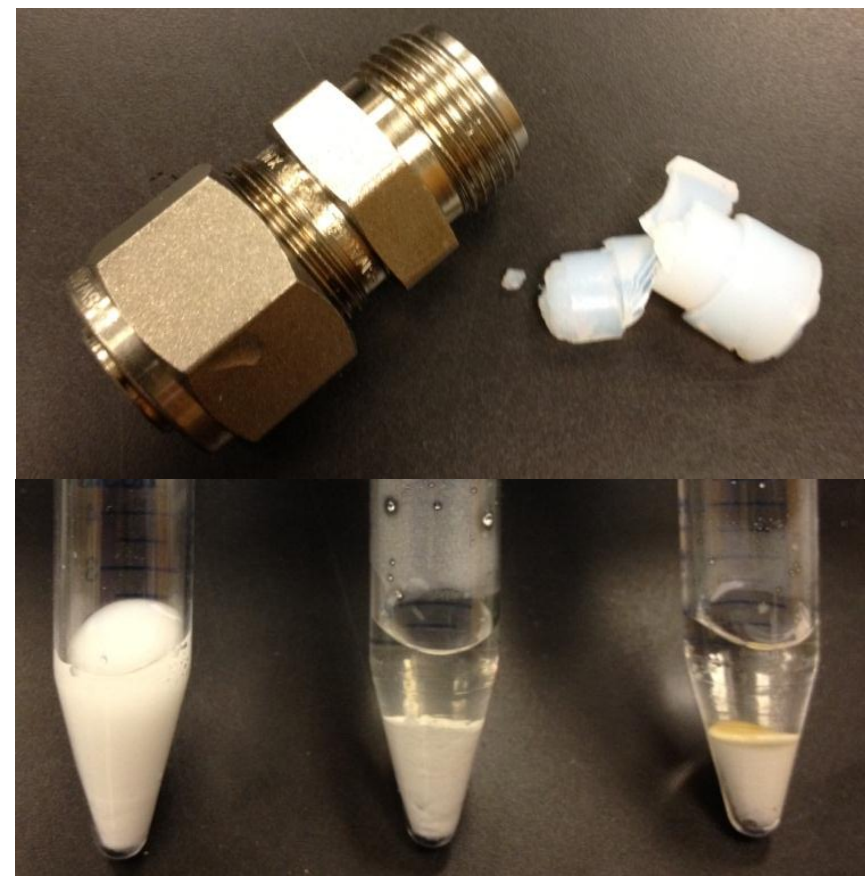

Figure 9. Above: Gel After 20 minutes at $300^{\circ} \mathrm{C}$. BELow: 4 HOURS (LEFT), 18 HOURS (MIDDLE), 72 HOURS (RIGHT).

Figure 5 reflects a gel time of approximately 45 minutes, including 15 minutes of heating time, at a nominal bath temperature of $150{ }^{\circ} \mathrm{C}$. This gel time was achieved using a solution 
chemistry of $15 \mathrm{wt} \% \mathrm{SiO}_{2}$, no added $\mathrm{NaCl}$, and a $\mathrm{Cl}^{-} / \mathrm{Na}^{+}$ratio of 0.5 . From trends available in the literature (Iler, 1979; Bergna \& Roberts, 2006), as well as observed and modeled gelation times at $25{ }^{\circ} \mathrm{C}$ in this project, there are two options to extend gel time: lower silica concentration, and lower $\mathrm{Cl}^{-} / \mathrm{Na}^{+}$ratio (i.e., raise $\mathrm{pH}$ ). Unfortunately, both of these trends will also tend to suppress the formation of gels, illustrated in Figure 10. However, the gel time may be extended if the silica concentration and $\mathrm{pH}$ are raised or lowered together.

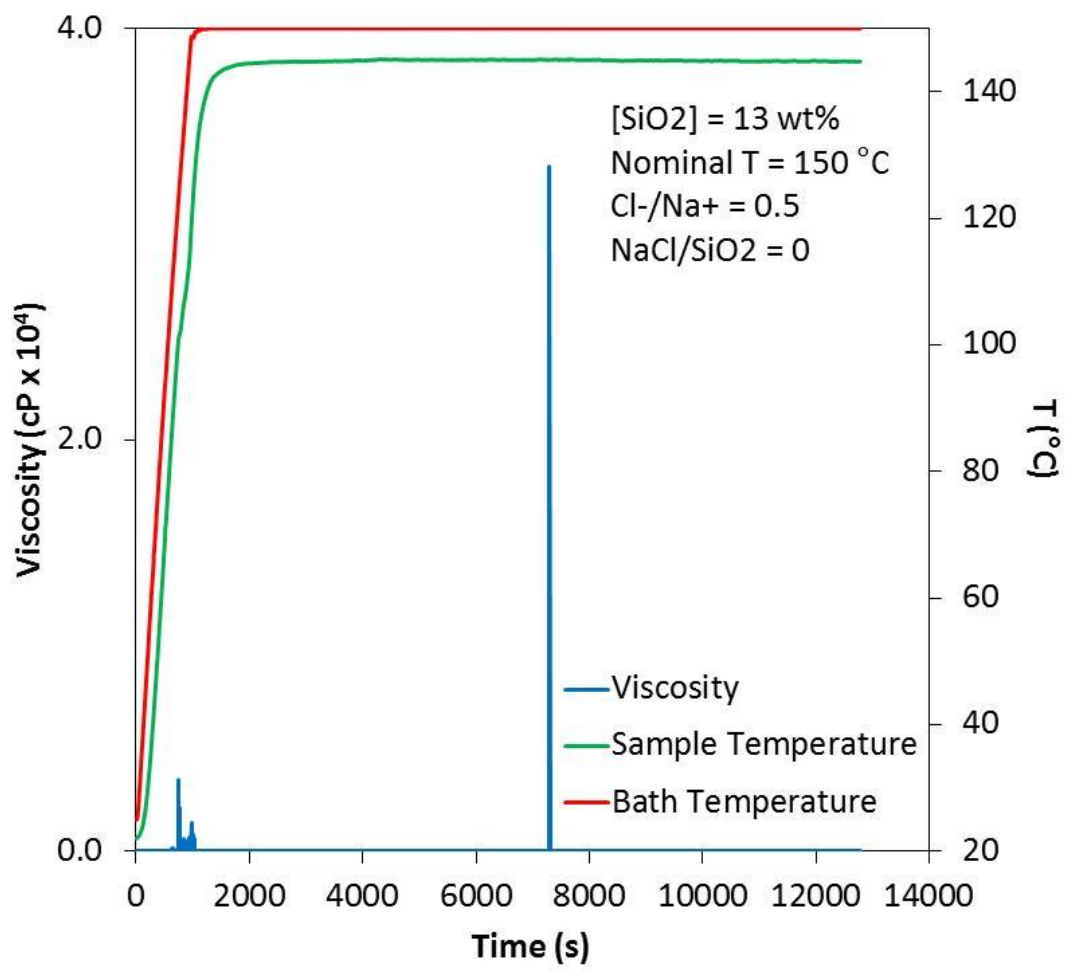

FiguRE 10. VISCOSITY, OIL BATH TEMPERATURE AND SAMPLE TEMPERATURE MEASUREMENTS AS A FUNCTION OF TIME.

THIS SOLUTION DID NOT GEL BUT MERELY DEPOSITED AMORPHOUS SILICA

ON THE SAMPLE CHAMBER WALLS.

It was discovered that, although Figure 10 is an illustration of a solution that did not gel at all, the single high data point at approximately 7300 seconds was not necessarily indicative of the fact that the solution would not gel. While it did indicate that a ring of amorphous silica was deposited on the sample chamber walls at the air-water interface, it was found that the presence of the ring did not preclude gelling at a later time, as these rings do not contain enough silica to meaningfully alter the bulk silica concentration. Nevertheless, a transition from a region of gelation to one of non-gelation does exist. Figure 11 shows a standard linear trend of gel time as a function of silica concentration. At 15 and $15.5 \mathrm{wt} \% \mathrm{SiO}_{2}$, a typical brittle gel forms. At $14.5 \mathrm{wt} \% \mathrm{SiO}_{2}$, though a well-defined gelation time exists, a ductile paste is formed instead of a brittle gel, denoted by the red outline on the data point. This ductile paste is shown in a weighing boat in Figure 12. A metal spatula is shown making an indentation into the paste, demonstrating its ductility. At $14 \mathrm{wt} \% \mathrm{SiO}_{2}$, however, no gelation occurs. According to the linear trend of the other data points, a $14 \mathrm{wt} \% \mathrm{SiO}_{2}$ solution should gel or turn to paste in about 7-8 hours. We left this solution at a nominal temperature of $150{ }^{\circ} \mathrm{C}$ for 64 hours (denoted by the open square data point), and no gelation was observed. It is certainly possible that the solution will gel, turn to a ductile paste, or deposit all the silica 
as an amorphous solid on a longer time frame, but regardless, these solutions do not follow the linear trends that allow prediction of well-defined gelation times.

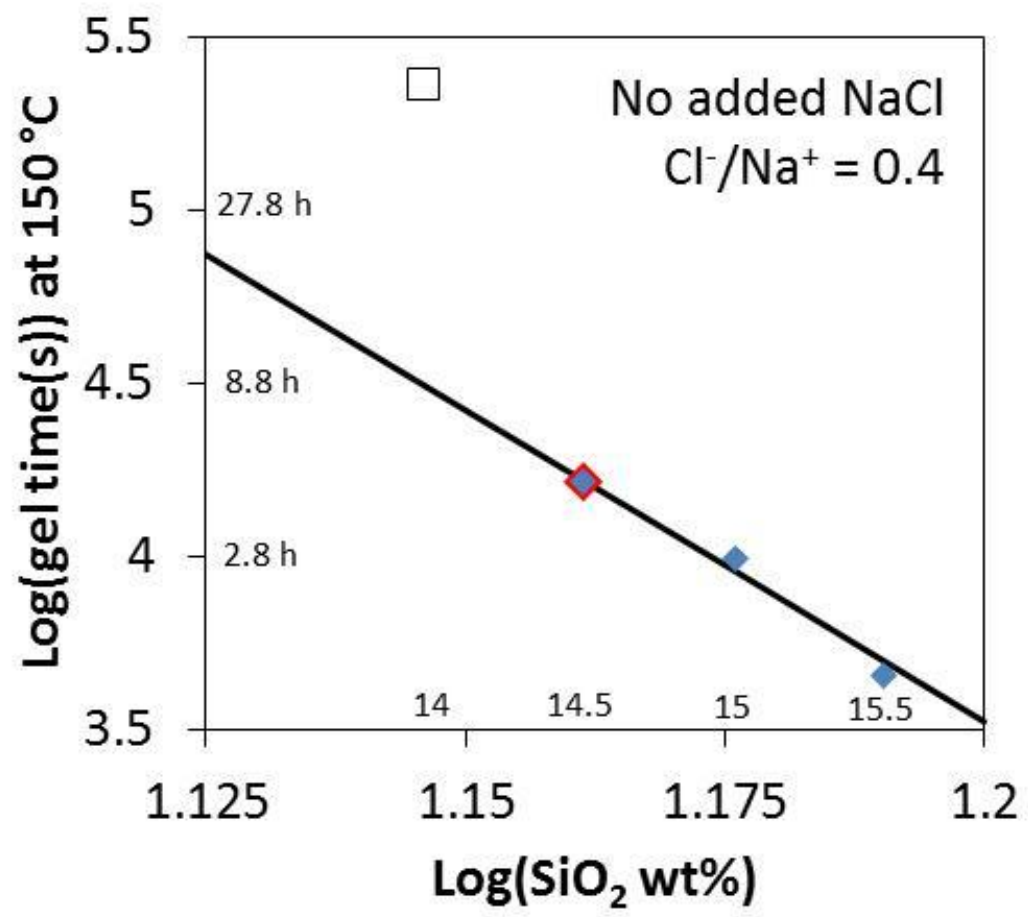

Figure 11. Gelation time as a function of Silica concentration at $150^{\circ} \mathrm{C}$

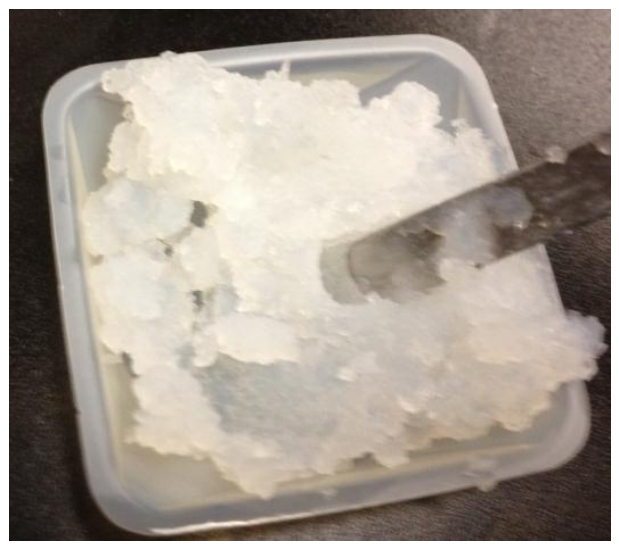

Figure 12. DUCTILE PASTE FORMED IN THE

TRANSITION BETWEEN GELATION AND NON-GELATION REGIMES.

Our investigation to extend gelation times while simultaneously ensuring that gelation actually occurs led us to vary both the silica concentration and $\mathrm{Cl}^{-} / \mathrm{Na}^{+}$ratio. Figure 13 shows the results of our investigation in this parameter space. While all of the experiments in Figure 13 were performed at a nominal temperature of $150{ }^{\circ} \mathrm{C}$, they were not all at the same effective temperature (per analysis via Equation 3), due to the high variability in the ratio of heating time to the experiment duration. We have therefore modeled the activation energies of these solutions, and plotted the projected gel time at exactly $150{ }^{\circ} \mathrm{C}$. 


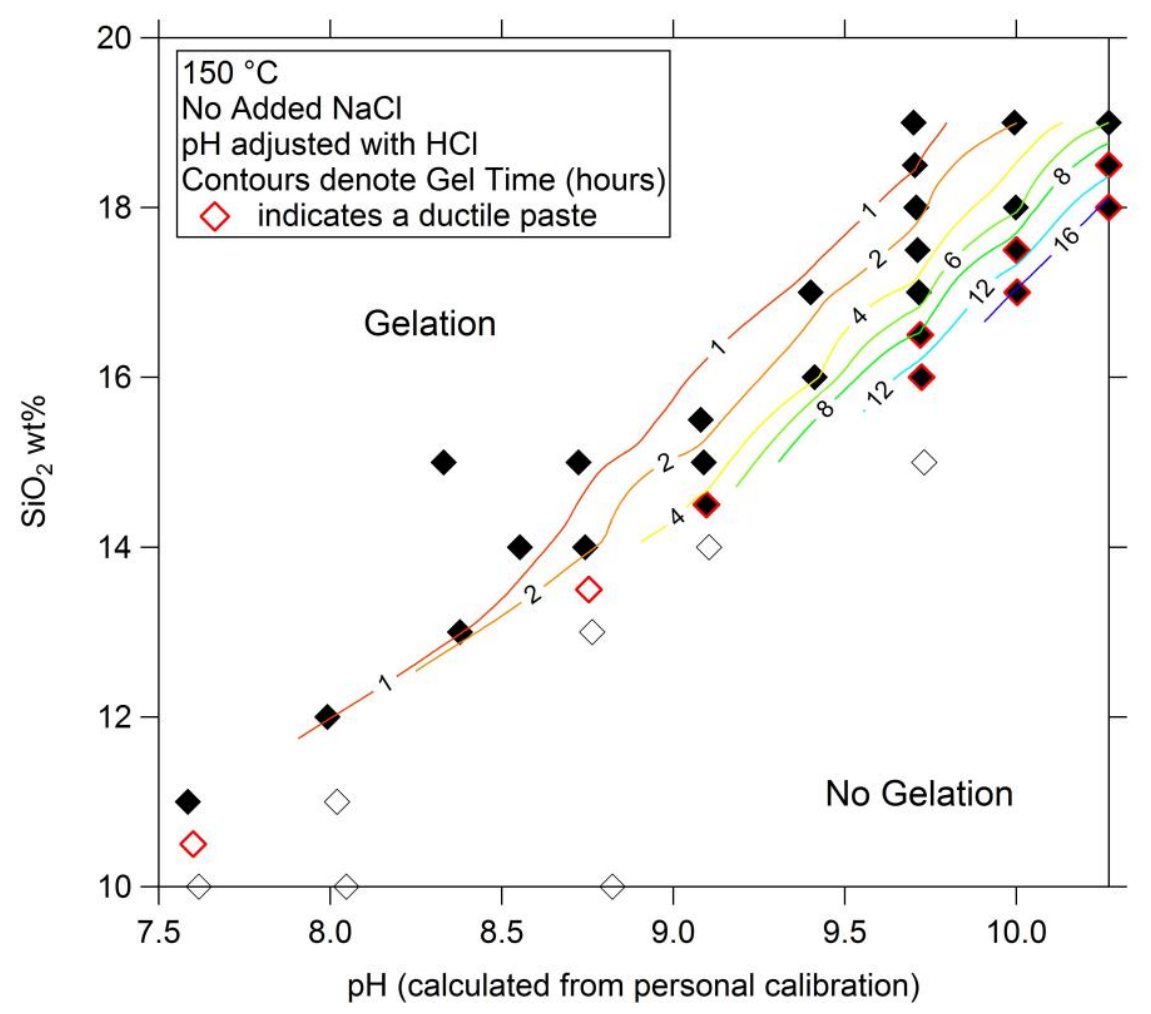

Figure 13. Contour Plot Of MOdeled Gel times At $150^{\circ} \mathrm{C}$

AS A FUNCTION OF SILICA CONCENTRATION AND PH

The modeled activation energies were obtained by using Equation 1, Equation 2, and Equation 3 to calculate the individual experiments' effective temperature and activation energy. A linear regression was then performed on the activation energies as a function of silica concentration and $\mathrm{Cl}^{-} / \mathrm{Na}^{+}$ratio. Activation energies were not modeled as a function of salt content. Due to the large effect that even a small amount of salt has on gelation time, we found that solutions containing any salt would gel too quickly for use in geothermal reservoirs. The linear regression equation $\left(\mathrm{R}^{2}=0.9608\right)$ to calculate the activation energy in $\mathrm{kcal} / \mathrm{mol}$ is as follows:

Equation 4: ACTIVATION ENERgy as a FUNCTION OF SILICA CONCENTRATION AND PH

$$
E_{A}=16.18\left(\frac{C l^{-}}{N a^{+}}\right)^{2}+\log \left(\left[\mathrm{SiO}_{2}\right]\right)\left(38.50-9.326\left(\frac{C l^{-}}{N a^{+}}\right)\right)-24.41
$$

The open data points in Figure 13 denote experiments that did not gel, and the red outlined data points indicate solutions that turned into a ductile paste. Some of these pastes did not have a well-defined "gelation" time, and are open symbols. The longest gel time that produced a brittle gel at $150{ }^{\circ} \mathrm{C}$ in this investigation is 6 hours $\left(19 \mathrm{wt} \% \mathrm{SiO}_{2}, \mathrm{Cl}^{-} / \mathrm{Na}^{+}=0\right)$, but pastes can be produced with "gelation" times of up to 17 hours $\left(18 \mathrm{wt} \% \mathrm{SiO}_{2}\right.$, $\mathrm{Cl}^{-} / \mathrm{Na}^{+}=0$ ). A full list of experiments performed at a nominal temperature of $150{ }^{\circ} \mathrm{C}$ can be found in Table 2. 
TAble 2: Experiments Performed at A nominal temperature of $150^{\circ} \mathrm{C}$

\begin{tabular}{|c|c|c|c|c|c|c|c|}
\hline $\begin{array}{l}\mathrm{SiO}_{2} \\
\mathrm{wt} \%\end{array}$ & $\mathrm{Cl}^{-} / \mathrm{Na}^{+}$ & $\mathrm{pH}$ & $\begin{array}{c}\mathrm{E}_{\mathrm{A}}(\text { Eqs. } \\
\text { Equation } \\
\text { 1,Equation } \\
\text { 2,Equation } \\
3 \text { ) }\end{array}$ & $\begin{array}{c}\text { Effective } \\
\text { Temperature }\end{array}$ & $\begin{array}{l}\text { Measured } \\
\text { Gel Time }\end{array}$ & $\begin{array}{l}\text { Modeled } \\
\text { Gel Time } \\
\left(150{ }^{\circ} \mathrm{C}\right)\end{array}$ & $\begin{array}{l}\text { Brittle } \\
\text { or } \\
\text { Ductile }\end{array}$ \\
\hline 18 & 0 & 10.27 & 24.33 & 144.3 & $21 \mathrm{~h}, 10 \mathrm{~m}$ & $17 \mathrm{~h}, 24 \mathrm{~m}$ & Ductile \\
\hline 18.5 & 0 & 10.27 & 24.17 & 143.6 & $17 \mathrm{~h}, 30 \mathrm{~m}$ & $10 \mathrm{~h}, 9 \mathrm{~m}$ & Ductile \\
\hline 19 & 0 & 10.27 & 24.24 & 143.9 & $12 \mathrm{~h}, 15 \mathrm{~m}$ & $6 \mathrm{~h}, 0 \mathrm{~m}$ & Brittle \\
\hline 17 & 0.1 & 10.00 & 22.38 & 143.3 & $21 \mathrm{~h}, 0 \mathrm{~m}$ & $16 \mathrm{~h}, 40 \mathrm{~m}$ & Ductile \\
\hline 17.5 & 0.1 & 10.00 & 22.69 & 141.7 & $14 \mathrm{~h}, 30 \mathrm{~m}$ & $9 \mathrm{~h}, 29 \mathrm{~m}$ & Ductile \\
\hline 18 & 0.1 & 9.99 & 22.50 & 142.9 & $10 \mathrm{~h}, 40 \mathrm{~m}$ & $5 \mathrm{~h}, 29 \mathrm{~m}$ & Brittle \\
\hline 19 & 0.1 & 9.99 & 24.63 & 140.7 & $2 \mathrm{~h}, 27 \mathrm{~m}$ & $1 \mathrm{~h}, 55 \mathrm{~m}$ & Brittle \\
\hline 16 & 0.2 & 9.72 & 20.36 & 143.9 & $21 \mathrm{~h}, 0 \mathrm{~m}$ & $14 \mathrm{~h}, 46 \mathrm{~m}$ & Ductile \\
\hline 16.5 & 0.2 & 9.72 & 20.48 & 145.3 & $13 \mathrm{~h}, 0 \mathrm{~m}$ & $8 h, 13 m$ & Ductile \\
\hline 17 & 0.2 & 9.72 & 21.07 & 142.3 & $8 \mathrm{~h}, 25 \mathrm{~m}$ & $4 \mathrm{~h}, 39 \mathrm{~m}$ & Brittle \\
\hline 17.5 & 0.2 & 9.71 & 21.63 & 143.5 & $4 \mathrm{~h}, 19 \mathrm{~m}$ & $2 \mathrm{~h}, 40 \mathrm{~m}$ & Brittle \\
\hline 18 & 0.2 & 9.71 & 21.97 & 141.5 & $3 \mathrm{~h}, 2 \mathrm{~m}$ & $1 \mathrm{~h}, 34 \mathrm{~m}$ & Brittle \\
\hline 18.5 & 0.2 & 9.70 & 22.41 & 140.0 & $2 \mathrm{~h}, 0 \mathrm{~m}$ & $0 \mathrm{~h}, 56 \mathrm{~m}$ & Brittle \\
\hline 19 & 0.2 & 9.70 & 22.86 & 139.9 & $1 \mathrm{~h}, 13 \mathrm{~m}$ & $0 \mathrm{~h}, 33 \mathrm{~m}$ & Brittle \\
\hline 16 & 0.3 & 9.41 & 19.96 & 141.8 & $6 \mathrm{~h}, 0 \mathrm{~m}$ & $3 \mathrm{~h}, 36 \mathrm{~m}$ & Brittle \\
\hline 17 & 0.3 & 9.40 & 21.32 & 141.9 & $1 \mathrm{~h}, 37 \mathrm{~m}$ & $1 \mathrm{~h}, 10 \mathrm{~m}$ & Brittle \\
\hline 17 & 0.3 & 9.40 & 21.83 & 104.9 & $16 \mathrm{~h}, 54 \mathrm{~m}$ & $1 \mathrm{~h}, 10 \mathrm{~m}$ & Brittle \\
\hline 14.5 & 0.4 & 9.10 & 18.57 & 143.4 & $6 \mathrm{~h}, 30 \mathrm{~m}$ & $4 h, 36 m$ & Ductile \\
\hline 15 & 0.4 & 9.09 & 18.91 & 143.8 & $3 \mathrm{~h}, 48 \mathrm{~m}$ & $2 \mathrm{~h}, 30 \mathrm{~m}$ & Brittle \\
\hline 15.5 & 0.4 & 9.08 & 19.76 & 142.1 & $1 \mathrm{~h}, 59 \mathrm{~m}$ & $1 \mathrm{~h}, 23 \mathrm{~m}$ & Brittle \\
\hline 14 & 0.5 & 8.74 & 18.37 & 142.0 & $2 h, 23 m$ & $1 \mathrm{~h}, 32 \mathrm{~m}$ & Brittle \\
\hline 15 & 0.5 & 8.72 & 20.23 & 135.6 & $0 \mathrm{~h}, 44 \mathrm{~m}$ & $0 \mathrm{~h}, 28 \mathrm{~m}$ & Brittle \\
\hline 14 & 0.55 & 8.55 & 18.62 & 137.4 & $1 \mathrm{~h}, 17 \mathrm{~m}$ & $0 \mathrm{~h}, 37 \mathrm{~m}$ & Brittle \\
\hline 13 & 0.6 & 8.37 & 17.51 & 139.2 & $1 \mathrm{~h}, 50 \mathrm{~m}$ & $0 \mathrm{~h}, 48 \mathrm{~m}$ & Brittle \\
\hline 15 & 0.6 & 8.33 & 19.65 & 124.3 & $0 \mathrm{~h}, 26 \mathrm{~m}$ & $0 \mathrm{~h}, 5 \mathrm{~m}$ & Brittle \\
\hline 12 & 0.7 & 7.99 & 17.67 & 135.0 & $0 \mathrm{~h}, 55 \mathrm{~m}$ & $0 \mathrm{~h}, 21 \mathrm{~m}$ & Brittle \\
\hline 11 & 0.8 & 7.59 & 18.82 & 123.2 & $0 \mathrm{~h}, 27 \mathrm{~m}$ & $0 \mathrm{~h}, 8 \mathrm{~m}$ & Brittle \\
\hline
\end{tabular}

We also explored two other avenues of investigation: additives and colloid size. Sodium tetrafluoroborate $\left(\mathrm{NaBF}_{4}\right)$ has been successfully used in the oil industry to delay the onset of gelation for up to 12 hours at $100-120^{\circ} \mathrm{C}$ (Jurinak, et al., 1991). At high temperatures, $\mathrm{NaBF}_{4}$ slowly decomposes in water and forms $\mathrm{HBF}_{4}$ and $\mathrm{B}(\mathrm{OH})_{3}$. Since both of these compounds are acids, this lowers the $\mathrm{pH}$ of the solution, which causes gelation. In effect, this would move a solution from the right to the left of Figure 13, from the non-gelation regime into the gelation regime, on a timescale determined by the decomposition of $\mathrm{NaBF}_{4}$. Unfortunately, it was found in the course of our investigation that the decomposition of $\mathrm{NaBF}_{4}$ also depends on temperature, and while it can delay gelation up to 12 hours at 100$120{ }^{\circ} \mathrm{C}$, the decomposition is much faster at $150{ }^{\circ} \mathrm{C}$, and therefore does not provide an appreciable delay in gelation times at geothermal reservoir temperatures. Exploring other additives in more detail may be of use in future investigations. 
The other parameter investigated is colloid size. While it was found that the 7-10 nm size of silica colloids produced from geothermal waters was relatively insensitive to on-site processing conditions (Bourcier, 2009), increasing the colloid diameter to larger values is commonly done in the silica manufacturing industry. Data for Ludox solutions show that increasing the colloid size from 7 to $21 \mathrm{~nm}$ increases the gelation time by a factor of 40 at $25{ }^{\circ} \mathrm{C}$ at a constant silica concentration. However, gels created using large colloids are generally not translucent, indicating density heterogeneity. At high temperature, we found that these solutions deposited nearly all the silica present in solution as scale. While the scale was voluminous enough to be space-filling, it was very difficult to remove it from the sample chamber walls, needing several days in a $50{ }^{\circ} \mathrm{C}$ bath of $\mathrm{NaOH}$. In the interest of time, we left a comprehensive investigation of large colloid size to future investigations.

As of the present moment, we can create gels at temperatures up to $150{ }^{\circ} \mathrm{C}$ easily, with brittle gel times as long as 6 hours (which will be lengthened in any real-world application, of course, due to the finite heating time required). From the activation energies determined in the course of this investigation, this indicates that gels at $175-200{ }^{\circ} \mathrm{C}$ can be created in 1.2 hours and 17 minutes, respectively.

\subsection{Solution chemistry "recipes" and pH calibration}

We have generally described the chemistry of the silica solutions in terms of molar ratios $\left(\mathrm{Cl}^{-}\right.$ $/ \mathrm{Na}^{+}, \mathrm{NaCl} / \mathrm{SiO}_{2}$ ) for two reasons. First, it is when these ratios are held constant that the linear relationship between the logarithm of silica concentration and the logarithm of gel time arises. Secondly, the ultimate goal for this project is to provide a recipe based on volumes that a geothermal operator can follow. It is far easier to provide this when starting from molar ratios than when starting from a salt concentration and $\mathrm{pH}$, as the silica concentration desired will affect both the salt concentration and $\mathrm{pH}$. For example, a gel with an $\mathrm{NaCl} / \mathrm{SiO}_{2}$ ratio of 0.0535 and a $\mathrm{Cl}^{-} / \mathrm{Na}^{+}$ratio of 0.5 (Table 1) has the following recipe: for every liter of starting silica sol, add $110 \mathrm{~mL}$ of $1 \mathrm{M} \mathrm{HCl}$, and $130 \mathrm{~mL}$ of $2.5 \mathrm{M} \mathrm{NaCl}$. This is true regardless of what silica concentration is desired. For a gel with $19 \mathrm{wt} \%$ silica (Exp. 26, Table 1), 480 $\mathrm{mL}$ of $\mathrm{H}_{2} \mathrm{O}$ should be added to the liter of silica sol before the salt and acid. This chemistry will take two hours to gel at $25{ }^{\circ} \mathrm{C}$. For a gel with $15 \mathrm{wt} \%$ silica (Exp. 71, Table 1), $992 \mathrm{~mL}$ of $\mathrm{H}_{2} \mathrm{O}$ should be used instead, and this chemistry will take approximately 17 hours to gel. The reason for adding the water first is simple: if the salt and acid were added first, the resulting solution would have a silica concentration of $25.34 \mathrm{wt} \%$, which would gel in 8 minutes, according to Equation 1. The time taken to then add the water would be a significant fraction of 8 minutes, which would irrevocably alter the gel time once the water is added.

The above paragraph notwithstanding, it will be useful for a geothermal operator to know what the $\mathrm{pH}$ of the solution is. Previous investigations of colloidal silica gels for the oil and gas industry have calibrated $\mathrm{pH}$ against $\mathrm{Cl}^{-} / \mathrm{Na}^{+}$ratio (Jurinak, et al., 1991), but have neglected the effect of silica concentration on $\mathrm{pH}$. We therefore performed our own calibration, based on the most likely solutions that will be used in geothermal reservoirs. The most likely solutions that will be used will be similar to the chemistry shown in Figure 5: no salt, low $\mathrm{Cl}^{-} / \mathrm{Na}^{+}$ratios, and silica concentrations between $10-20 \mathrm{wt} \%$. We therefore did not investigate if or how salt influences the $\mathrm{pH}$ of the solutions, and only calibrated up to a $\mathrm{Cl}^{-}$ $/ \mathrm{Na}^{+}$ratio of 0.8 . The calibration equation $\left(\mathrm{R}^{2}=0.9994\right)$ is as follows: 


$$
p H=10.262-0.0395\left[\mathrm{SiO}_{2}\right]\left(\frac{\mathrm{Cl}^{-}}{\mathrm{Na}^{+}}\right)-1.768\left(\frac{\mathrm{Cl}^{-}}{N a^{+}}\right)-1.429\left(\frac{\mathrm{Cl}^{-}}{\mathrm{Na}^{+}}\right)^{2}
$$

\subsection{Calculation and choice of parameters}

The full calculation of gelation time based on $\mathrm{SiO}_{2} \mathrm{wt} \%, \mathrm{Cl}^{-} / \mathrm{Na}^{+}$ratio, $\mathrm{NaCl} / \mathrm{SiO}_{2}$ ratio, and temperature can be done by combining Equation 1, Equation 2, and Equation 4, resulting in Equation 6: CALCUlation of Gel time

$$
\begin{aligned}
& \text { Gel Time }(s) \\
& \qquad \begin{aligned}
& \operatorname{EXP}\left[\frac{E_{A}(E q .5) \times 1000}{1.98721} \times\left[\frac{1}{T(K)}-\frac{1}{298.15}\right]\right. \\
& \left.+2.303\left[\log \left(G T_{25}\right)(E q .1)\right]\right]
\end{aligned}
\end{aligned}
$$

where

and

$$
E_{A}(E q .5)=16.18\left(\frac{\mathrm{Cl}^{-}}{N a^{+}}\right)^{2}+\log \left(\left[\mathrm{SiO}_{2}\right]\right)\left(38.50-9.326\left(\frac{\mathrm{Cl}^{-}}{N a^{+}}\right)\right)-24.41
$$

$$
\begin{aligned}
\log \left(G T_{25}\right)(E q .1) & \\
& =\log \left(\mathrm{SiO}_{2} w t \%\right) \\
& \times\left[\frac{\mathrm{NaCl}}{\mathrm{SiO}_{2}}\left(-16.5\left(\frac{\mathrm{Cl}}{\mathrm{Na}^{+}}\right)^{2}+27.3\left(\frac{\mathrm{Cl}}{\mathrm{Na}^{+}}\right)+4.54\right)+5.64\left(\frac{\mathrm{Cl}^{-}}{\mathrm{Na}^{+}}\right)^{2}-11.4\right] \\
& +\left(\frac{\mathrm{NaCl}}{\mathrm{SiO}_{2}}+0.067\right)^{-1}\left[0.479-0.385\left(\frac{\mathrm{Cl}}{\mathrm{Na}^{+}}\right)^{2}\right] \\
& -18.2 \frac{\mathrm{NaCl}}{\mathrm{SiO}_{2}}-7.34\left(\frac{\mathrm{Cl}}{\mathrm{Na}^{+}}\right)+17.1
\end{aligned}
$$

For example, a silica solution with $17 \mathrm{wt} \% \mathrm{SiO}_{2}, \mathrm{Cl}^{-} / \mathrm{Na}^{+}=0.2$, and no added salt has a log gel time of 8.84 at $25^{\circ} \mathrm{C}$ (Equation 1). The activation energy of this solution is $21.32 \mathrm{kcal} / \mathrm{mol}$ (Equation 4). To calculate the gel time at $130{ }^{\circ} \mathrm{C}(403.15 \mathrm{~K})$, we plug these values into Equation 6, which yields a gel time of approximately 16.4 hours. The accompanying Excel spreadsheet on the geothermal data repository will do all of these calculations, including error analysis and unit transformations (e.g., using $\mathrm{pH},{ }^{\circ} \mathrm{F}$, or simple volume ratios of components)

The reverse problem, to determine a solution chemistry based on a desired gelation time at a given temperature, is not as straightforward, since multiple solution chemistries can give the same gelation time (see contour lines in Figure 13). For example, to obtain a gelation time of 4 hours at $130{ }^{\circ} \mathrm{C}$, a solution with $18.35 \mathrm{wt} \% \mathrm{SiO}_{2}$ and a $\mathrm{Cl}^{-} / \mathrm{Na}^{+}$ratio of 0.2 can be used, but a solution with $15.6 \mathrm{wt} \% \mathrm{SiO}_{2}$ and $\mathrm{a} \mathrm{Cl}^{-} / \mathrm{Na}^{+}$ratio of 0.4 will also gel in four hours. 
However, if a desired silica concentration or $\mathrm{pH}$ is known, it is a simple matter to use an iterative solver to determine the unknown parameter to obtain the desired gelation time (i.e., goal seek or solver in the Excel spreadsheet provided to the geothermal data repository for this project). Care must be taken to select an appropriate chemistry, however. A solution with $11 \mathrm{wt} \% \mathrm{SiO}_{2}$ and $\mathrm{Cl}^{-} / \mathrm{Na}^{+}$ratio of 0.7 should also have a gelation time of 4 hours, but this chemistry is well into the non-gelling region of Figure 13, and would therefore be a poor choice of chemistry. Choosing an appropriate $\mathrm{Cl}^{-} / \mathrm{Na}^{+}$ratio and silica concentration will ultimately be up to an individual geothermal operator, as there may be a cost difference between various chemistries (price of $\mathrm{HCl}$ vs. production cost of colloidal silica), and the ultimate strength of the gel will vary depending on how close the chemistry is to the brittle/ductile transition. For field applications, it may be advisable to perform some specific gelation tests prior to use, once the desired gel time and temperature/time path is known, especially if the colloidal silica is produced on-site, as it may differ slightly from the commercially available sols. The available model should be used as an initial guide, but specific gelation tests will minimize error from slight composition variations (e.g. trace dissolved components in the water) as well as model extrapolation error.

\subsection{Transparent flow cell experiments}
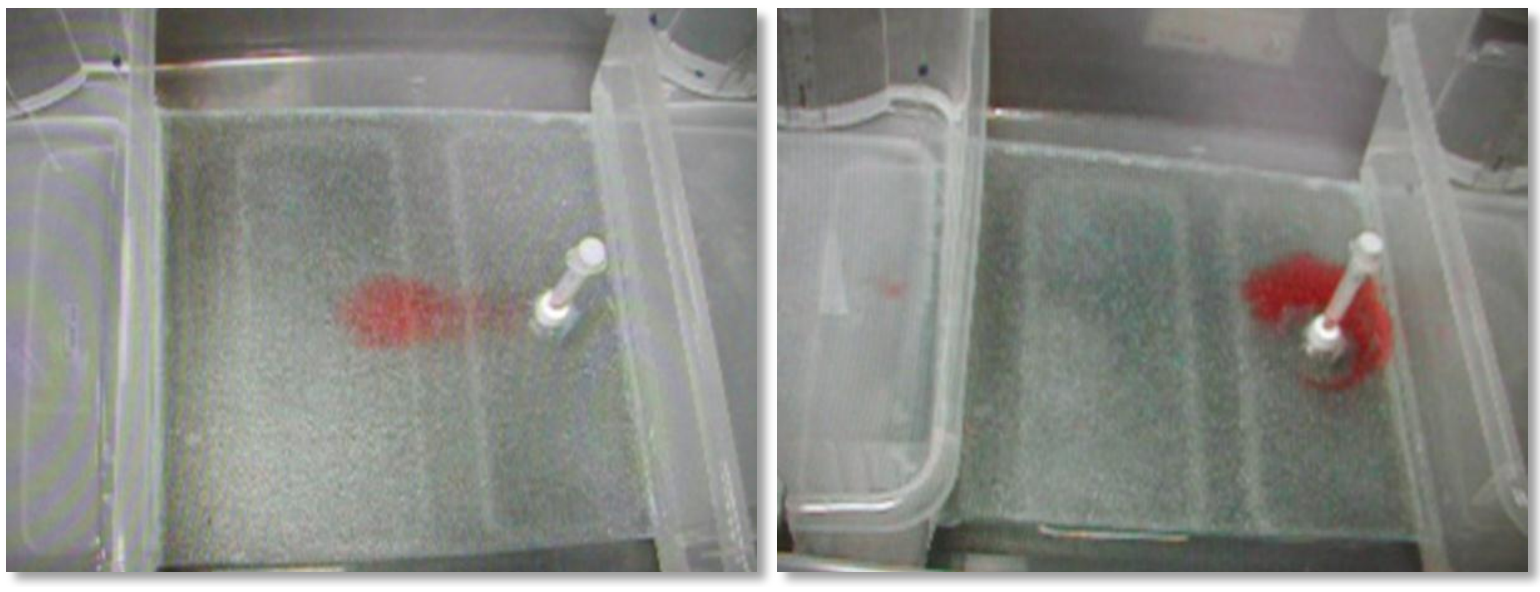

Figure 14. TRANSPARENT FLOW CELL EXPERIMENTAL SETUP SHOWING GEL EMPLACEMENT

To observe fluid diversion in a fracture, we designed a Hele-Shaw transparent flow cell. Using two sheets of shower glass (to simulate subsurface fracture wall roughness), we flowed water through the system until all surfaces were wetted. Next, we injected red dyed water and observed the flow from the syringe injection port (our simulated injection well). As shown in Figure 14 on the left, the dyed water initially flows directly from the injection site because silica gel is not yet deployed. To test the concept of gel emplacement, we injected a silica gel with a short gelation time, waited till the gel had set, then injected additional dyed water into the system. We observed that the injected dye was forced to flow around the blockage providing us with a rudimentary proof-of-concept for gel emplacement (Figure 14, right). These experiments are a direct tie-in to the two dimensional parametric study with gel deployment discussed in the modeling section (see Figure 24, zonal isolation). 


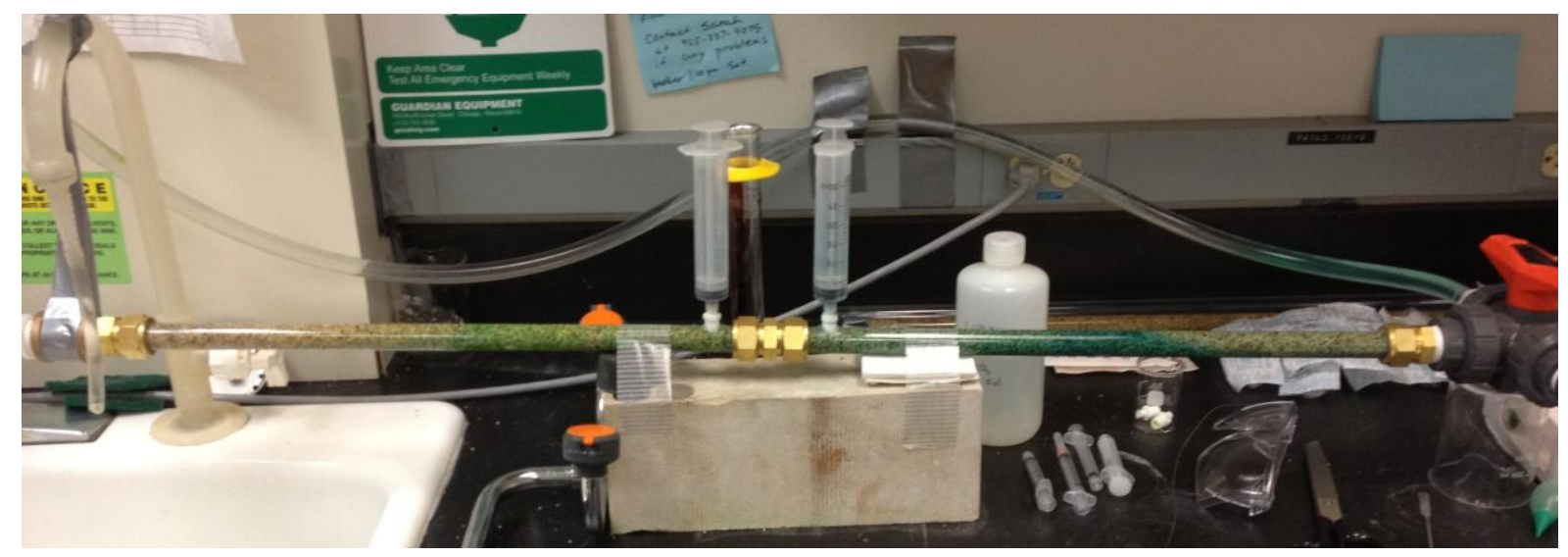

Figure 15. FLOW-THROUGH APPARATUS TO OBSERVE FLUID DIVERSION IN POROUS MEDIA

To observe fluid diversion in porous media, we designed a flow-through apparatus, shown in Figure 15. Porous media (sand-sized granitic rock) was loaded into a straight plastic tube (with a mesh of $250 \mu \mathrm{m}$ at each end to hold the sand in the tube) and agitated until the total porosity was at a minimum for uniformly-sized, irregularly shaped particles ( 40\%). Water was then allowed to flow through the medium for several days from a height of approximately three feet. The water is flowing into the tube in Figure 15 from the three-way valve on the right. It then travels right to left, through both tubes which are joined by a compression fitting, and drains into the sink on the left. Injection and production "wells" are located in the center of the apparatus, with syringes in place to keep water from flowing out of the wells. If the water flow is turned off by the three-way valve (to avoid well overflow), solutions (water, tracers, silica gels) can be injected into either well. The water can then be turned back on to simulate background water pressure on the solution of interest.

In the specific example of Figure 15 and Figure 16, we have injected two separate slugs of silica gel, one dyed green and one dyed blue, each tuned to a 10 minute gel time (the food coloring used to dye each solution had no effect on the gel time). The green-dyed silica gel was injected first, followed by an injection of pure water, in the hope that the water would split the slug of silica gel into two parts, which would travel far enough to surround both wells without blocking the immediate area around either one (see Figure 25 and Figure 26 for a 2D modeled version of this idea). While this did in fact occur, the silica gel that flowed against the background water pressure (left to right, from the injection well in Figure 15) mixed too thoroughly with the water, and therefore became diluted enough that it did not gel overnight. However, the gel that flowed with the background water pressure was able to flow as a plug, and gelled readily. We then injected another silica gel, dyed blue, which was forced to flow against the background water pressure due to the blockage of the tube by the green-dyed gel. The blue gel was able to flow as a plug, and gelled readily. We then tested the communication between the two wells. When water was injected into the injection well, it flowed up out of the production well into the syringe. No water was observed flowing out of either end of the tube during this injection. This is therefore an experimental proof-ofconcept of an isolated circulation cell, minimizing water losses to the surrounding formation. This concept will be modeled and discussed in detail in section 4.5. 


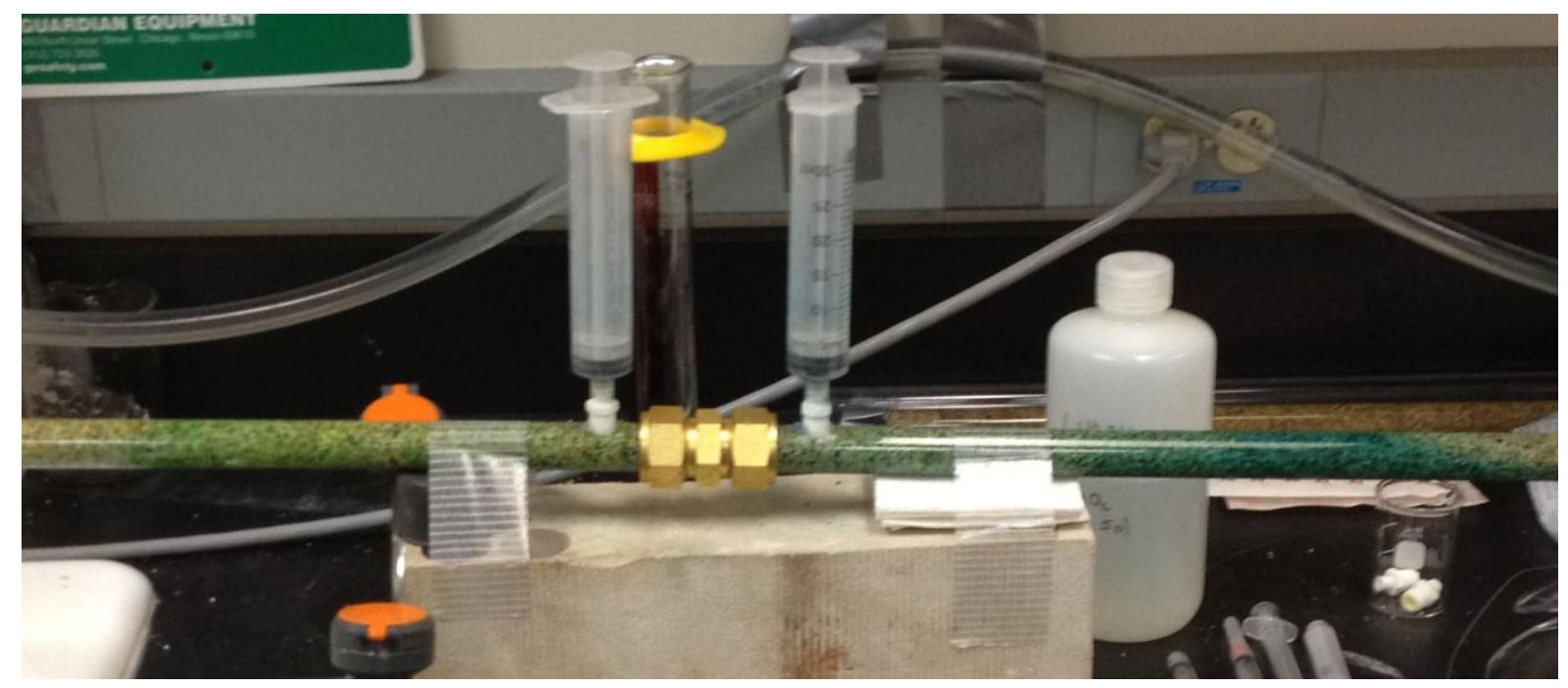

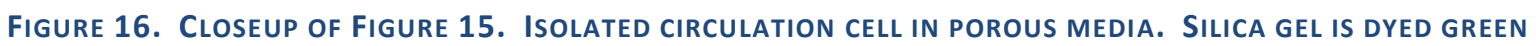
(ON THE LEFT) AND BLUE (ON THE RIGHT) TO INDICATE LOCATION OF BLOCKAGES. THE INJECTION AND PRODUCTION WELLS ARE STILL ABLE TO COMMUNICATE WITH EACH OTHER.

\section{Modeling of Gel Deployment}

\subsection{Modeling Philosophy}

Our modeling philosophy calls for a multi-level approach by increasing the level of modeling difficulties. It encompasses three steps:

1. Implement the physical-chemical process of gel transport in a single smooth and rough-surface fracture.

2. Expand the single fracture model into a simple fracture network for technology evaluation.

3. Integrate the resulting model into a SDFN-THMC model for technology assessment and predictive response.

However, uncertainty quantification is needed to assess model responses under non deterministic, stochastic, conditions to evaluate key design factors. Such uncertainties are, but not limited to:

- Intrinsic uncertainties: e.g. fracture characterization (e.g., size, orientation etc... see Figure 17)

- Parametric uncertainty: e.g. rheological laws, gelation time etc...

- Model uncertainties: e.g. conceptual model, physical processes etc...

By using existing codes and/or leveraging other code developments we will be able to develop gel deployment protocol in predictive mode with an estimated probability of success. 


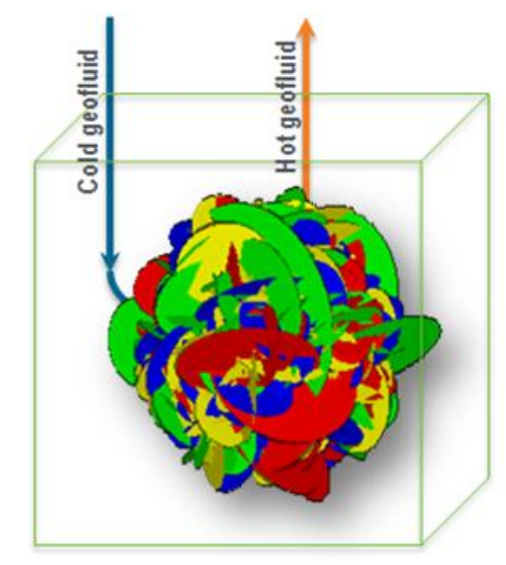

FigURE 17. SiMPLISTIC SCHEMATIC OF AN EGS

\subsection{The numerical simulation tool: SDFN-THMC}

The model used to perform the subsequent simulations is described in Ezzedine (2005) and has been extensively used in recent years to address the impact of uncertainties in the geological characterization of fractures on the thermal response of an EGS (see Ezzedine, (2010-5) (2010-4) (2010-1) (2010-3) (2010-2)). It was originally coded to simulate the system at Soults-sous-Forêts. Fractures are either deterministic or stochastic.

Fractures are characterized by their density, orientation, size and aperture. The model allows for multiple set of fractures, each having their own probability distribution (density) functions. The model is equipped with several numerical schemes for solving the different previously mentioned processes and different protocol for the numerical coupling of those processes (see Figure 18). Moreover, it offers different geological conceptualization of the fractures and how the physical processes are solved within each fracture of the fracture network.
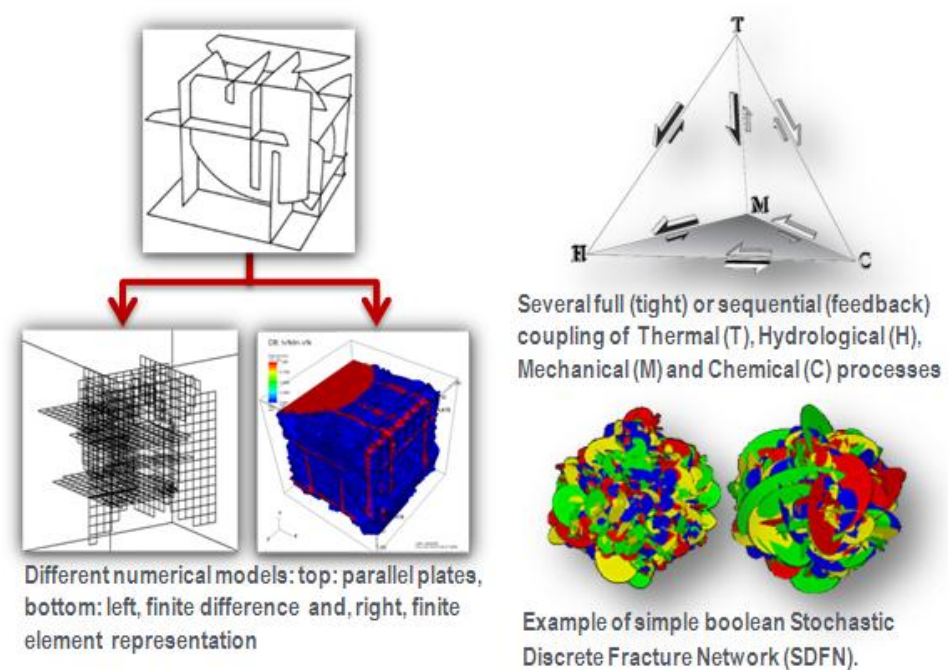

FIGURE 18. SDFN-THMC (EZZEDINE, 2005) OFFERS AN IDEAL NUMERICAL FRAMEWORK TO ADDRESS THE PROBLEM OF DEPLOYING SILICA GEL IN EGS. THE MOdEL ALLOWS FOR FLOW, THERMAL, AND MECHANICAL \& CHEMICAL SIMULATION IN A 3D STOCHASTIC DISCRETE FRACTURE NETWORK. 


\subsubsection{Newtonian vs. non-Newtonian fluids}

It is worth noting that gels behave as non-Newtonian fluids (gel viscosity is dependent on the shear rate). To better mimic the physical processes we have implemented the non-Newtonian fluid behavior in the model. Figure 19 depicts the velocity profile with the aperture for three different cases: a) sub-Newtonian (flat profile), b) Newtonian (parabolic profile), and c) hyper-Newtonian (peaked profile). We expect that silica gel velocity profile shape will be non-parabolic and thus non-Newtonian.

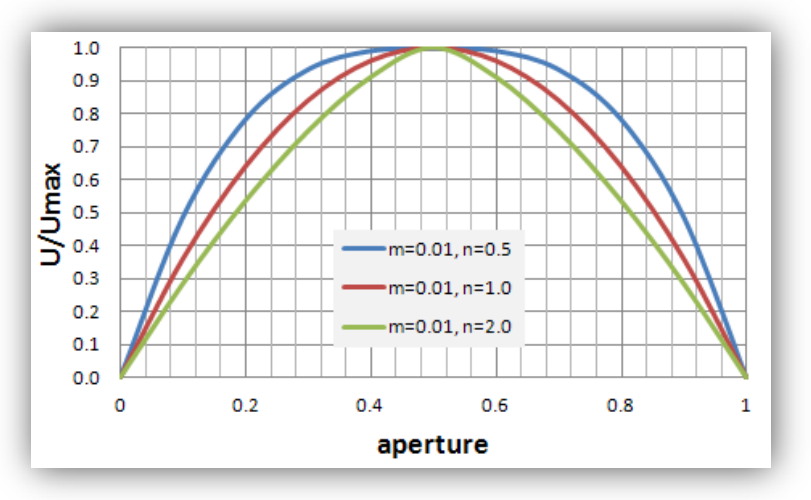

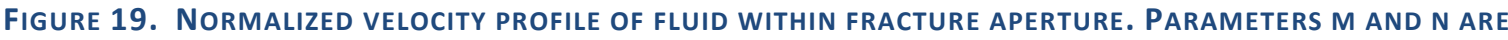
CHARACTERISTICS OF THE FLUID AND THE PROFILE. RED PROFILE, PARABOLIC, IS THE NEWTONIAN, THE OTHER TWO (BLUE AND GREEN) ARE NON-NEWTONIAN.

\subsubsection{Two dimensional simulations of gel deployment}

We have simulated the flow without gel deployment in a two dimensional setting. As an initial step, the fracture is assumed to have smooth walls (i.e. constant aperture, $200 \mu \mathrm{m}$ ). A geothermal doublet (one injection and one production well) shown in Figure 20 (left) depicts the pressure field distribution throughout the fracture, the location of the injection and production wells as well the streamlines.
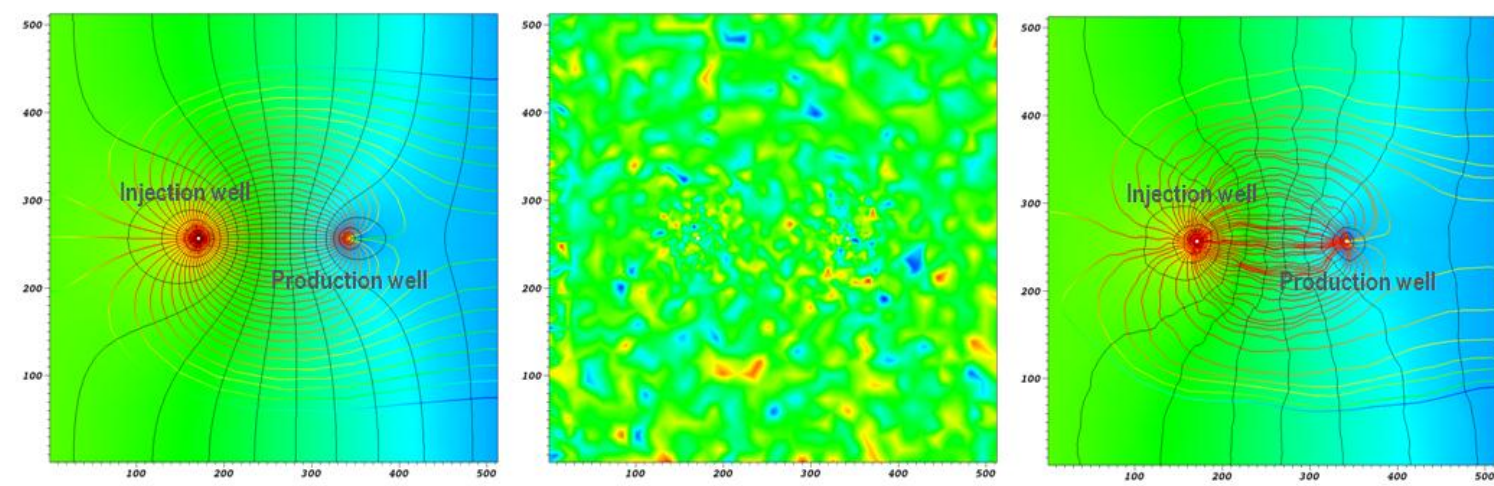

Figure 20. TWO dimENSIONAL DOUBLET FLOW SIMULATIONS IN A SINGLE FRACTURE. LefT: FLOW NETWORK (PRESSURE AND STREAMLINES) IN A SMOOTH FRACTURE. CENTER: APERTURE RANDOM FIELD, RED DEPICTS LARGE APERTURE WHILE BLUE DEPICTS SMALL APERTURE. RIGHT: FLOW NETWORK IN A ROUGH FRACTURE.

The flow network shows the circulation cell and stagnation point. As a second step toward a more complex fracture, we have simulated a fractal aperture field. Figure 20 (center) depicts the random fractal field of the aperture with a mean aperture equal to the smooth fracture initially simulated, i.e. $200 \mu \mathrm{m}$. The flow and streamlines are then resolved for this case and 
depicted on Figure 20 (right). It is worth noting the impact of heterogeneity in the aperture field on the flow streamlines. Flow circulation cells are no-longer smooth and their roughness reflects the tortuous paths that the fluid emanating from the injection well takes to reach the extraction well.

Now we consider the deployment of the silica gel. To illustrate the impact of gel deployment on the thermal response of the doublet we have solved not only the flow and transport of gel within the fracture but also the heat transfer from the host rock. A thermal test of 250 hours has been simulated. At $\sim 80$ hours the temperature signature started to decrease from it maximum of $120{ }^{\circ} \mathrm{C}$. At this time we have started injecting the silica with a gelation time of 20 hours (see Figure 21, left). Once the gel settled in the initial circulation cell it created a crescent-like shape (blue area on Figure 21, center which should be compared to Figure 20 , center). Because the streamlines now have been diverted by the presence of gelled silica the injected flow follows different paths to reach the extraction well thus creating a new sweeping zone (circulation cells) from both sides of the crescent diverter. The new pressure field and streamlines impacted with the gel deployment are depicted on Figure 21 (right). It is expected that the aperture field around the gelled area will dictate the roughness of the streamlines. It should be noted however that the newly injected geofluid now contacts new surface area leading to an increase in the fluid temperature to $\sim 110^{\circ} \mathrm{C}$ from $\sim 95^{\circ} \mathrm{C}$. The temperature did not reach its initial $120^{\circ} \mathrm{C}$ which is attributed to mixing, losses to the surrounding area and, most importantly, that the flow and thus the streamlines are sweeping area with different apertures and therefore different advective flux (velocities).
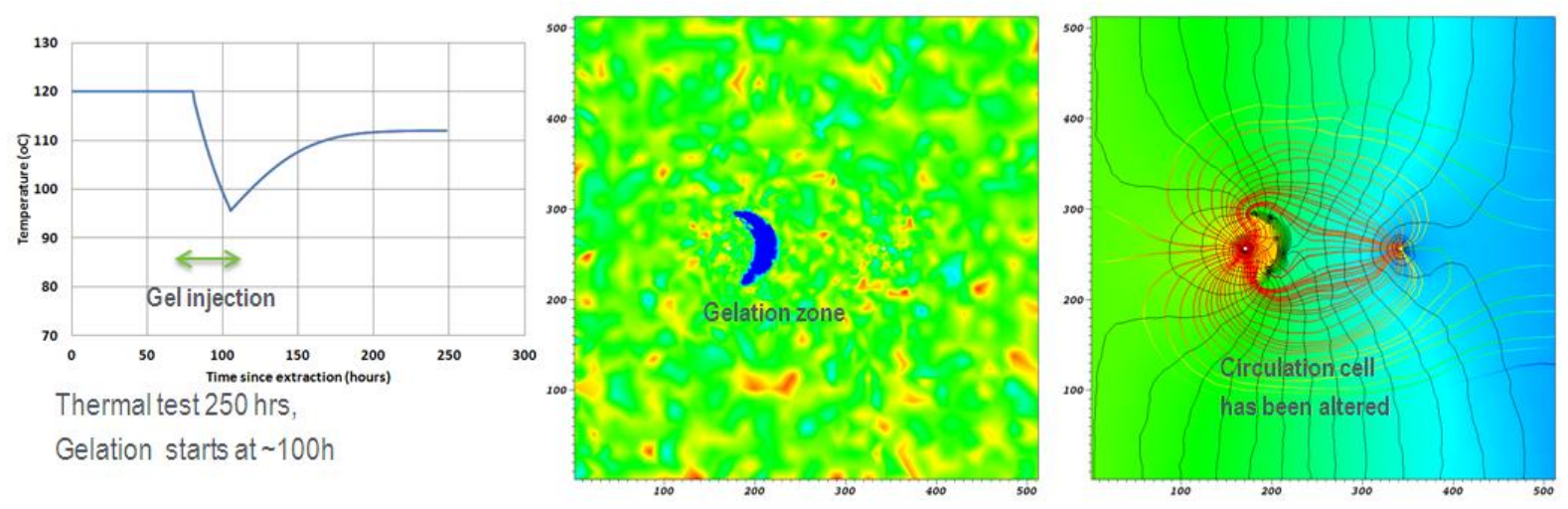

Figure 21. TWO dimensional DOUBLET FLOW AND tRANSPORT SIMULATIONS OF GEL IN A SINGLE ROUGH

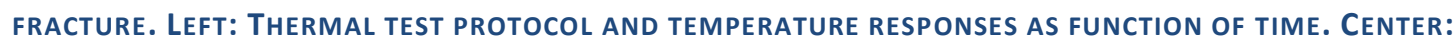

APERTURE RANDOM FIELD WITH CRESCENT-LIKE DIVERTER E.G. GELLED SILICA. RIGHT: FLOW NETWORK SHOWING THE IMPACT OF GELLED SILICA ON STREAMLINES AND FLOW CELLS.

It should be noted that this simple exercise serves as proof of concept of positive impact of gel deployment on the thermal response of an EGS, when it is used appropriately and judicially. It is also worth noting that the response of the system and the gelled area prediction depends on how well the fracture is characterized. Often we are faced with limited data, especially when fractures are too deep. Prediction under conditions of uncertainty is therefore a must and will be touched upon later.

\subsection{Impact of uncertainties on gel deployment in an EGS}

When dealing with real three dimensional subsurface applications we have to cope with the uncertainties associated not only with the intrinsic thermo-hydrological properties of the host 
rock but also the chemical uncertainty associated with the gelation time of silica (see experimental results). Moreover, the deeper the geothermal system, the more expensive is the data collection. We often deal with incomplete characterization of the site at the target depth and moreover it is practically impossible to characterize each fracture of the fracture network in detail. Uncertainties and limited data usually call for uncertainty propagation, quantification and sensitivity analysis (UQ) of key design parameters. We have already touched on this matter in the previous sections using a single realization of each aperture field for each fracture. A probabilistic UQ could be accomplished through a classic Monte Carlo analysis. The prediction of the system response is the ensemble average of all realizations. As stated before, there are several keys design parameters and several fractures; each is characterized by several other parameters (e.g. correlation length, mean aperture, correlation function of the aperture and others). Furthermore, the characterization of the fracture network (density of fractures, fracture size etc.) is itself tainted with limited data and thus uncertainties in the geological characterization of the fracture network. LLNL has already invested for several years in this problem. For example Figure 22 shows a flowchart of UQ analysis that has been customized for UQ in EGS (see Ezzedine, (2010-3) with several applications).
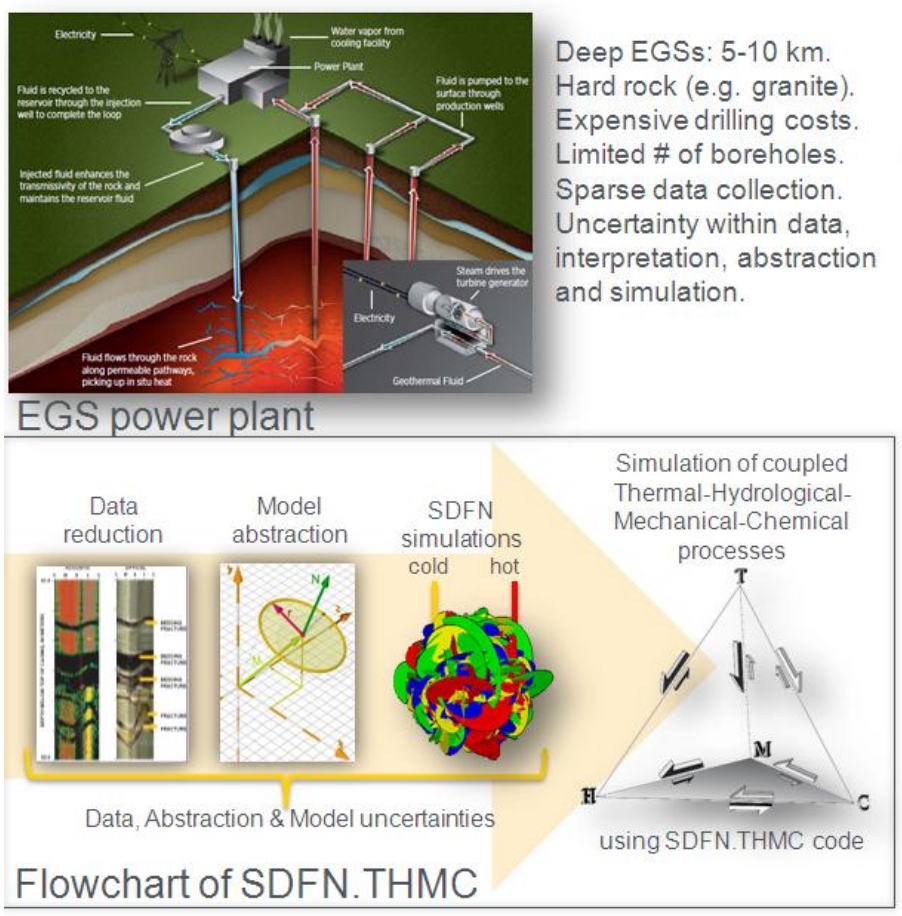

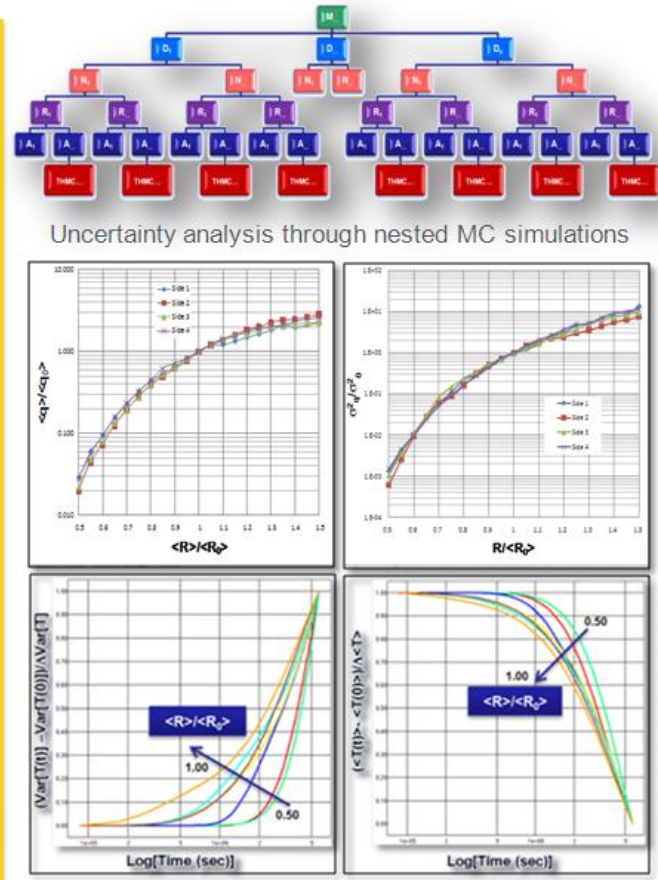

Impact of uncertainty of fracture size on flow \& heat responses of an EGS.

FIGURE 22. FLOWCHART OF UNCERTAINTY PROPAGATION AND QUANTIFICATION FOR EGS APPLICATIONS. USING A

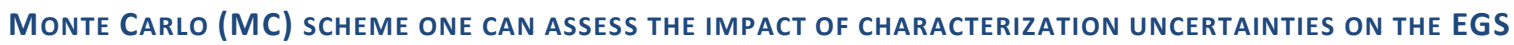
RESPONSE. HERE THE IMPACT OF THE SIZE OF FRACTURE ON PRODUCTION RATE IS QUANTIFIED THROUGH A SENSITIVITY ANALYSIS USING MC SIMULATIONS.

\subsection{D Parametric study with gel deployment}

Our recent work on gel deployment scenarios has focused on the sensitivity of gel emplacement to key parameters used to characterize fluid flow in the subsurface. Gel deployment in fractures involves several parameters that govern flow and transport processes, such as the Peclét, Reynolds, Damkohler, and Fourier numbers. For example, for a high Peclét number (where advection dominates) the gel deployment topology takes a different shape than in previous simulations with much lower Peclét numbers. Several simulations have been conducted and a large data set is being analyzed and results will be presented in 
the next report. Figure 23 depicts a series of snapshots for an advective flow with a short gel injection time. Gel is injected into the left well while extraction is performed via the right well. Each snapshot shows the distribution of the gel in the fracture.

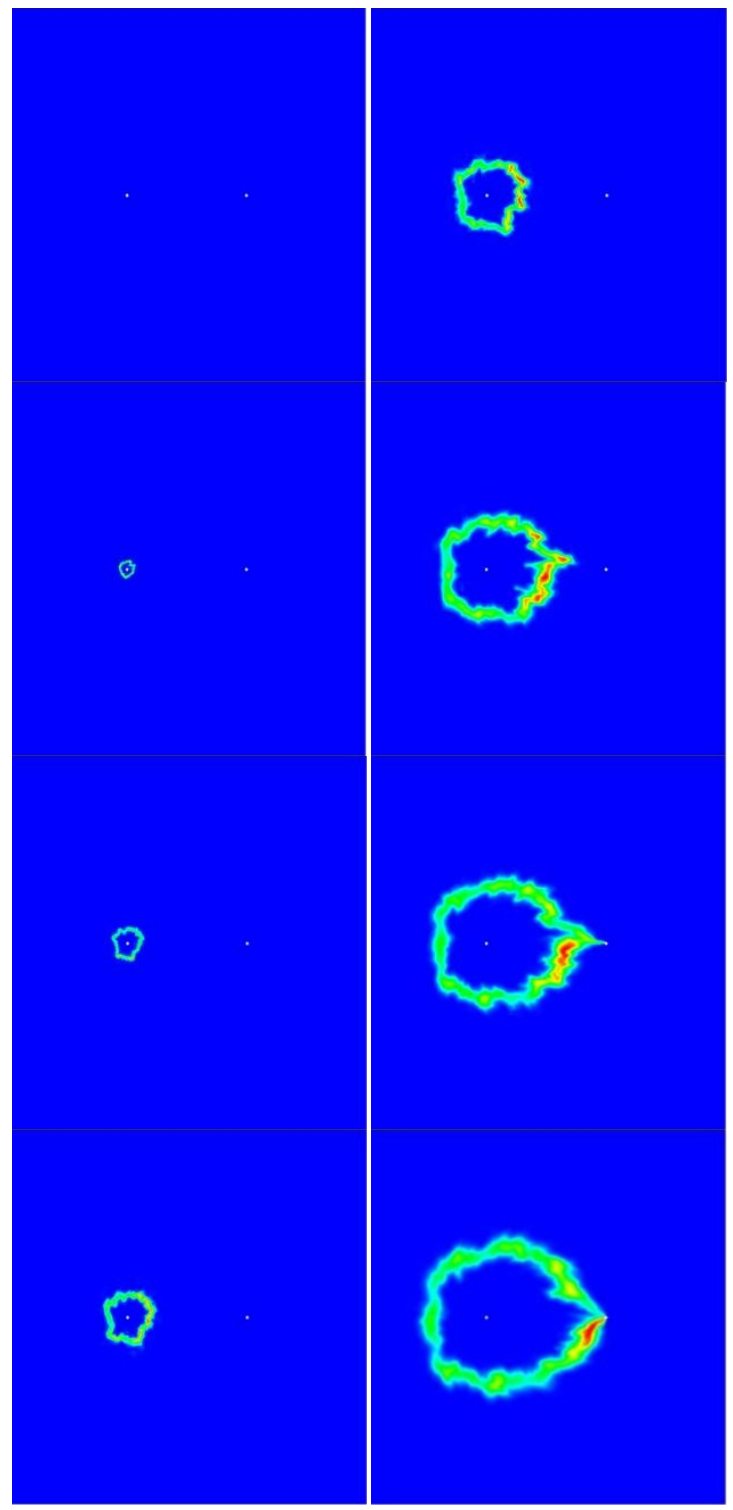

FIGURE 23. SNAPSHOTS OF TWO DIMENSIONAL DOUBLET FLOW AND TRANSPORT SIMULATIONS OF GEL IN A SINGLE ROUGH FRACTURE. TIME FLOWS FROM TOP TO BOTTOM AND LEFT TO RIGHT. TOP LEFT PICTURE DEPICTS THE HYDROLOGICAL CONDITIONS. PAINTED COLORS ARE NOT AT THE SAME SCALE; THESE PICTURES ARE FOR ILLUSTRATION PURPOSES.

Early in the simulation, a ring-like signature of the gel diverges away from the injection well and then travels downstream and gets captured by the extraction well. If designed correctly, each one of these snapshots could correspond to a particular gelation time leading to a closed circulation cell. By changing the values of the key parameters one can expect different outcomes of the shape topology of the gel. For illustration purposes, Figure 24 depicts several outcomes as functions of two key parameters. This strategy might be used to reduce water use in geothermal power production. 


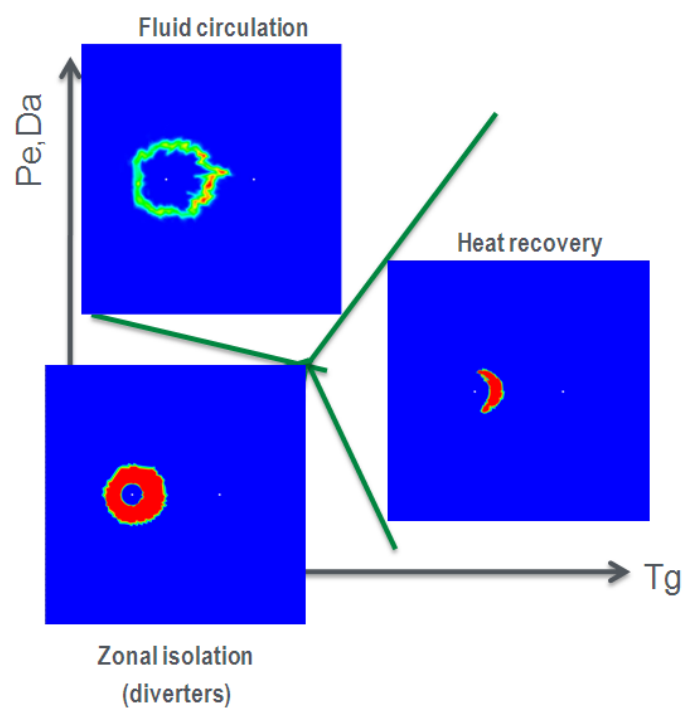

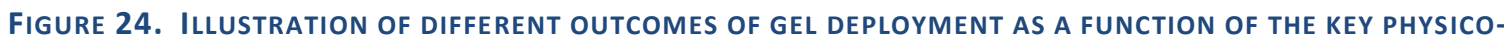
CHEMICAL PARAMETERS THAT GOVERN FLOW, HEAT, GEL TRANSPORT AND GELATION TIME.

Given an ultimate goal of the gel deployment in fractures one can design different reservoir engineering outcomes such as enhanced heat recovery, zonal isolation, or modified fluid circulation. Charts such as the one presented in Figure 24 will assist technologists to target the right set of space parameters to produce the right design. We have begun exploring the space parameters and correlating the outcomes. In the subsequent section we illustrate the use of silica gel to minimize the injected water losses to the surrounding formation.

\subsection{Minimizing water losses from EGS using gel emplacement}

To illustrate the use of silica gel for minimizing water losses to the formation we revisit the problem of Figure 23. First, we have turned off the extraction well allowing the ring-like slug of silica to propagate through the fracture until it encloses the extraction well. The silica gelation time should be designed to allow gelation only after the silica-ring enfolds both wells.
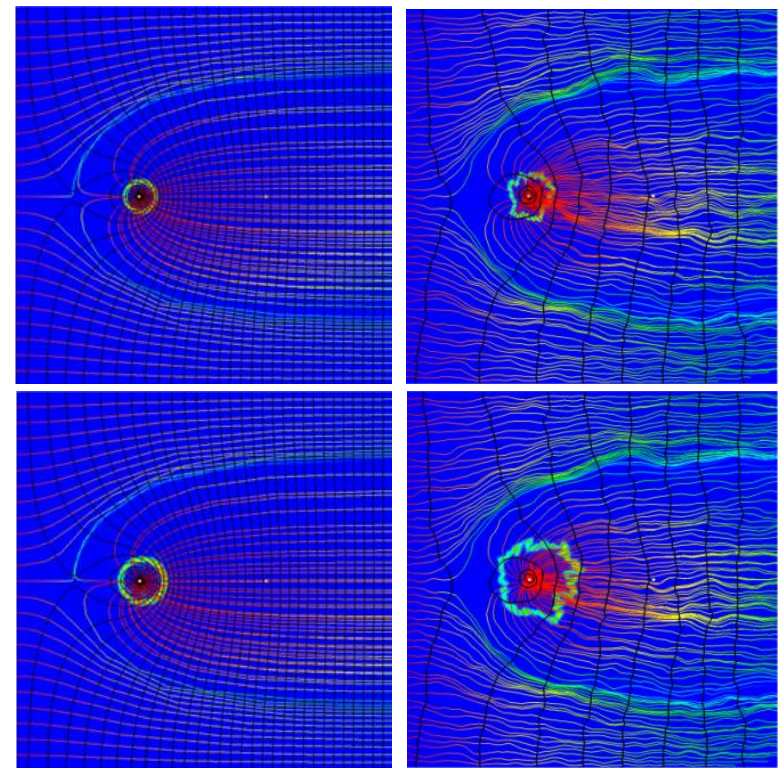

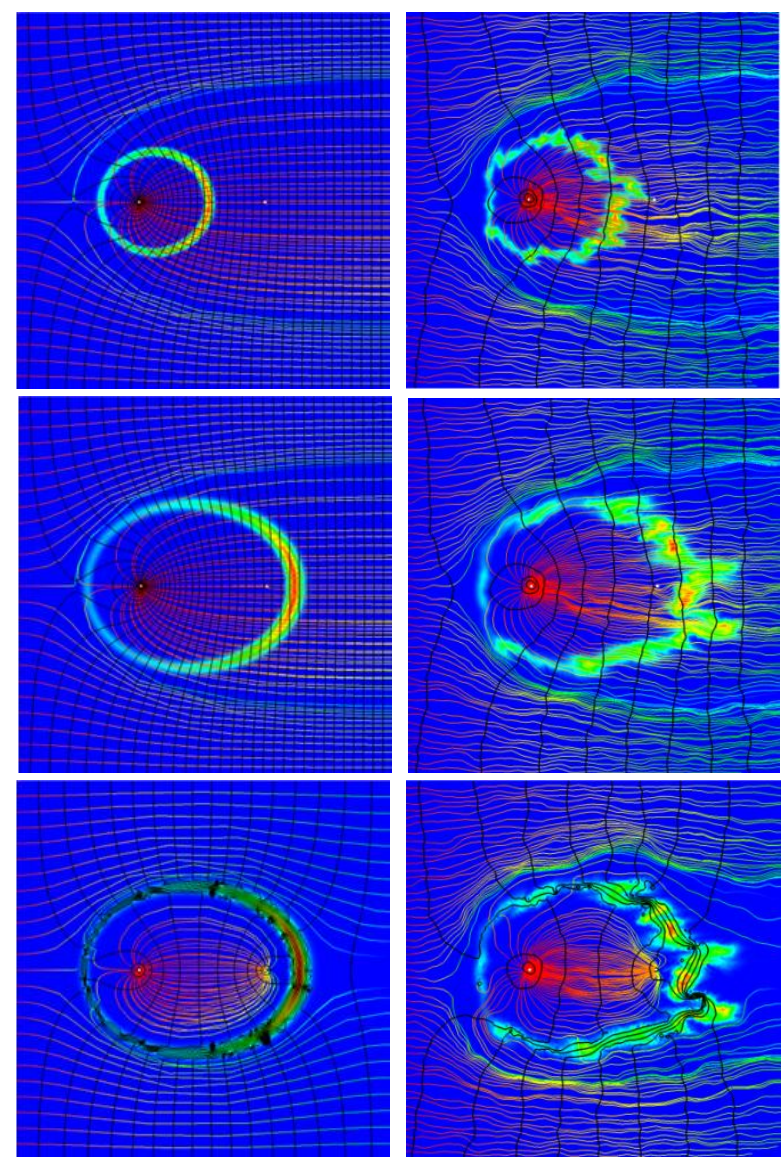

FIGURE 25. SNAPSHOTS OF TWO DIMENSIONAL DOUBLET FLOW AND TRANSPORT SIMULATIONS OF GEL IN A SINGLE SMOOTH (LEFT) ROUGH FRACTURE (RIGHT). TIME FLOWS FROM TOP TO BOTTOM. EACH FRAME DEPICTS THE GEL LOCATION AND THE FLOWNET. IN THE 4 TOP FRAMES THE PRODUCTION WELL IS OFF, WHILE IN THE LAST ROW THE PRODUCTION WELL IS ON.

Once the silica gel has hardened, the extraction well can be turned on and the injected water will be limited to the circulation cell bounded by the hardened silica. This technology will definitely limit the water losses to the surrounding formation and will minimize the production costs. Figure 25 depicts the process of creating the silica-gel bounded circulation cell. The left column depicts the process in a smooth fracture while the right column depicts the emplacement of silica-gel in a rough fracture. The first four rows depict the process of deployment while the last row depicts the process of the extraction mode when the production well is turned on. Each frame depicts the location of the silica gel and the flow net (pressure and stream lines). Figure 26, however, depicts the initial and the last frames of Figure 25 to better illustrate the impact of silica deployment and the roughness of the fracture.

It is worth noting that within the inner circulation cells (Figure 23, Figure 25, Figure 26, right column) one could apply the same concept of enhancing heat extraction, discussed in previous reports, within the inner cell: creating different sweeping surface areas within the inner circulation cell, thus enhancing heat extraction while minimizing water losses to the surrounding formation. 


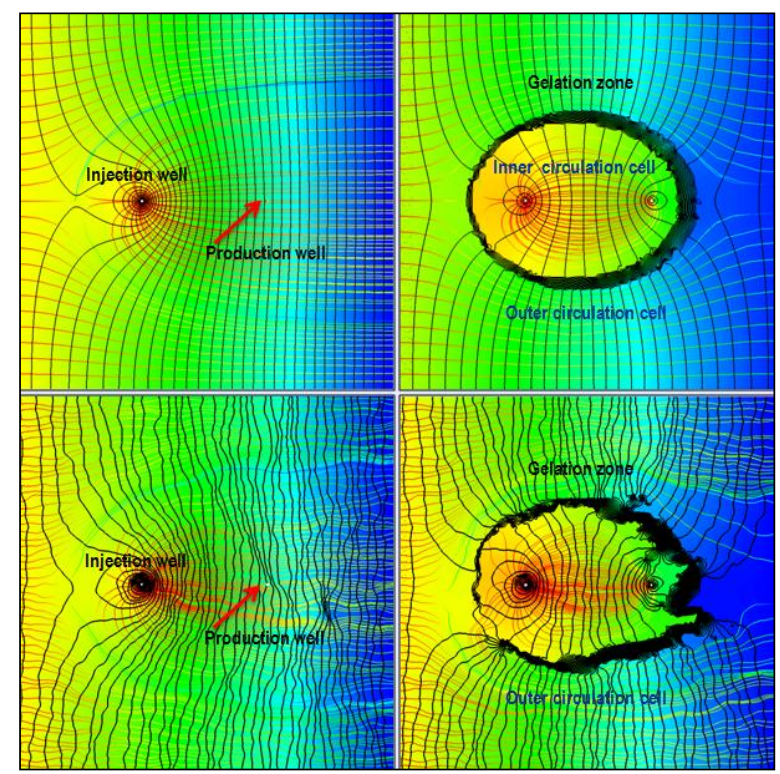

FIGURE 26. INITIAL (LEFT) AND FINAL (RIGHT) SNAPSHOTS OF TWO DIMENSIONAL DOUBLET FLOW AND TRANSPORT SIMULATIONS OF GEL IN A SINGLE SMOOTH (TOP) ROUGH FRACTURE (BOTTOM). EACH FRAME DEPICTS THE GEL LOCATION AND THE FLOWNET. IN THE LEFT FRAMES THE PRODUCTION WELL IS OFF, WHILE IN THE RIGHT FRAMES THE PRODUCTION WELL IS ON.

\subsection{Gels in 3D porous media: sedimentary geothermal reservoirs}

Real applications are three dimensional. Because we have found that the silica gel may exhibit thermal instabilities in reservoirs at high temperatures (such as deep EGS with temperatures greater than $200{ }^{\circ} \mathrm{C}$ ) we have decided to explore the use of silica gel for water diversion and circulation containment for conventional sedimentary geothermal reservoirs. To illustrate this application of gel deployment, we show a simple 3-D sedimentary geothermal reservoir in Figure 27. The reservoir is maintained at a natural flow gradient from left to right. The silica is then injected at the injection well while the extraction well is maintained off. Several snapshots of gel transport are depicted in Figure 28(a-f). The gel deployment affects the streamlines which are depicted in Figure 28g.

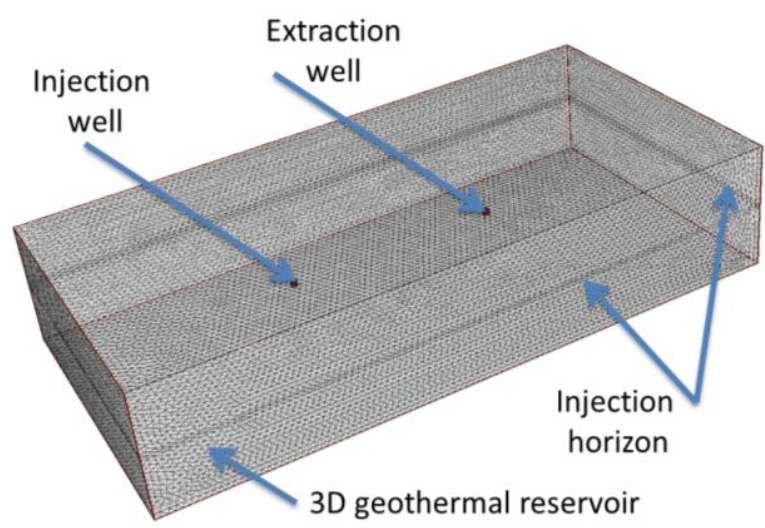

FigURE 27. ILLUSTRATION OF 3D SEDIMENTARY GEOTHERMAL RESERVOIR. THIS FIGURE SHOWS BOTH INJECTION AND PRODUCTION WELLS INTERSECTING THE INJECTION/EXTRACTION HORIZON. 

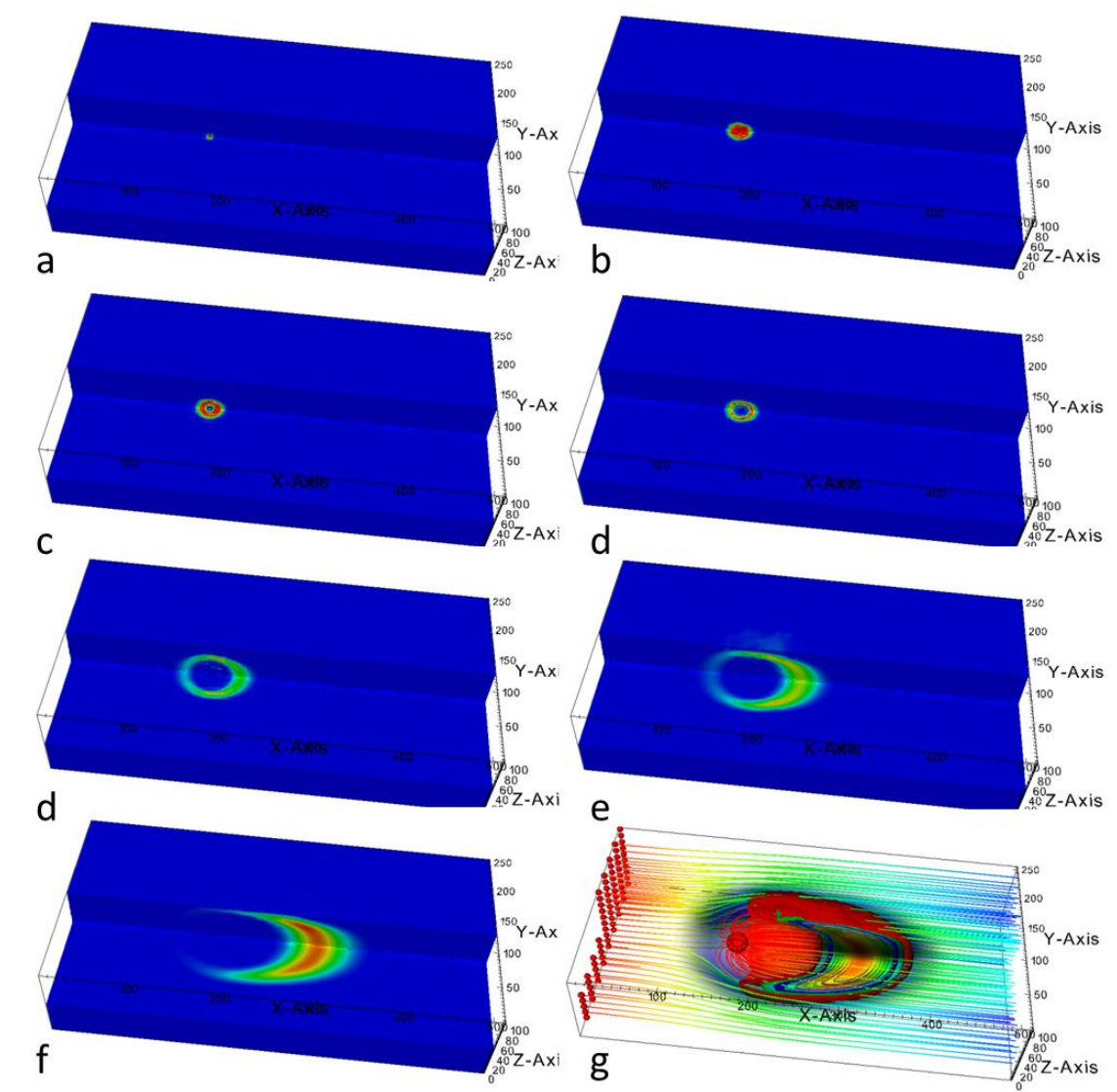

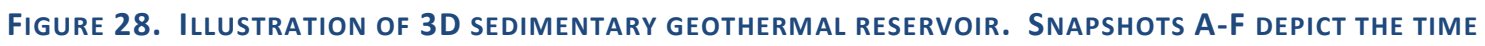
EVOLUTION OF THE INJECTED SILICA WHILE FRAME (G) DEPICTS THE COMPLEX STREAMLINES AROUND THE SILICA GEL.

\subsection{Modeling of gel deployment for remediating short-circuits}

We have demonstrated in previous work the benefit of gel deployment on enhancing the thermal extraction and reduction of water losses to formation for fractured and porous media reservoir, application to porous conventional geothermal reservoir. In the current subsection we will demonstrate the impact of deployment of silica for remediating short-circuits between the operational wells. We have numerically built a finite element model that mimics the following problematic conditions: the reservoir is a porous fractured one; two fast-pathways fractures are embedded within the reservoir, an upper one that intersect both wells and can easily be characterized through the wells while the bottom one, a more conductive than the first, can only be characterized, for example, through tracer or thermal tests. The geological settings of the problem are depicted in Figure 29. An adaptive finite element scheme has been used to mimic with high fidelity the geological settings especially the fractures themselves. The use of homogenized properties or non-adaptive numerical schemes will fail to capture the essence and the challenges that this problem present. Figure 30 illustrates the vertical cross-section through a 3D mesh used to solve the problem. The number of nodes used in the current 3D exercise counts 500 Million nodes.

We have enhanced the model with a streamline solver. Streamlines are essential for tracking the silica gel though not only the porous medium but more importantly in the fractures themselves. Because we are targeting short-circuits, which are essentially highly conductive fractures, resolving the physics of mixing and transport within fractures is essential to the 
successful deployment of silica gel by assessing the impact of mixing within fractures on the gelation time. Figure 31 depicts the schematic of a vertical cross-section through a 3D geothermal reservoir near the injection well. It depicts streamlines with the domain. Adaptive mesh refinement was used to represent the fractures and the streamlines with high fidelity and illustrated though several zoom-outs.

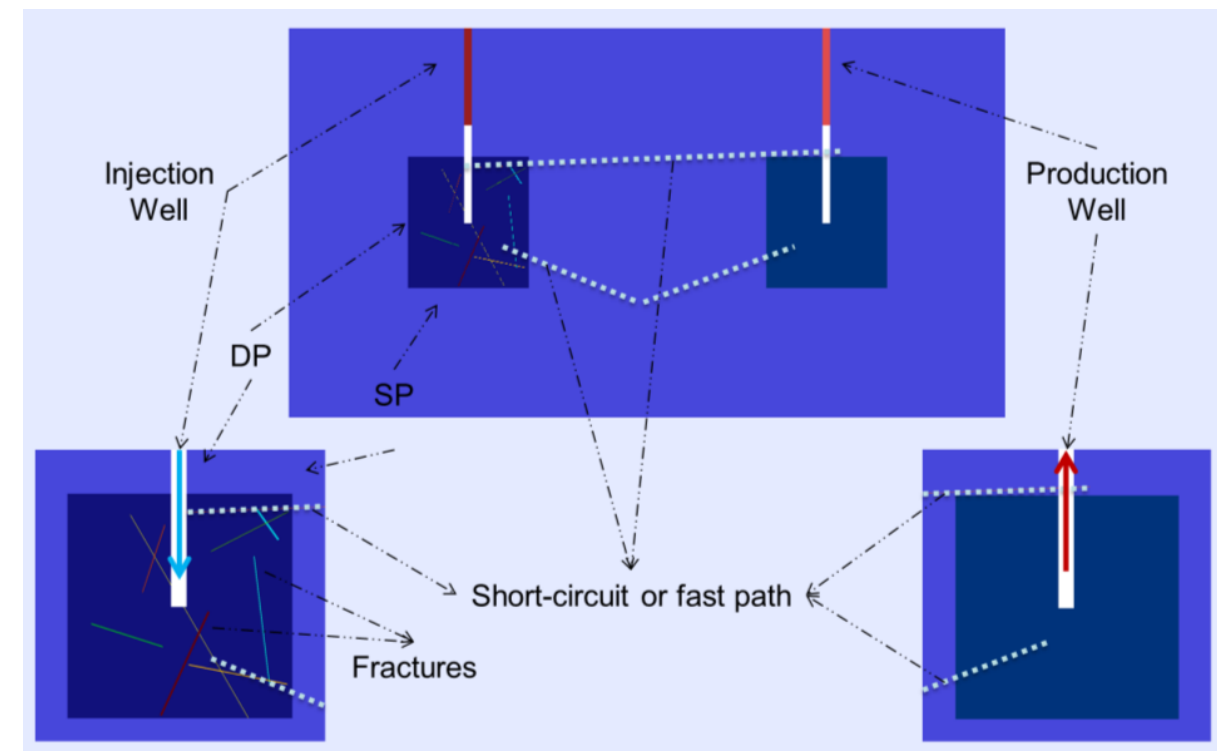

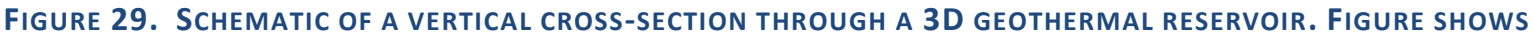
THE OPERATIONAL WELLS WHICH ARE EMBEDDED IN A DOUBLE POROSITY MEDIUM (DP), THE BACKGROUND RESERVOIR IS CONSIDERED AS A SINGLE POROUS MEDIUM (SP). SEVERAL FRACTURES ARE ALSO EMBEDDED WITH THE RESERVOIR; TWO OF THEM INTERSECT BOTH WELLS. THE BOTTOM FRACTURE, UNSEEN BY BOTH WELLS, PLAYS THE ROLE OF HIGH CONDUCTIVE FRACTURE AND THUS SHORT-CIRCUITING BOTH "WELLS".

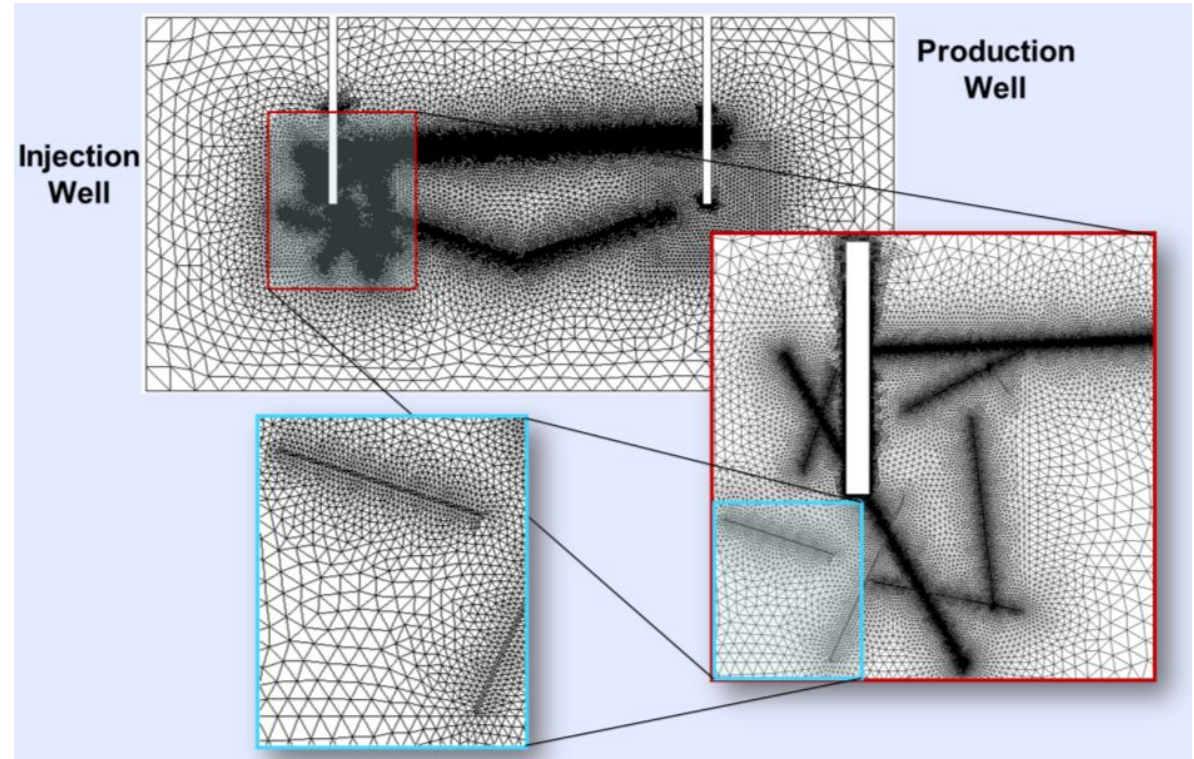

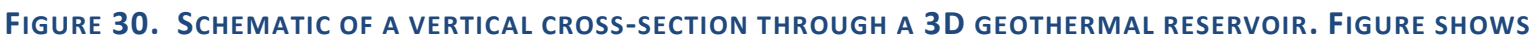

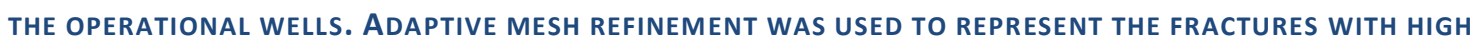
FIDELITY AND ILLUSTRATED THOUGH SEVERAL ZOOM-OUTS. 


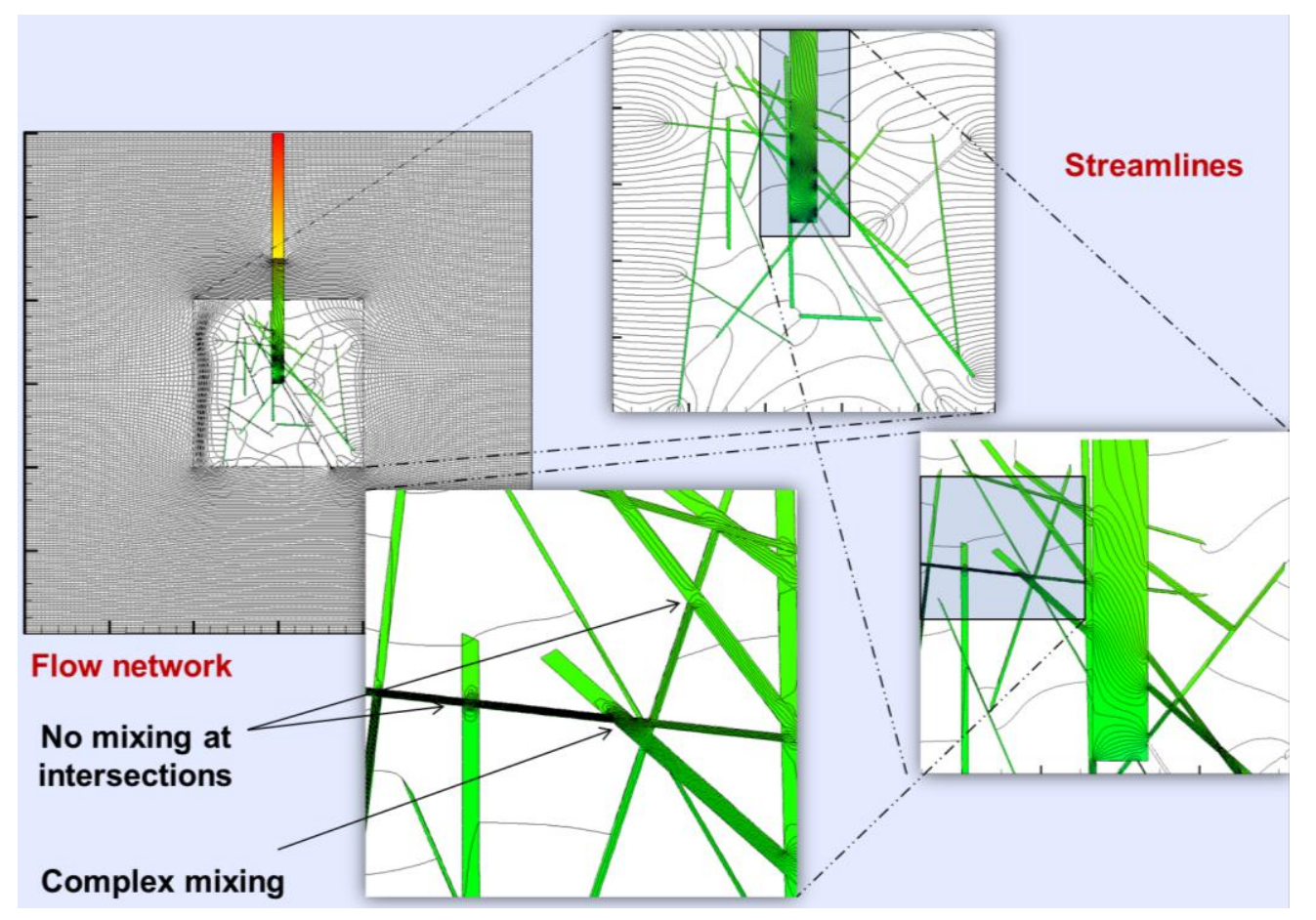

Figure 31. SCHEMATIC OF A VERTICAL CROSS-SECTION THROUGH A 3D GEOTHERMAL RESERVOIR NEAR THE

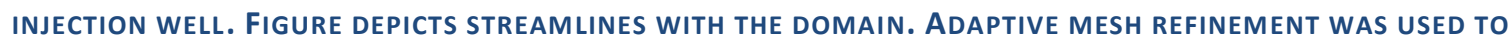
REPRESENT THE FRACTURES AND THE STREAMLINES WITH HIGH FIDELITY AND ILLUSTRATED THOUGH SEVERAL ZOOMOUTS. STREAMLINES ARE ESSENTIAL FOR TRACKING THE SILICA GEL DEPLOYMENT AND TO ASSESS THE IMPACT OF MIXING WITHIN FRACTURES ON THE GELATION TIME.

In order to illustrate the impact of silica gel deployment on the circulation of the fluid within the geothermal system we proceeded by: 1) simulating the injection of a tracer (or thermal test) in the subsurface prior to silica emplacement, 2) simulating the deployment of silica gel to obstruct the fast path and 3) re-simulating the injection of a tracer (or thermal test) to illustrate the difference between 1 and 3. Figure 32 depicts a vertical cross-section through a 3D geothermal reservoir before gel deployment. A thermal tracer test was performed by injecting the reservoir with cold water. From left to right and top to bottom, the effect of the cold water can be seen spreading through the geothermal reservoir. One can see that the bottom fracture plays the role of a fast-path short-circuiting fracture by noting the arrival of cold water at the heel of the extraction well. Based on Figure 32, we have simulated the deployment of silica gel to block the highly conductive fracture and then re-conduct the same simulation as in Figure 32. Results posterior to silica gel deployment are depicted in Figure 33. It displays a schematic of a vertical cross-section through a 3D geothermal reservoir after gel deployment. A thermal tracer test was performed in the same manner as in Figure 32. In Figure 33, one can see that the bottom fracture is obstructed after silica gel has been deployed and that the cold region initially observed before gel deployment has vanished. We can conclude through this exercise that silica gel can be effectively used to remediate shortcircuits and thus enhance the heat extraction and the longevity of the reservoir. 

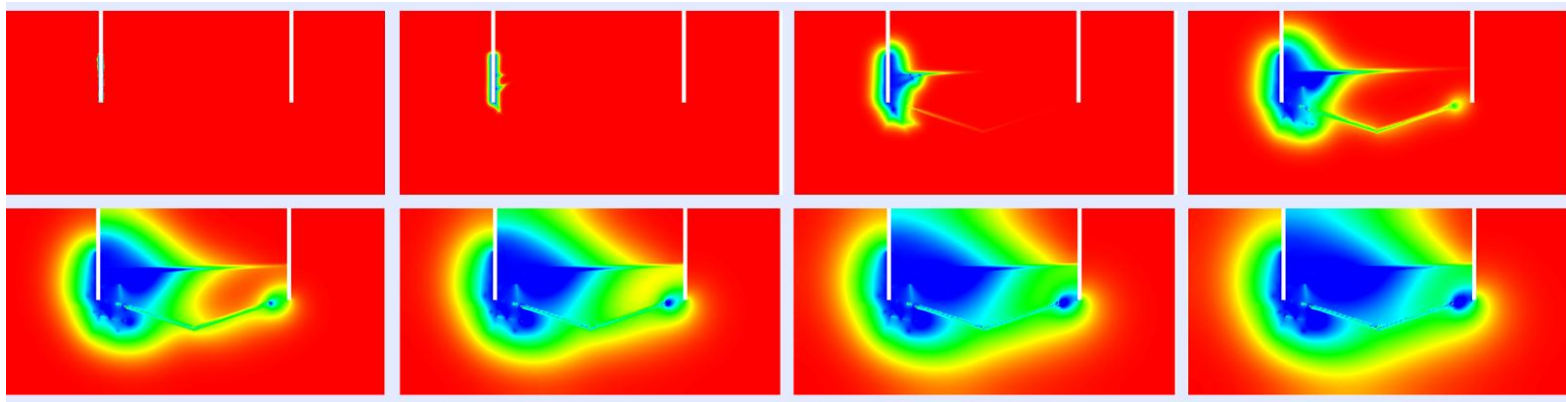

Figure 32. SCHEMATIC OF A VERTICAL CROSS-SECTION THROUGH A 3D GEOTHERMAL RESERVOIR BEFORE GEL DEPLOYMENT. A tRACER (THERMAL) TEST WAS INJECTED. FIgURE DEPICTS TIME-SNAPSHOTS OF THE TRACER/HEAT TRANSFER THROUGH THE RESERVOIR. TIME FLOWS FROM LEFT TO RIGHT AND TOP TO BOTTOM. BLUE COLOR DEPICTS COLD REGIONS WHILE RED COLOR REPRESENTS HOT REGIONS. ONE CAN SEE THAT THE BOTTOM FRACTURE PLAYS THE

ROLE OF A FAST-PATH SHORT-CIRCUITING FRACTURE, NOTE THE ARRIVAL OF COLD WATER AT THE HEEL OF THE EXTRACTION WELL.
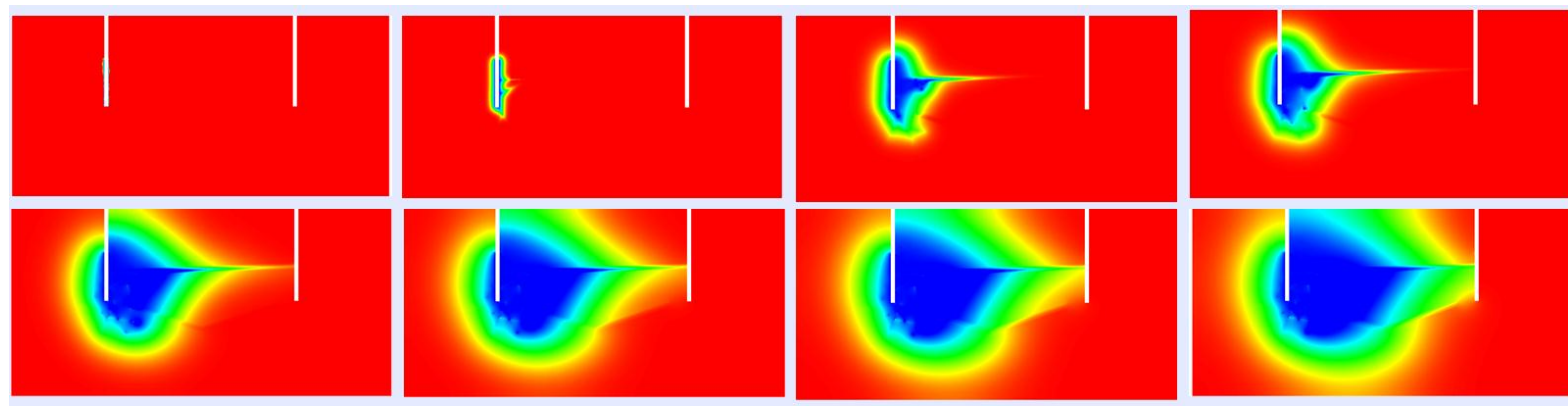

Figure 33. SCHEMATIC OF A VERTICAL CROSS-SECTION THROUGH A 3D GEOTHERMAL RESERVOIR AFTER GEL DEPLOYMENT. A tracer (THERMAL) TEST WAS INJECTED. FIgURE DEPICTS TIME-SNAPSHOtS OF THE TRACER/HEAT TRANSFER THROUGH THE RESERVOIR. TIME FLOWS FROM LEFT TO RIGHT AND TOP TO BOTTOM. BLUE COLOR DEPICTS COLD REGIONS WHILE RED COLOR REPRESENTS HOT REGIONS. ONE CAN SEE THAT THE BOTTOM FRACTURE IS OBSTRUCTED AFTER SILICA GEL HAS BEEN DEPLOYED AND THAT THE COLD REGION INITIALLY OBSERVED BEFORE GEL DEPLOYMENT HAS VANISHED.

\section{Summary}

\subsection{Summary of Laboratory Experiments}

We have successfully investigated the effects of temperature on a variety of solution chemistries, and have found solution compositions for use in geothermal systems at or below $\sim 150-175^{\circ} \mathrm{C}$, with gel times of multiple hours (depending on the exact heating path). Fast gelation times and thermal instability of silica gels indicate that optimized gel formulations will be needed for routine use at high temperatures. The combination of Equation 1, Equation 3, and Equation 4 can be used to calculate the gel time for a particular solution chemistry (assuming no salt is added) given a heating path of interest. We have conducted laboratory tests of gel emplacement in fractured and porous media to serve as validation tests of the gel emplacement strategies derived from our numerical modeling task, and believe that deployment of silica gels will be a viable strategy for maximizing heat production and minimizing water losses in low to medium temperature $\left(<200^{\circ} \mathrm{C}\right)$ geothermal reservoirs. 


\subsection{Summary of Modeling Results}

We have investigated various parameters in order to design specific, desired, gel deployment topologies. Previous work has shown that gel deployments can enhance heat production in a single fracture. Our work this year shows that gel deployments can be tailored to minimize water losses from a circulation cell and block fast pathways in three-dimensional fracture networks in addition to the enhancement of heat production. We have also investigated gel deployments in sedimentary geothermal reservoirs.

\section{References}

Bergna, H. E. \& Roberts, W. O., 2006. Colloidal Silica: Fundamentals and Applications:Taylor \& Francis.

Bourcier, W., 2009. Pilot Scale Geothermal Silica Recovery at Mammoth Lakes, CEC Report CEC-500-2009-077).

Bourcier, W. et al., 2012. Enhancing the sustainability of EGS using colloidal silica gel. San Francisco, AGU Fall Meeting, December 3-7.

Bourcier, W. et al., 2013. Maximizing heat extraction and minimizing water losses in hydrothermal systems: A numerical investigation. Stanford, Stanford Geothermal Workshop, February 11-13.

Ezzedine, S. M., 2005. Stochastic modeling of flow and transport in porous and fractured media. In: Encyclopedia of Hydrological Sciences.:Wiley, pp. Chapter 154, 34 pages.

Ezzedine, S. M., 2010-1. Impact of Geological Characterization Uncertainties on Subsurface Flow Using Stochastic Discrete Fracture Network Models. Stanford, Stanford Geothermal Workshop, February 1-3.

Ezzedine, S. M., 2010-2. Thermo-hydrological uncertainty quantification in EGS. Los Angeles, Engineering Mechanical Institute Annual Meeting, American Society of Civil Engineering, August.

Ezzedine, S. M., 2010-3. A Stochastic Framework for UQ and Risk Assessment of EGS. Sacramento, Geothermal Resources Council Annual Meeting, October 24-27.

Ezzedine, S. M., 2010-4. A Comprehensive flow and heat and mass transport UQ in discrete fracture network systems. San Francisco, AGU Fall Meeting, December 13-17.

Ezzedine, S. M., 2010-5. Simulation of CO2 leaks from an injection well and implications on subsurface flow and transport. San Francisco, AGU Fall Meeting, December 13-17.

Ezzedine, S. M. et al., 2012-2. Enhancing the sustainability of EGS using colloidal silica gel. Reno, NV, Geothermal Resources Council Annual Meeting, October 1-3. 
Ezzedine, S. M. et al., 2012-1. Impact of silica gel deployment on subsurface flow and heat extraction from enhanced geothermal systems. Stanford, Stanford Geothermal Workshop, January 30 - February 1.

Hunt, J. D., Ezzedine, S., Bourcier, W. \& Roberts, S., 2012-1. Silica gel behavior under different EGS chemical and thermal conditions: an experimental study. Stanford, Stanford Geothermal Workshop, January 30 - February 1.

Hunt, J. D., Ezzedine, S., Bourcier, W. \& Roberts, S., 2012-2. Kinetics of colloidal silica gelation at EGS conditions and implications for reservoir modification. Reno, NV, Geothermal Resources Council Annual Meeting, October 1-3.

Hunt, J. D., Ezzedine, S. M., Bourcier, W. \& Roberts, S., 2012-3. Colloidal silica gelation at geothermal conditions: Kinetics and implications for reservoir modification. San Francisco, AGU Fall Meeting, December 3-7.

Hunt, J. D., Ezzedine, S. M., Bourcier, W. \& Roberts, S., 2013. Kinetics of the gelation of colloidal silica at geothermal conditions, and implications for reservoir modification and management. Stanford, Stanford Geothermal Workshop, February 11-13.

Iler, R. K., 1979. The Chemistry of Silica:Wiley.

Jurinak, J. J., Summers, L. E. \& Bennett, K. E., 1991. Oilfield Applications of Colloidal Silica Gel. SPE Production Engineering, pp. 406-412.

Roberts, S. et al., 2012. Transport of colloidal silica in fractured and porous media: Applications to geothermal and geological carbon sequestration. San Francisco, AGU Fall Meeting, December 3-7. 

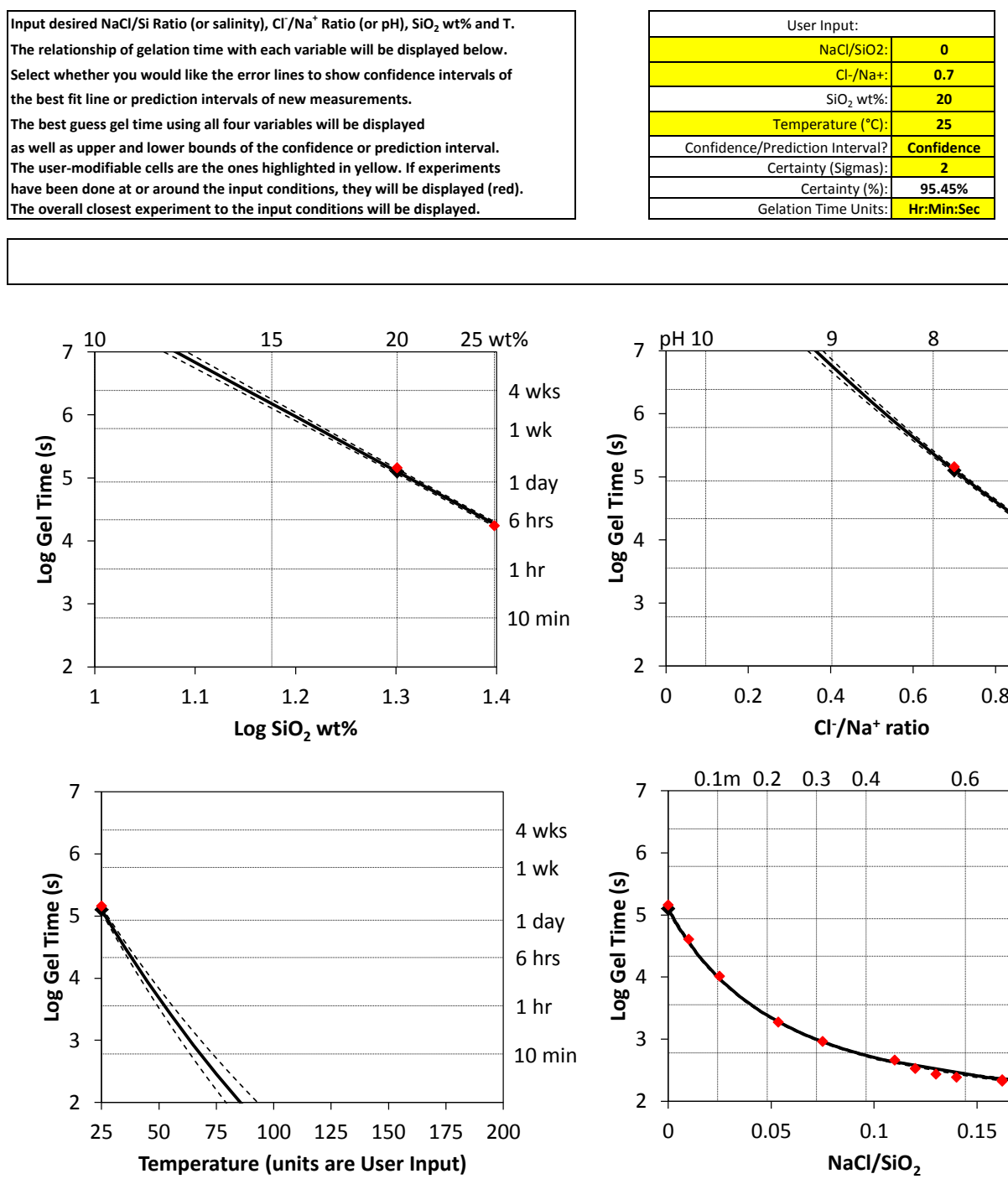
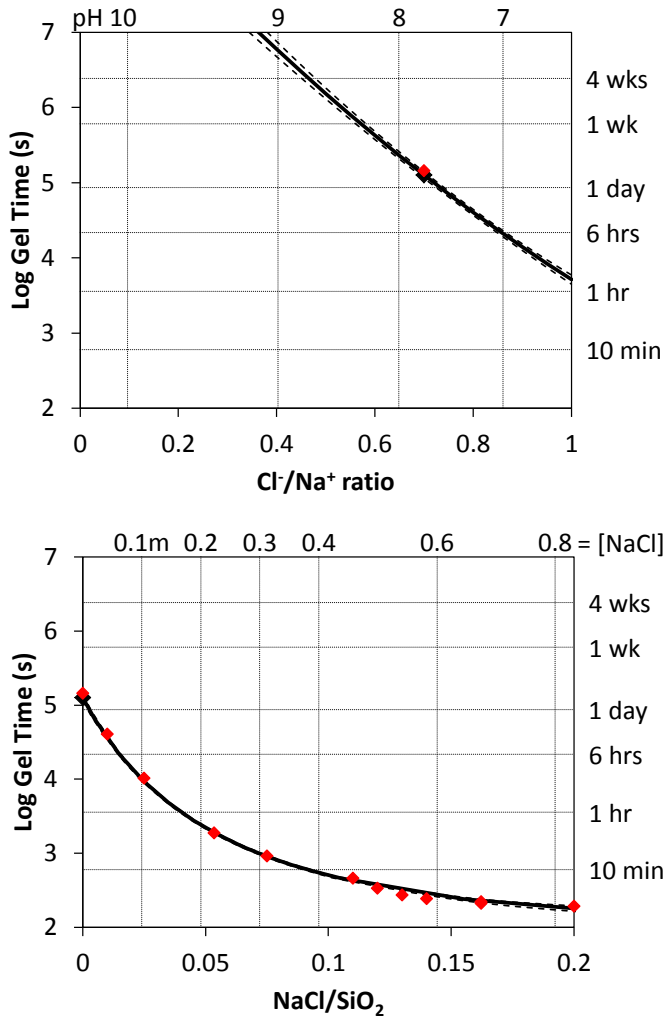

Volume Ratios:

To calculate a chemistry

based on ingredient ratios,

enter ingredient ratios and

click the Calculate button.

\begin{tabular}{|c|l|}
\hline 6 & $\mathrm{SiO}_{2} \mathrm{Sol}$ \\
\hline 1 & $1 \mathrm{~N} \mathrm{HCl}$ \\
\hline
\end{tabular}

\begin{tabular}{l|l|}
1 & $1 \mathrm{~N} \mathrm{HCl}$ \\
\hline 0 & $2.5 \mathrm{NaCl}$ \\
\hline
\end{tabular}

\begin{tabular}{lll}
\hline 0 & $2.5 \mathrm{~N} \mathrm{NaCl}$ \\
\hline 5 & $\mathrm{H}_{2} \mathrm{O}$ \\
\hline
\end{tabular}

\begin{tabular}{|l|l|}
\hline 5 & $\mathrm{H}_{2} \mathrm{O}$ \\
\hline
\end{tabular}

\begin{tabular}{|c|}
\hline Gelation Time: \\
\hline 35:3:28 Hr:Min:Sec \\
\hline Upper Bound: \\
\hline 38:41:51 Hr:Min:Sec \\
\hline Lower Bound: \\
\hline 31:45:37 Hr:Min:Sec \\
\hline
\end{tabular}

\begin{tabular}{|c|}
\hline Closest Experiment: \\
\hline $\mathrm{SiO}_{2}: 20 \mathrm{wt} \%$ \\
\hline $\mathrm{Cl}^{-} / \mathrm{Na}^{+}: 0.7$ \\
\hline $\mathrm{NaCl} / \mathrm{SiO}_{2}: 0$ \\
\hline $\mathrm{pH}: 7.77$ \\
\hline $\mathrm{T}: 25^{\circ} \mathrm{C}$ \\
\hline
\end{tabular}

Please Note:

The input salinity should NOT include the $\mathrm{Na}^{+}$stabilizer, nor the $\mathrm{Cl}$ from added $\mathrm{HCl}$. It is only a measure of the added $\mathrm{NaCl}$. Likewise, the acidity (represented by the $\mathrm{Cl} / \mathrm{Na}^{+}$ ratio) does NOT include the added NaCl. 
Example 1:

We have prepared a colloidal silica solution with $10 \mathrm{wt} \% \mathrm{SiO} 2,0.1 \mathrm{molal} \mathrm{NaCl}$, and a pH of 8 .

We are injecting this into an oil well in order to seal the well bore against leakage.

The temperature at the bottom of the well is $110^{\circ} \mathrm{C}$. What is the time before

gelation, assuming the solution is instantly heated to $110^{\circ} \mathrm{C}$ ?

Answer 1:

Input $0.1,8,10$, and 110 into cells F2-F5 on the Calculator tab, respectively.

Make sure that cell $\mathrm{C} 2$ is set to " $\mathrm{NaCl}(\mathrm{m}):$ ", C3 is set to "pH:", and C5 is

set to "Temperature $\left({ }^{\circ} \mathrm{C}\right):$ " via the drop-down menus in those cells.

The best-guess gelation time is displayed as 17 minutes, 50 seconds.

The 2-sigma prediction interval, however, is between 11 minutes, 4 seconds and 28 minutes, 45 seconds.

Example 2:

How is the gelation time of the above example affected if exsolved $\mathrm{CO} 2$ bubbles through the gel solution and reduces the $\mathrm{pH}$ of the solution to 7 ?

Answer 2:

If the $\mathrm{pH}$ is lowered to 7 , the best-guess gel time is lowered to 49 seconds.

Example 3:

The 49-second gel time is too short for our operational procedures. How can we modify the chemistry to obtain a longer gel time?

Answer 3:

Since it has been determined that the $\mathrm{pH}$ is fixed via subsurface addition of $\mathrm{CO} 2$, and the temperature of the wellbore is fixed, we can vary the gel time by lowering the added salt content. If, instead of adding 0.1 molal salt, no salt is added, the best-guess gelation time rises to 10 minutes, 41 seconds. 


\begin{tabular}{|l|c|c|}
\hline \multicolumn{2}{|l|}{$\begin{array}{l}2{ }^{\circ} \mathrm{C} \text { Model } \\
\text { Parameters: }\end{array}$} & Error (+/-): \\
\hline Q & 0.06689 & N/A \\
\hline B & 17.09159 & 0.36217 \\
\hline X1 & -16.53088 & 1.95826 \\
\hline X2 & 27.28008 & 3.03773 \\
\hline X3 & 4.53767 & 1.83601 \\
\hline X4 & 5.64358 & 0.22425 \\
\hline X5 & -11.37328 & 0.21985 \\
\hline X6 & -0.38468 & 0.01570 \\
\hline X7 & 0.47911 & 0.01098 \\
\hline X8 & -18.16077 & 1.76086 \\
\hline X9 & -7.33731 & 0.37698 \\
\hline
\end{tabular}

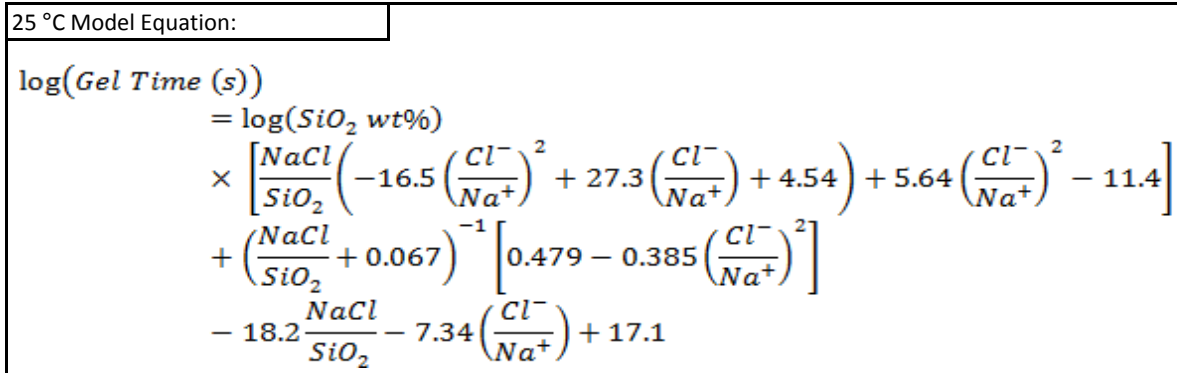

\begin{tabular}{|l|r|c|r|r|r|c|}
\hline $25^{\circ} \mathrm{C}$ Model & $\mathrm{R}^{2}:$ & 0.9961 & $\mathrm{~F}_{\text {stat }}:$ & 2261 & $\mathrm{SS}_{\text {reg }}:$ & 35.77 \\
\cline { 2 - 6 } Statistics: & Std Err: & 0.0419 & $\mathrm{dF}:$ & 80 & SS $_{\text {resid }}:$ & 0.141 \\
\hline
\end{tabular}

\begin{tabular}{|l|c|c|}
\hline \multicolumn{2}{|l|}{$\begin{array}{l}\text { pH Calibration } \\
\text { Parameters: }\end{array}$} & Error (+/-): \\
\hline X1 & -1.4286 & 0.1066 \\
\hline X2 & -1.7680 & 0.1038 \\
\hline X3 & -0.0395 & 0.0036 \\
\hline B & 10.2617 & 0.0150 \\
\hline
\end{tabular}

$$
\begin{array}{|l|l}
\hline \mathrm{pH} \text { Calibration Equation: } & \\
\hline p H=10.262-0.0395\left[\mathrm{SiO}_{2}\right]\left(\frac{\mathrm{Cl}^{-}}{\mathrm{Na}^{+}}\right)-1.768\left(\frac{\mathrm{Cl}^{-}}{\mathrm{Na}^{+}}\right)-1.429\left(\frac{\mathrm{Cl}^{-}}{\mathrm{Na}^{+}}\right)^{2}
\end{array}
$$

\begin{tabular}{|l|r|c|r|c|r|c|}
\hline $\begin{array}{l}\text { pH Calibration } \\
\text { Statistics: }\end{array}$ & $\mathrm{R}^{2}:$ & 0.9994 & $\mathrm{~F}_{\text {stat }}:$ & 6528 & $\mathrm{SS}_{\text {reg }}:$ & 14.96 \\
\cline { 2 - 6 } & Std Err: & 0.0276 & $\mathrm{dF}:$ & 11 & SS $_{\text {resid }}:$ & 0.0084 \\
\hline
\end{tabular}

\begin{tabular}{|l|c|c|}
\hline \multicolumn{2}{|l|}{$\begin{array}{l}\text { E Model } \\
\text { Parameters: }\end{array}$} & Error (+/-): \\
\hline X1 & 16.1808 & 1.8180 \\
\hline X2 & -9.3264 & 1.0105 \\
\hline X3 & 38.5043 & 4.1870 \\
\hline B & -24.4068 & 5.2956 \\
\hline
\end{tabular}

Activation Energy Model Equation:

$$
E_{A}=16.18\left(\frac{\mathrm{Cl}^{-}}{\mathrm{Na}^{+}}\right)^{2}+\log \left(\left[\mathrm{SiO}_{2}\right]\right)\left(38.50-9.326\left(\frac{\mathrm{Cl}^{-}}{\mathrm{Na}^{+}}\right)\right)-24.41
$$

\begin{tabular}{|l|r|c|r|r|r|c|}
\hline $\mathrm{E}_{\mathrm{A}}$ Model & $\mathrm{R}^{2}:$ & 0.9608 & $\mathrm{~F}_{\text {stat }}:$ & 187.8 & $\mathrm{SS}_{\text {reg }}:$ & 111.43 \\
\cline { 2 - 7 } Statistics: & Std Err: & 0.4447 & $\mathrm{dF}:$ & 23 & $\mathrm{SS}_{\text {resid }}:$ & 4.55 \\
\hline
\end{tabular}

Gelation Time Calculation Equations:

$$
\begin{aligned}
& t_{g e l}\left(T_{0}\right)=\int_{0}^{t_{g e l}} e^{\frac{-E_{A}}{R}\left(\frac{1}{T(t)}-\frac{1}{T_{0}}\right)} d t \\
& \ln \left[\frac{t_{g e l}(T)}{t_{g e l}\left(T_{0}\right)}\right]=\frac{E_{A}}{R}\left[\frac{1}{T}-\frac{1}{T_{0}}\right]
\end{aligned}
$$




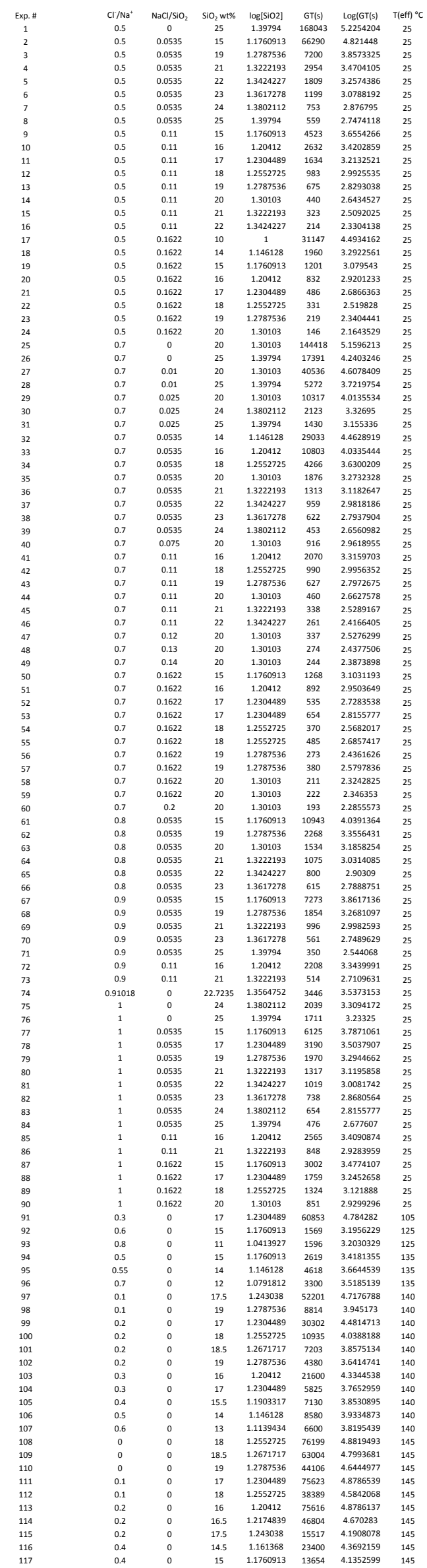




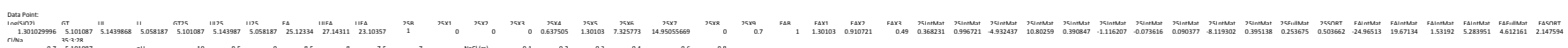

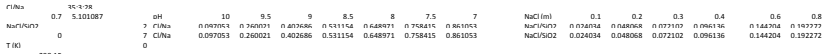

so2:

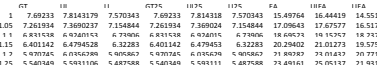

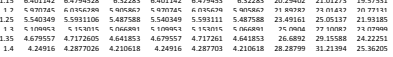

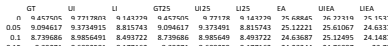

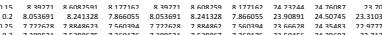

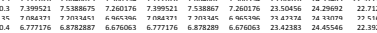

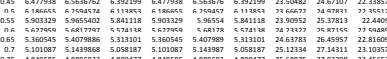

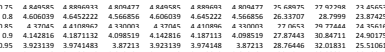

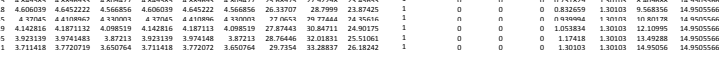
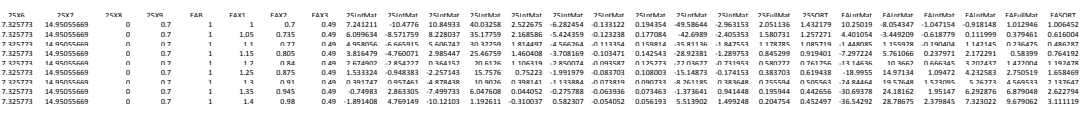

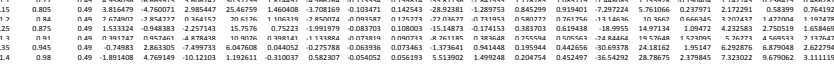

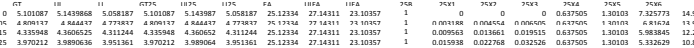

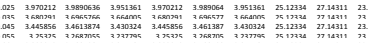

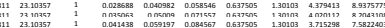

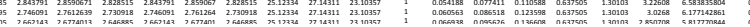

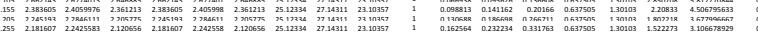
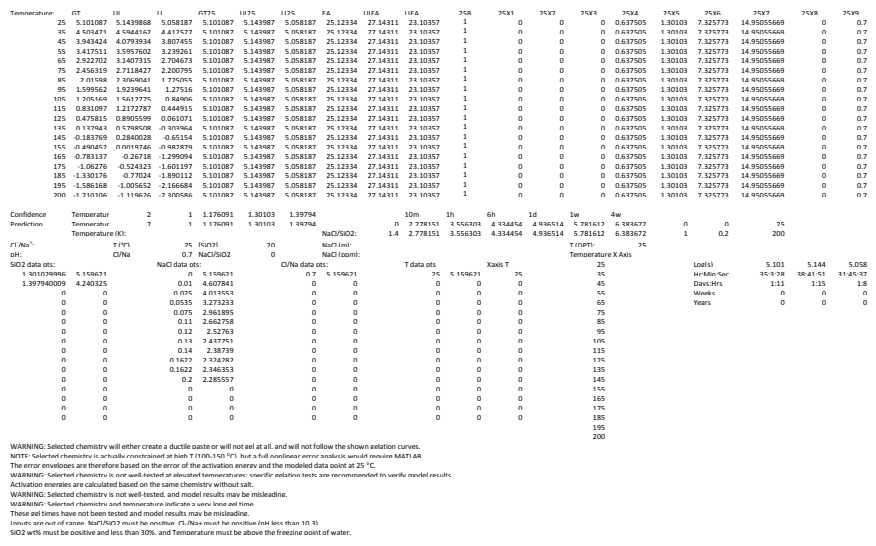
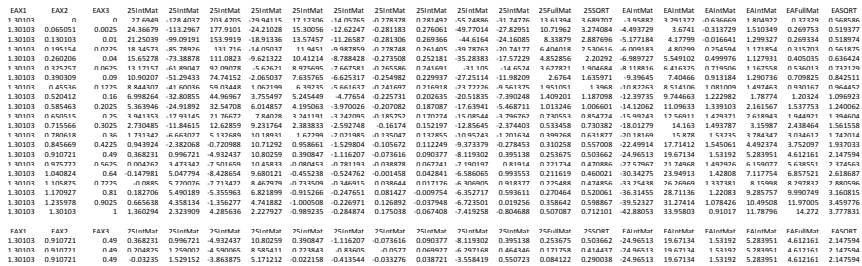

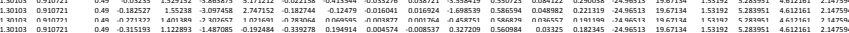

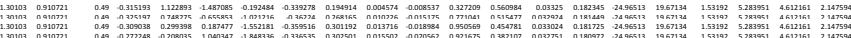

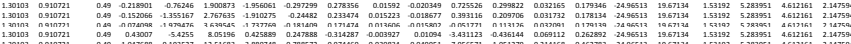

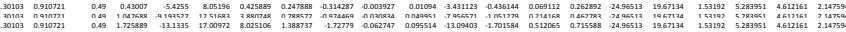
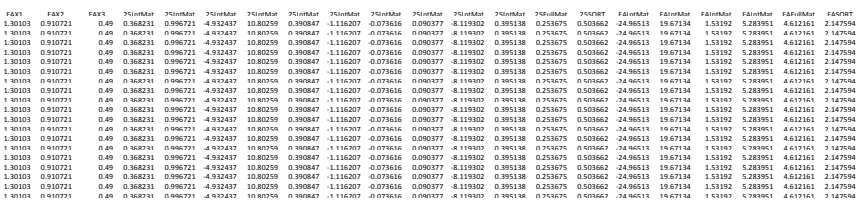


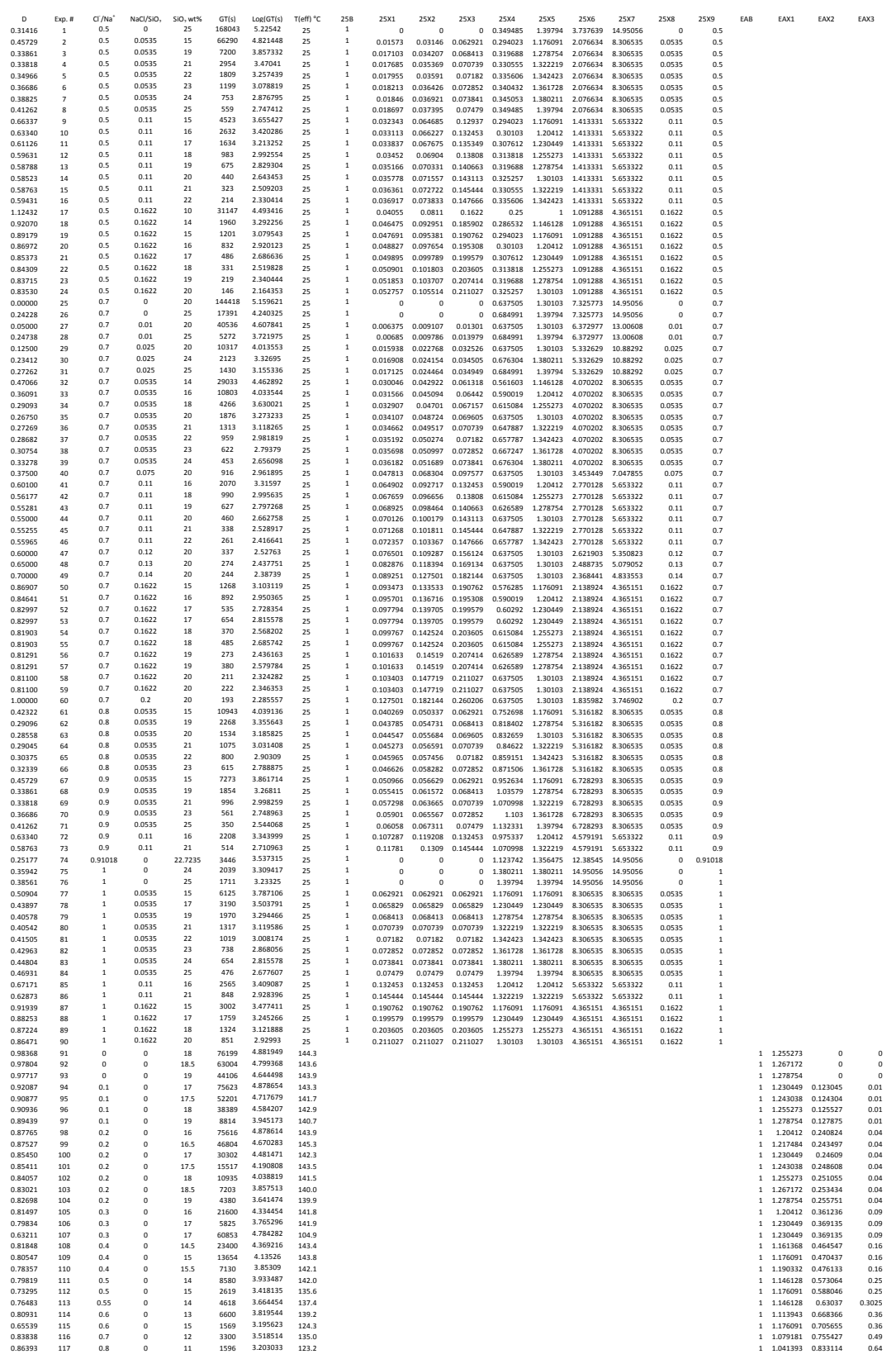

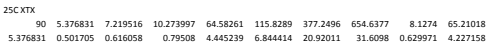

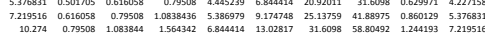

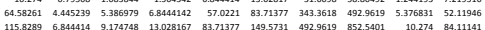

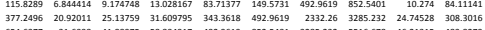

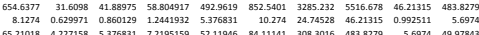

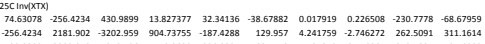

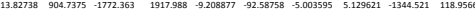

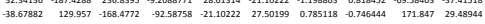

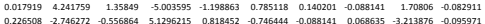

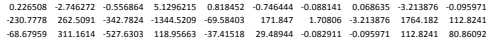

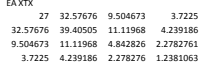

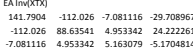

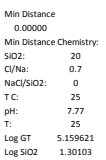

